\title{
Brine-Dependent Recovery Processes in Carbonate and Sandstone Petroleum Reservoirs: Review of Laboratory-Field Studies, Interfacial Mechanisms and Modeling Attempts
}

\author{
Adedapo N. Awolayo ${ }^{1}$, Hemanta K. Sarma ${ }^{1, *}$ and Long X. Nghiem ${ }^{1,2}$ \\ 1 Chemical and Petroleum Engineering Department, University of Calgary, Calgary, AB T2N 1N4, Canada; \\ adedapo.awolayo@ucalgary.ca (A.N.A.); Long.Nghiem@cmgl.ca (L.X.N.) \\ 2 Computer Modelling Group Ltd., Calgary, AB T2L 2M1, Canada \\ * Correspondence: hemanta.sarma@ucalgary.ca; Tel.: +1-403-220-3065
}

Received: 6 October 2018; Accepted: 29 October 2018; Published: 2 November 2018

\begin{abstract}
Brine-dependent recovery, which involves injected water ionic composition and strength, has seen much global research efforts in the past two decades because of its benefits over other oil recovery methods. Several studies, ranging from lab coreflood experiments to field trials, indicate the potential of recovering additional oil in sandstone and carbonate reservoirs. Sandstone and carbonate rocks are composed of completely different minerals, with varying degree of complexity and heterogeneity, but wettability alteration has been widely considered as the consequence rather than the cause of brine-dependent recovery. However, the probable cause appears to be as a result of the combination of several proposed mechanisms that relate the wettability changes to the improved recovery. This paper provides a comprehensive review on laboratory and field observations, descriptions of underlying mechanisms and their validity, the complexity of the oil-brine-rock interactions, modeling works, and comparison between sandstone and carbonate rocks. The improvement in oil recovery varies depending on brine content (connate and injected), rock mineralogy, oil type and structure, and temperature. The brine ionic strength and composition modification are the two major frontlines that have been well-exploited, while further areas of investigation are highlighted to speed up the interpretation and prediction of the process efficiency.
\end{abstract}

Keywords: smart waterflooding; low salinity waterflooding; potential determining ions; interfacial mechanisms; sandstone and carbonate rocks; wettability alteration; oil-brine-rock interactions

\section{Introduction}

The life cycle of petroleum reservoirs typically undergoes three modes of oil recovery: primary recovery uses the reservoir natural energy; secondary recovery mainly uses an injection of water or gas for maintenance of pressure; while the tertiary waterflooding or enhanced oil recovery (EOR) utilizes diverse forms of injection fluid [1,2]. The recovery performance depends on several factors; such as fluid type, reservoir management strategies, reservoir heterogeneities and drive mechanisms [3]. Almost all light-to-medium gravity oil reservoirs go through a water injection cycle to produce some portions of the oil left behind after the depletion of the reservoir natural energy due to the ease of water injection, water availability, small capital investment, and operating costs among other benefits [4]. It is estimated that after the first two stages of production, the average oil recovery can only reach $10-50 \%$ of the original oil in place (OIIP) and a considerable amount remains trapped underground $[5,6]$.

The brine-dependent recovery process (which is also referred to as smart or low salinity waterflooding) has gained recognition as an emerging improved and enhanced oil recovery (I/EOR) 
technique to extract more oil in sandstone or carbonate reservoirs. The process has drawn industry attention not only because it is virtually identical to conventional waterflooding but also serves an upgrade as it delivers higher recovery and displacement efficiency. While the process necessitates additional surface facilities for water sourcing and disposal, it has more favourable economics and environmentally friendlier than other I/EOR techniques. During conventional waterflooding, the nearest accessible water supply has always been sourced for water injection, which implies that seawater is often used for offshore applications and brine-dependent recovery, and keen attention is paid to only the ionic content of the water to ensure compatibility. The potential of this recovery process was first noted in the late 1950s in sandstone reservoirs [7-9] but gained significant interest in the 1990s when the Morrow research group [10-15] published experimental findings on outcrop and Berea sandstone rocks. Meanwhile, the recovery process was only identified in carbonate rocks when an unexpected, remarkable success was reported during seawater injection into the Ekofisk mixed-wet fractured chalk reservoir, significantly leading to high oil recovery [16-19]. Since these early studies, a significant volume of research studies at laboratory-scale and a few limited field-scale trials [20-22] have been conducted in both sandstone and carbonate rocks. Many of the published studies showed a positive response [11,13,21,23-34], which translates into additional oil production, but a few others showed no benefit [28,35-40]. Generally, an increase in oil recovery as high as 30\% in laboratory experiments and a decrease in residual oil saturation ranging from $2-50 \%$ in field trials have been reported as compared to conventional water injection.

Despite its success, this process has only been explored on two major frontlines: ionic strength and composition modification [23]. The mineralogical differences between sandstone and carbonate rocks appear to dictate the performance of brine-dependent recovery in the different rocks. For sandstone rocks, the presence of clay minerals and injected water salinity level as less as $2000 \mathrm{ppm}$ and as high as 7000 ppm gives optimum performance [32,33,41-43]. Meanwhile, a salinity range between 20,000-33,000 ppm appears to work well in carbonate rocks [44]. There were cases where the salinity range of 5000-10,000 ppm resulted in improved oil recovery [26,37,45-47], but this has been attributed to the presence of dissolvable minerals $[45,48]$. In addition, on the composition modification front, the process performance is optimum using injected water with less multivalent ions for sandstone reservoirs and more potential determining ions (PDIs) for carbonate reservoirs. PDIs (like $\mathrm{Ca}^{2+}, \mathrm{Mg}^{2+}$, and $\mathrm{SO}_{4}{ }^{2-}$ ) are those ions whose concentration in the aqueous solution controls the polarity and density of electrical charge on the mineral surface and influence interactions between oil and the rock surface [49]. Aside reporting oil recovery factors and residual oil saturation from displacement and imbibition tests, most experimental studies focused on collection of a plethora of laboratory data (such as, produced brine composition and $\mathrm{pH}$, pressure differential, water cut and breakthrough, contact angle/wettability index, zeta $(\zeta)$ potential, oil-brine interfacial tension, surface relaxation and adhesion, etc.) to explain the recovery mechanisms $[23,25,26,30,50-59]$. The major consensus reached is that wettability alteration is considered as a consequence rather than as a cause of the processes underlying brine-dependent recovery process. Several different mechanisms have been proposed to justify the wettability shift towards less oil-wetness as will be discussed further in this paper. Despite all the research efforts, there appears to be no unanimity about the recovery mechanism. There have been inconsistencies in the report of many experimental studies. In addition, the some of the proposed mechanisms could only explain cases that showed a positive response and failed to explain cases with no significant benefit. Nonetheless, there are ongoing studies to reconcile how the wettability alteration occurs, as it is required for any dominant mechanism to elucidate and predict both successful and failed cases of brine-dependent recovery.

Despite this shortcoming, few modeling works [60-72] have been performed to simulate pore-to-surface-scale mechanisms that have been proposed to explain the complex oil-brine-rock interactions. Even so, a correct representation of the pertinent mechanisms in a mathematical model is required for an accurate prediction of fluid flow. Most modeling attempts to present solutions to the mathematical equations describing brine-dependent recovery process have explored numerical 
approximations, while a few have attempted the application of analytical solutions $[69,70,73,74]$. The practical value of these models lies in the fact that they aid to improve interpretations of the process and help conduct fast sensitivity computations. This review addresses the subjects of current interests about gathering information on past and recent developments, and challenges of brine-dependent recovery processes in sandstone and carbonate rocks. There have been several recent summaries that discussed different aspects of this subject [75-83]; hence, this review builds upon these summaries to further explore the published data to build theoretical understanding and identify potential opportunities for further investigation. Overall, the outcome of this review will potentially be of immense benefit to the oil industry.

The first part of the review will focus on describing the different systematic observations from laboratory experiments and field studies, taking into consideration the critical factors affecting the process performance. In the second part, the proposed fundamental mechanisms with its associated contradiction and resolutions will be discussed. The second part will be followed by outlining the major modeling attempts, including their potential challenges and lessons learned. Finally, a summary of the major compatibility issues associated with the injection water and the possible remediation will be presented and conclude with main highlights and potential opportunities for further investigation.

\section{Laboratory Experimental Studies}

Ever since waterflooding has been introduced to recover hydrocarbons left after the primary recovery process, numerous attempts to investigate the fundamental mechanism have been made in order to understand, design and optimize the displacement process $[84,85]$. The driving mechanism was then seen more as a physical process, and less attention was paid to the process chemistry. It was not until 1950 when some researchers [8,9] noted an improved production after freshwater injection during core experiments, which they credited to sweep efficiency as a result of clay swelling and pore throat plugging. However, the process chemistry considering the quality of the injected brine did not generate significant attention until the 1990s. The earliest comprehensive study undertaken by Morrow and colleagues [11-14,86,87] demonstrated the effect of oil-brine-rock interactions on improving oil recovery in a clay-rich rock formation and presented additional oil recovery from the brine-dependent process due to salinity gradient and wettability shift. Since then, numerous studies have been conducted with most tests showing positive results [13,21,23-34], while no response was observed in other tests [28,36-40].

Because of the large size of subsurface rocks with diverse mineralogical contents occupied by complex reservoir fluids, systematic investigations are usually conducted at all levels (from the molecular scale to macroscale, see Figure 1) in no particular order to completely understand and reliably predict subsurface processes. The scale of investigation often determines the type and degree of effects that are observed about gaining a complete knowledge of the process. As such, a systematic investigation of brine-dependent recovery has been explored at molecular scale (from atomic to nanometric level) through Atomic Force Microscopy (AFM), scanning electron microscopy (SEM), nuclear magnetic resonance (NMR) and $\zeta$-potential. At micro-scales, experiments (such as coreflooding, spontaneous imbibition, chromatographic and contact angle tests) typically investigate crude oil and brine flowing through or occupying pore spaces in the order of micrometres up to centimetres. Then, mechanisms and integrated effects can be further examined in a more magnified view at the macro-scale level through field trials and implementation.

Most of the laboratory evidence to support improvement in oil recovery during the brine-dependent process is mostly presented at different reservoir conditions through coreflood experiments (at microscale), in both secondary and/or tertiary mode, and augmented by spontaneous imbibition experiments. Some of the coreflood experiments are performed at low flooding rate $\left(<3.53 \times 10^{-6} \mathrm{~m} / \mathrm{s}\right.$ or 1 foot/day) on short core samples, which often results in the erroneous estimation of residual oil saturation, because the fluid movement and production are susceptible to capillary end-effects [88]. Meanwhile, increasing the injection rates to reduce the capillary 
end-effects did not lead to remobilization of trapped oil in many studies $[25,89,90]$, which emphasized the positive impacts of the injected brine on improved oil recovery. Spontaneous imbibition, on the other hand, is not only used to determine the initial wetting state but also to quantify the associated wettability changes when invading brine enters the pore-space [11,91,92]. This has reportedly yielded higher imbibition rate and total oil production with the invading brine in both secondary and tertiary mode $[11,13,31,48,93]$. Moreover, for wettability assessment, a lower rate and smaller extent of imbibition often indicate oil-wetting nature, while higher rate and larger extent of imbibition are indicative of water-wetness [13]. Determination of the rock surface wettability inferred/directly measured through different techniques at both molecular and micro scales such as contact angle measurements $[25,26,94-96]$, chromatographic test $[57,59,97]$, electrokinetic ( $\zeta$-potential) measurements [51,56,98-100], NMR [25,101,102], AFM [54,103,104], etc., has reported data consistent with a change to more water-wet conditions.

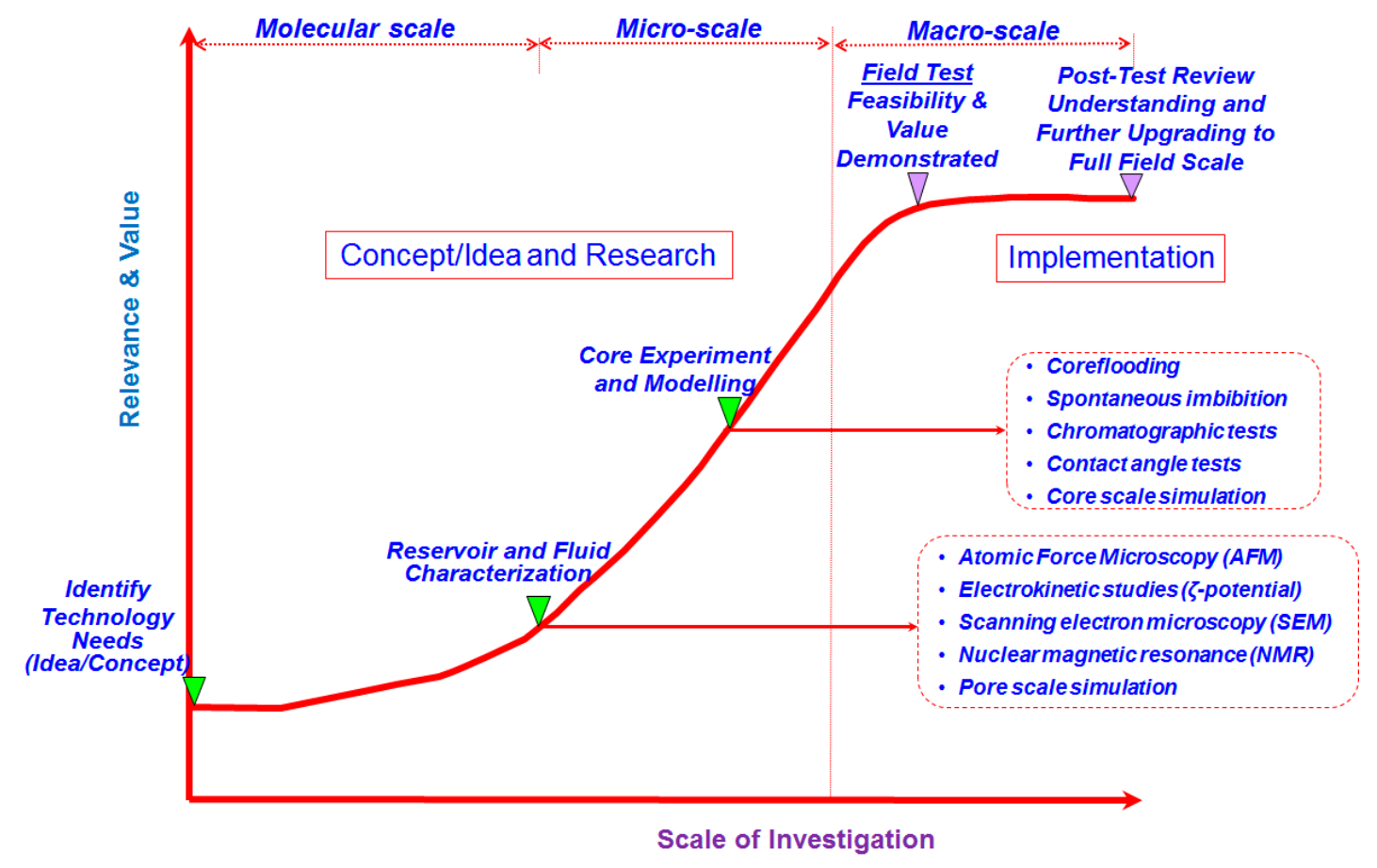

Figure 1. R\&D-to-Field sketch of the systematic investigation for brine-dependent recovery design and implementation (adapted from Sarma [105]).

The chromatographic test is a technique centred on the chromatographic partitioning of two water-soluble compounds, an adsorbing ion (like PDIs) and a non-adsorbing tracer ion (like $\mathrm{SCN}^{-}$), with the aim to calculate the water-wet fraction after the rock samples are exposed to various brines. The ratio of the area between the relative effluent concentration of the two water-soluble compounds and the corresponding area of completely water-wet cores are then related to the wetting conditions (0-oil-wet and 1-water-wet) of the rock samples [106]. The contact angle measurement is used to quantitatively express the degree of wetting when a solid surface is in contact with two fluids as measured through the denser fluid. The oil-wetting condition is often considered to be greater than $115^{\circ}$, water-wetting as less than $75^{\circ}$ while intermediate/neutral wetting is considered to be between both extremes [107]. AFM is used to directly measure intermolecular adhesion forces between two surfaces by generating force-distance curves, which provide valuable information about hydrodynamic interactions between deformable surfaces, the nature of each force, surface energies and indirect clues of surface mineral chemistry [108]. The $\zeta$-potential measurement is used to evaluate the electrokinetic behaviour of two interfaces in contact; the positive magnitude of one interface as compared to the negative magnitude of the other interface often result in electrostatic attraction between the two 
interfaces and consequently rupture the thin water film layer and lead to less water-wetness, and vice versa [109]. NMR is often based on $T_{2}$ relaxation time and surface relaxivity of fluid samples in a porous rock to determine different rock properties, especially pore occupancy and wettability because the relaxation time of the wetting phase is shorter than the bulk fluid phase $[47,101,102]$. These different scales of investigation have been well tested, though some were more tested compared to others, many of which will be discussed below. However, studies $[25,30,110-112]$ that reported interfacial tension measurements were not highlighted in this review because changes in the brine-oil interfacial tension observed is considerably less to associate the recovery process to IFT reduction compared to those associated with gas-dependent recovery processes and alkaline waterflooding.

Based on these previous studies, various aspects of the experimental method have been investigated, including reservoir and the injected brine parameters, to identify the optimum condition for brine-dependent process performance. The important parameters which have been given much attention in the literature in recent years, include the injection brine composition and ionic strength, connate water composition and saturation, rock type, clay content and type of clays present in the rock material, temperature, initial wettability of the rock surface, and crude oil composition and its acid/base number, as summarized below.

\subsection{Connate Water Content and Saturation}

Most oil reservoirs initially contain formation water, which is highly saline and more often contains a high concentration of multivalent ions. Table 1 compares the variation in water compositions in different regions with successful brine-dependent recovery field application, such as the Endicott, Ekofisk and Arabian Gulf. The $\mathrm{Ca}^{2+}$ concentration is usually high in the formation water and can be a factor of more than ten as compared to that of $\mathrm{Mg}^{2+}[113,114]$. The composition, salinity and saturation of the connate reservoir water can significantly influence the initial rock wetting state, which in turn based on its interactions with the injected water affects the efficiency of oil recovery.

Table 1. Different common formation water and seawater contents applied during brine-dependent recovery process (adapted from [21,25,79,115].

\begin{tabular}{ccccccc}
\hline \multirow{2}{*}{ Ions } & \multicolumn{3}{c}{ Seawater (ppm) } & \multicolumn{3}{c}{ Formation Water (ppm) } \\
\cline { 2 - 6 } & Endicott & Ekofisk North Sea & Arabian Gulf & Endicott & Ekofisk North Sea & Arabian Gulf \\
\hline $\mathrm{Na}^{+}$ & 10,812 & 10,345 & 18,043 & 11,850 & 15,748 & 59,491 \\
$\mathrm{~K}^{+}$ & 386 & 391 & 0 & 110 & 0 & 0 \\
$\mathrm{Ca}^{2+}$ & 402 & 521 & 652 & 320 & 9258 & 19,040 \\
$\mathrm{Mg}^{2+}$ & 1265 & 1093 & 2159 & 48 & 607 & 2439 \\
$\mathrm{Ba}^{2+}$ & 0 & 0 & 0 & 7 & 0 & 0 \\
$\mathrm{Sr}^{2+}$ & 7 & 0 & 11 & 24 & 0 & 0 \\
$\mathrm{Fe}^{2+}$ & 0 & 0 & 0 & 10 & 0 & 132,060 \\
$\mathrm{Cl}^{-}$ & 18,964 & 18,719 & 31,808 & 17,275 & 42,437 & 350 \\
$\mathrm{HCO}_{3}{ }^{-}$ & 147 & 122 & 119 & 2000 & 0 & 354 \\
$\mathrm{SO}_{4}^{2-}$ & 2645 & 2305 & 4450 & 63 & 0 & 0 \\
$\mathrm{CO}_{3}^{2-}$ & 0 & 0 & 27 & 0 & 0 & 213,734 \\
$\mathrm{TDS}_{\text {Ionic Strength }}$ & 34,628 & 33,498 & 57,269 & 31,707 & 68,051 & 4.317 \\
pH & 0.688 & 0.659 & 1.146 & 0.541 & 1.453 & \\
\hline
\end{tabular}

\subsubsection{Sandstone Rocks}

It was documented that a reduction of initial water saturation results in a shift towards oil-wetness [11,15]. Xie and Morrow [92] observed that a decrease in initial water saturation (in the range 9.6-31.2\%) systematically increases the imbibition rate for weakly water-wet rocks. Tang and Morrow [13] observed a similar oil recovery and imbibition rate from a high-saline water injection and a low-saline water injection in cores aged in crude oil with no initial formation brine. The authors emphasize that the presence of initial water play a key role in the mechanism by which oil recovery can be affected by salinity. Zhang and Morrow [116] observed improved oil recovery in both secondary 
and tertiary injection modes in oil-aged sandstone rocks and reported better response to oil recovery in the secondary mode as initial water saturation increases. Meanwhile, Sharma and Filoco [35] reported that the connate water salinity primarily controls the oil recovery efficiency, similar to observations made by Tang and Morrow [12]. With varying connate water salinities $(0.3 \%, 3 \%$ and $20 \% \mathrm{NaCl})$ and the injected water salinity of $3 \% \mathrm{NaCl}$, the oil recovery was higher when the connate water salinity was reduced. This was attributed to wettability alteration from water-wet conditions to mixed-wet conditions. This is in line with the fact that as injection salinity increased; the electrostatic repulsion reduces, leading to the electrical double layer contraction, which would result in less stable water layer films. In another study, Lager et al. [24] argued that multivalent ions must be initially present to promote an oil-wetting state of clay mineral surfaces through cations bridging mechanisms. They reported that no positive response was observed in cores (where multivalent ions were removed from the mineral surfaces, prior to ageing in oil and high saline brine with no multivalent ions) flooded with the same brine of lower salinity. The argument of the initial presence of multivalent ions and its effect on rock wettability was further supported by numerous studies $[11,32,95,117,118]$, though other key parameters were also identified. Similarly, Buckley et al. [119] observed that the initial brine composition influences the wetting alteration and $\mathrm{Ca}^{2+}$ ions are specifically involved in ion-binding mechanisms for highly acidic oil. Meanwhile, the apparent wettability was independent of brine compositions for less acidic crudes [120].

In contrast, Suijkerbuijk et al. [114] found an obvious dependency of similar less acidic crudes on initial brine compositions and further reported that cores aged with $\mathrm{Ca}^{2+}$-rich formation brine became less water-wet compared to those aged with the same concentration of $\mathrm{Mg}^{2+}$-rich formation brine (wettability to oil-wetness in the order $\mathrm{Na}^{+}<\mathrm{Mg}^{2+}<\mathrm{Ca}^{2+}$ ). Several other studies (like $[8,100,121]$ ) have shown that in the absence of multivalent ions, positive benefits are still observed when the brine salinity is reduced. $\mathrm{Li}$ [122] reported higher incremental recovery in the absence of initial water saturation during secondary and tertiary injection modes for the weakly water-wet core. They concluded that with same rock wettability, oil recovery increased with lower initial water saturation while at same initial water saturation, oil recovery increased with reduced water-wetness. Gamage and Thyne [123] reported that $6-8 \%$ more oil was produced in the secondary mode when the water saturation was low compared to a tertiary mode with the same low saline brine in Berea sandstone while $10-22 \%$ more oil was produced for Minnelusa rock. Rezaeidoust et al. [124] proposed that the initial $\mathrm{pH}$ of the connate water also plays a critical role; with reduced $\mathrm{pH}$, the adsorption of organic material in the oil onto clay minerals is promoted $[41,125,126]$. The authors stated that the positive response from brine-dependent recovery was doubled when $\mathrm{CO}_{2}$ was present, as the presence of $\mathrm{CO}_{2}$ decreased the initial $\mathrm{pH}$. This was supported by numerous studies (such as $[12,21,33,41,95,118,124]$ ) that further established a link between an increase in effluent brine $\mathrm{pH}$ and improved oil recovery as low saline brine is injected, which indicates wettability changes. A few other studies (such as $[24,33,124,127]$ ) have reported constant $\mathrm{pH}$ through the flooding process rejecting the claim of a link between the $\mathrm{pH}$ gradient and observed oil recovery.

\subsubsection{Carbonate Rocks}

In contrast to sandstone rock, an increase in initial water saturation up to $34 \%$ leads to an increase in imbibition rate in Chalk as reported by Viksund et al. [128]. It was reported that the scaled imbibition curves for chalk in the absence of initial saturation closely agrees with that of sandstone rock. Strand et al. [97] reported twice the oil recovery observed using similar salinity brine in the core with the initial saturation of $9.1 \%$ than that of $14.8 \%$ initial water saturation, even though much of the improved recovery was attributed to the presence of sulfate in water injected into $14.8 \%$ water saturated cores. Similarly, Puntervold et al. [129] compared the effect of a range of initial water saturations (high-30-50\%, low-10\% and no water saturation- $-\%$ ) on oil recovery and observed that the cores became less water-wet as the water saturation decreases. This led to reduction in the imbibition rate and it was proposed that at low water saturation, high oil saturation increases the 
amount of crude oil surface-active materials such that the oil can easily adsorb on the rock surface. In a subsequent study, Puntervold et al. [130] observed no difference in oil recovery when two cores were initially saturated with deionized water at $22 \%$ and $10 \%$ water saturation, respectively and flooded with similar brines at $90^{\circ} \mathrm{C}$ and $130^{\circ} \mathrm{C}$. The authors further proved through chromatographic tests and spontaneous imbibition that a small amount of sulfate in the formation brine can significantly improve the rock water wetness and oil recovery. A similar study conducted on Stevns outcrop chalk reported that when initial sulfate was removed from the core by flooding with distilled water prior to aging, the effect of sulfate on the oil recovery was greater compared with core plugs where the sulfate was initially present [131]. Furthermore, Shariatpanahi et al. [113] conducted additional studies on impacts of sulfate present in the initial brine on the initial wetting state and confirmed that increasing sulfate concentration to $2 \mathrm{mmol} / \mathrm{L}$ increased oil recovery and decreased water-wetness. The improvement in oil recovery and water-wetness was reported to increase as the aging temperature decreased (130-50), while no noticeable improvement was observed as the sulfate concentration was increased beyond $2 \mathrm{mmol} / \mathrm{L}$ in the initial brine. In addition, Zhang et al. [93] reported that increasing $\mathrm{Ca}^{2+}$ concentration in the initial brine has a very marginal effect on the rock wetting condition. In a recent study by Shariatpanahi et al. [132], it was shown that increasing $\mathrm{Ca}^{2+}$ concentration decreased the water-wetness while $\mathrm{Mg}^{2+}$ in the formation brine makes the rock more water wet.

\subsection{Crude Oil Composition}

Crude oil usually contains both acids and bases that are ionizable and exhibit surface activity [133]. The ionizable acidic and basic surface-active groups of the crude oil form as a result of the presence of typical hetero-elements (like nitrogen, oxygen, and sulphur) found in oil [134]. Petroleum bases are identified as heterocyclic aromatics with nitrogen atom, quantified by basic number (BN); while the quantity of carboxylic materials in crude oil are used in characterizing petroleum acids, quantified by acid number (AN). The carboxylic group and the nitrogen-containing bases, as mostly found in crude oil heavy end fractions, i.e., asphaltene and resins, plays such a vital role on the rock initial wetting. The polarity and the chemical properties of crude oil as determined by its ionizable acidic and basic surface groups can influence rock wettability [119].

\subsubsection{Sandstone Rocks}

Various earlier studies [134-138] have described the role of heavy fractions, asphaltenes or acid and basic components in crude oil on rock wetting state. However, not all crude components have been reported to be influential in altering the preference of the rock towards oil wetting. Denekas et al. [134] presented that sandstones seem not to have any selective affinity for a specific type of polar product, as both the acidic and basic components of the crude oil alters the rock wettability. The authors also established a trend of increased wettability effect as the boiling point and molecular weights of the crude oil fractions increased, which was similar to observations made by Cuiec [135]. Elsewhere, Ehrlich [136] showed that removing the acid fraction of the crude oil subjects the Berea sandstone rock to preferential oil wet nature. Many authors have also found that the basic component is strongly adsorbed on the surface of glass $[137,138]$ and quartz [139], whereas the acidic component (stearic acid) is not. Meanwhile, several other authors (such as: $[87,135,138,140-144])$ have declared the prominence of the heavy fractions, especially asphathene, in promoting sandstone rock affinity to oil. This was further supported by further studies $[135,145]$, where it was highlighted that asphathene was the most highly retained fractions of the crude oil when comparing the fraction of the oil before and after with sandstone rock. In contrast, Johansen and Dunning [146] demonstrated that propane fraction precipitates from Rio Bravo, Tatums and Bartlesville Dewey promoted the oil wettability of a glass surface. While Ehrlich [136] showed that deasphalted propane precipitates lower the affinity of the oil towards the Berea sandstone rock.

Many of these studies, as discussed above, were conducted in the absence of interstitial water, however as pointed out by Cuiec [135], same rock/crude-oil interactions would have occurred in the 
presence of interstitial water but more impact would be on the kinetics and the distribution of retained oil fractions. A number of studies were conducted by Buckley and coworkers [119,147-149] on the relationship between wettability and oil composition, where they categorized the variety of ways the functional groups in oil can rapidly interact with the rock surfaces to alter the rock wettability in the absence of water as polar interactions. Yildiz and Morrow [14] ascribed the difference in oil recovery when similar low saline brine was injected into two different oils (Moutray and Alaskan) to the wettability difference created by crude oil. Similarly, Jadhunandan and Morrow [11] carried out a wettability and coreflood experiment on two different oils and reported that the oil with higher asphaltene content and acid number showed higher sensitivity to wettability changes under brine composition changes and distinctly higher recovery efficiency. Tang and Morrow [12] observed that the addition of light components to the crude oil led to decrease in water wetness of the rock through spontaneous imbibition. This was further affirmed by Buckley et al. [119] that increasing the proportion of poor asphaltene solvent in the oil can decrease the water wetness. The crude oil/brine/rock interaction through which the wettability was altered was categorized surface precipitation, where destabilization and precipitation of asphaltene resulted in more adsorption of asphaltene and less water wet conditions. Meanwhile, for the acid/base interactions, Buckley et al. [119] emphasized that the functional groups in both the crude oil and rock phases can behave as acids and bases depending on the salinity of the brine composition and the interaction $\mathrm{pH}$ to adsorb oil at the rock surface. They observed that three oils with increasing ratio of base to acid numbers resulted in less water wetting nature as the basic component in the oil adsorbed onto the acidic silica surfaces. It was further stated that a combination of oil compositional characteristics (G-AB parameters-API gravity, acid and base numbers) is required to give a qualitative indication of the extent to which oil alters wettability [148]. Similar observations on base/acid ratio were made by Skauge et al. [150] as they reported an increase in contact angle (more water-wet behavior) with increase in base/acid ratio. It was proposed that as the base number increased, the number of positive sites at the oil/water interface would increase and consequently enhance its electrostatic attraction towards the negatively charged quartz/water interface.

In another study, Lager et al. [24] stated that there is no direct correlation between improved recovery by low saline brine and acid number of crude oil as some of the best coreflood experiments were carried out on crude oil with low acid number $(\mathrm{AN}<0.05)$ as opposed to different studies (especially alkaline flooding) that showed that high acid number is necessary to induce wettability reversal. Jackson et al. [75] also found no correlation between improved oil recovery and acid number by collating data sets from different sources (see Figure 2). Rezaeidoust et al. [124] compared oil recovery from two opposite crude oils and stated that the oil with high basic content gave lower recovery, indicating less water wetness during high saline secondary recovery. They acknowledged that the basic component is strongly adsorbed to the negatively charged quartz as compared to the acidic component during high saline water injection. However, both oils gave quite similar recovery during the tertiary low saline injection and concluded that both basic and acidic components in the crude oil contributed to the adsorption onto clay minerals. Furthermore, Fjelde et al. [120] conducted flooding experiments in packed columns with reservoir rock and reported that polar oil components were more retained when using oil with the highest base/acid ratio and the retention was not dependent on brine salinity. In contrast, Suijkerbuijk et al. [114] could not clearly correlate asphaltene stability, acid and base numbers to wettability changes as oils with varying asphaltene content and acid and base numbers gave diverse oil-wetting behavior. Meanwhile, observations from both interfacial tension and contact angle experiments indicate that acid structures/types are more important than acid concentrations, as oil enriched in phenols, alkyl and cyclic acids had more impact on silicate surface wetting whereas more complicated aromatic ring-structured acids did not affect the rock wetting state [151]. In a recent study, Mwangi et al. [152] observed that the AN alone is not sufficient to predict the effect of crude oil on wettability as different acids do have opposite effects. 
It was reported that long-chained acids decreased water wetting as salinity was reduced, while the short-chained acids increased water wetting under the same conditions.

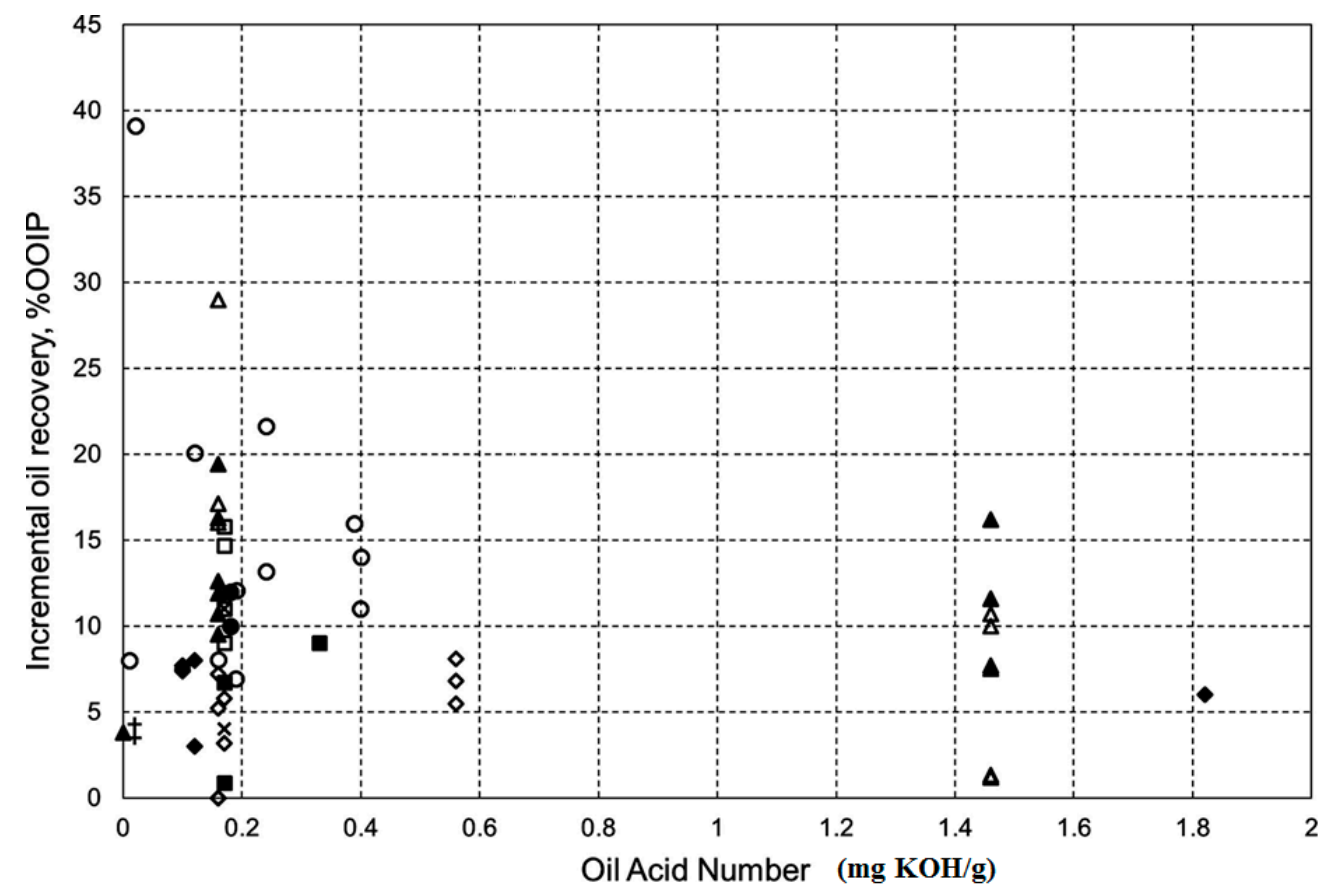

Figure 2. Collection of data showing lack of correlation between improved oil recovery and acid number (AN) of the crude oil (see more information about the plotted data in Jackson et al. [75]).

\subsubsection{Carbonate Rocks}

In contrast to their observations on sandstone rocks, Denekas et al. [134] confirmed that limestones seem to be more sensitive to basic products containing nitrogen. Many other authors [153-155] have expressed contradictory opinions about the above assertion that indicate the possibility of the chemisorption of the acid components (most notably naphthenic acids) of crude oils on the basic carbonate surface. The differences in opinions could be as a result of increased decarboxylation of carboxylic material in crude oil at elevated temperatures, catalyzed by the presence of formation itself $\left(\mathrm{CaCO}_{3}\right)$, and leading to a reduction in acid number compared to basic number over geological time [156]. In a different study, Standnes and Austad [91] reported that acid number is a crucial wettability factor for carbonate rocks as the imbibition rate and water-wetness was observed to decrease as the AN increased in the absence of initial water (see Figure 3). The authors didn't observe any correlation between the imbibition rates and the asphaltenes content and stated that the functional acid groups did not dominate the asphaltene fraction of the oil. In several tests performed on chalk wetting properties using oils with different $\mathrm{AN}(0.17-2.07 \mathrm{mg} \mathrm{KOH} / \mathrm{g})$ and synthetic seawater, an increased water-wetness as the AN decreased was reported by Zhang and Austad [157]. Austad et al. [45] also compared imbibition rate of limestone cores aged in two different crude oils, imbibed in formation water and reported that the imbibition rate decreased as the AN increased, while the contribution from $\mathrm{BN}$ was ignored. In a similar study, the imbibition rate was observed to further increase as the brine was switched to brine of higher sulfate concentration with increased AN [158].

A wider range of organic compounds were investigated for carbonate rock adsorption and wettability by Thomas et al. [159]. Fatty acids were observed to strongly and nearly irreversibly adsorb to the carbonate surface, whereas aromatic and branched carboxylates and long chain acids were moderately adsorbed and alcohols, amines, short-chain acids were weakly-adsorbed/non-adsorbed. It was also stated that the overall structure of the compound determined its adsorption strength, for example, the small size of the carboxyl group and long straight chains of the fatty acids lead 
to formation of a closely-packed hydrophobic layer, thereby providing multiple attachment sites to stabilize the adsorption and make the carbonate surfaces oil-wet. Standnes and Austad [91] also claim that carboxyl groups are the most active polar functional groups of crude oil in adsorbing organic material onto the chalk surface. Several other authors [152,160-163] have shown that long chain acids are the most effective among researched acidic species to alter the carbonate rock to a more oil-wet state. Despite that the effect of basic materials on wettability was not widely studied, Puntervold et al. [129], observed that an increase in the amount of natural bases led to decrease in water-wetness as AN was held constant. It was suggested that the natural base forms a large molecular weight acid-base complex to be in equilibrium with the carboxylic materials in the oil, thereby preventing the carboxylates from adsorbing to the rock. In many of the discussed studies, it is well agreed that the AN and BN of the crude oil, associated with the presence of long chain acids, play a significant role in wettability alteration of carbonate surfaces.

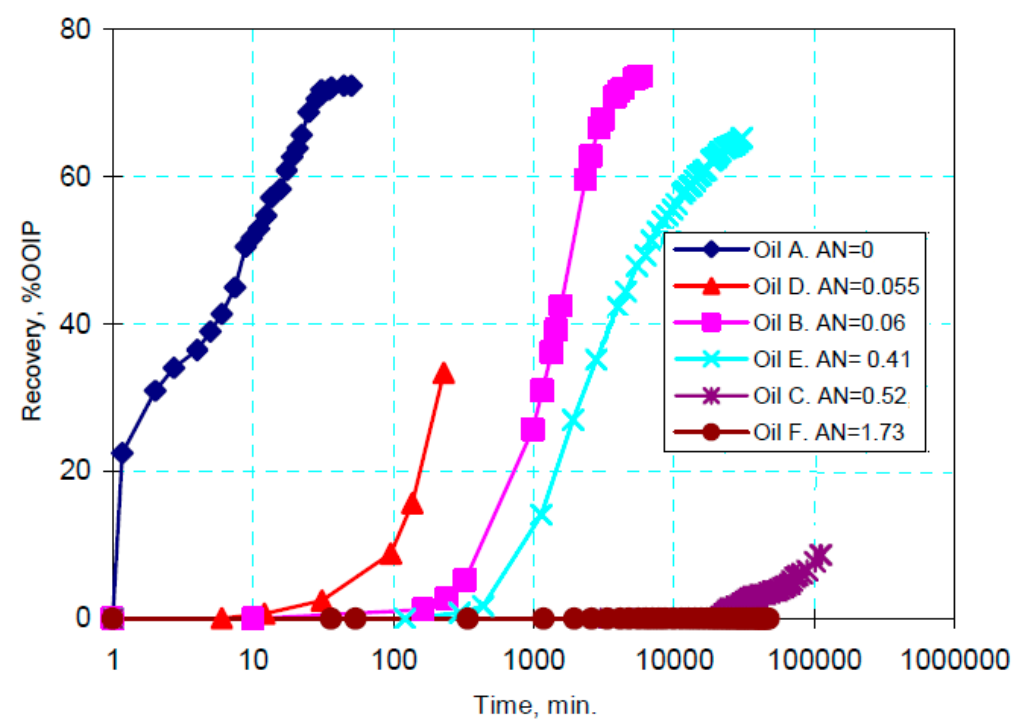

Figure 3. Effect of acid number (AN) on spontaneous imbibition of brine into chalk cores saturated with different crude oil (reproduced from Standnes and Austad [91] with permission).

\subsection{Rock Mineral Composition}

Different rock types have varying mineral compositions that affect the rock's surface area, grain structure, crystalline texture, and reactivity towards diverse ions in brines and this reflects the heterogenous nature of the reservoir and difference in their responses towards brine-dependent recovery processes. Therefore, understanding the effect of rock properties as it influences the initial wetting state and response to brine-dependent recovery is essential for valid comparison.

\subsubsection{Sandstone Rocks}

Sandstone rocks are composed of many different minerals primarily of the silica type (most commonly quartz, feldspar, and clays) that are negatively charged at the typical reservoir $\mathrm{pH}$ range. Typical clay minerals include swelling clays like smectite (montmorillonite) and non-swelling clays like kaolinite, chlorite, and illite [52,164]. The importance of clay content and type has been widely studied amidst all the silica type minerals of sandstone rocks and has been identified to be significant by acting as cation exchangers in promoting the adsorption of oil polar components to the rock surface. Early studies by various researchers [7-9,165-167] have related the improvement in oil recovery with low saline brine to the presence of clay in both synthetic and natural cores, which is accompanied with clay swelling and pressure drop increment. Further investigation conducted by Tang and Morrow [13] reported no increase in oil recovery as low saline brine was injected into sandstones with destroyed clay structure through firing and acidizing. Meanwhile, sandstone cores with higher clay content 
exhibited higher imbibition rate and oil recovery. Similarly, Wickramathilaka et al. [168] suggests that higher incremental recovery by low saline brine was achieved by cores of higher total clay content. It was also suggested that based on no significant difference in responses to imbibition and waterflood by two sandstone rocks of widely different clay content, different pore geometry and concomitant clay mineral distributions may have impacted the results. Austad et al. [52] argued that brine-dependent recovery is more favored by clay minerals with high cation exchange capacity (CEC), which varies in the following ascending order of clay types: kaolinite $>$ chlorite $>$ illite $>$ smectite $[52,75,164,169,170]$. Several other studies worked on the premise of the necessity of clay minerals for optimum performance of brine-dependent recovery, without identifying the clay minerals type(s) that had a greater impact on flooding performance. Zhang and Morrow [116] identified the significance of the type of clay mineral and attributed the lack of response to low saline brine in a block of Berea sandstone samples to the presence of chlorite, serving as baffles to inhibit kaolinite mobility and contact with the oil, similarly observed by Ligthelm et al. [32]. Similar observations were made by Tong et al. [171] as electron micrographs showed coating of grain surfaces by chlorite and no response in oil recovery was observed even though pressure changes was observed. Researchers at BP $[172,173]$ later published a correlation that suggested that oil recovery with low saline brine increased as the kaolinite content increased. Kaolinite was considered effective, because of its high surface charge density and $\mathrm{pH}$ dependency of its surface charge [174], which makes its surface electric effect much greater when compared to other clay minerals. Similarly, Rezaeidoust et al. [42] observed a decrease in oil recovery from $6 \%$ to $2 \%$ when clay content reduced from $16 \mathrm{wt} . \%$ to $8 \mathrm{wt} . \%$.

In a pore-scale study conducted by Lebedeva and Fogden [175], low saline brine injection was observed to improve recovery in quartz sandpacks with kaolinite-coated mineral, ascribing that the oil-wetness wettability due to kaolinite was altered to more water-wetness. Hassenkam et al. [103] also stated results from AFM experiments on sandstone minerals model surfaces (like silica, illite and mica) that the carboxylic acid is less adhered onto the amorphous silica and mica surfaces during exposure to low saline brine, while the adhesion was the same on illite during exposure to both low and high saline brines. Improvement in oil recovery has also been demonstrated with other clay mineral types (like chlorite, Illite, and muscovite) in the absence of kaolinite [118]. Likewise, several other studies (like $[29,104,176,177])$ have observed oil recovery improvement in clay-free sandpacks and sandstone cores. It was proposed that oil component adsorption on quartz surfaces [54] and the presence of anhydrite/dolomite cementing the quartz matrix $[104,176]$ may have triggered wettability alteration that led to improvement in oil recovery. Lee et al. [178] conducted small angle neutron scattering experiments (SANS) to identify and characterize the presence and structure of water layers using different sandstone particles and reported a more amplified sensitivity in water layer thickness with clay surfaces than silica surfaces. Hilner et al. [54] also stated that the decrease in adhesion observed through AFM on quartz is at least one order of magnitude less than on clay surfaces, because of the much lower surface charge on quartz compared to the type of clay minerals usually found in sandstone. Brady et al. [179] stated that the quartz surface site is composed of a Si site ( $>\mathrm{SiOH})$ while clay like kaolinite is composed of an $\mathrm{Al}$ and $\mathrm{Si}$ site $(>\mathrm{Al}: \mathrm{SiOH})$ as illustrated in Figure 4. The main difference is that kaolinite possesses more negatively charged sites at higher $\mathrm{pH}$ and its $\mathrm{Al}$ site can acquire a $\mathrm{H}^{+}$to become positively charged at low $\mathrm{pH}$, while quartz surfaces are negatively charged above a $\mathrm{pH}$ of 2 . Both mineral surfaces showed a similar trend with increasing $\mathrm{pH}$ and $\mathrm{NaCl}$ brine salinity. Therefore, it is possible to observe improved water-wetness due to low saline brine injection on quartz grain, but the presence of clays can either increase pore surface charge or provide a higher surface area and an anchor point for the oil compounds to further increase the effect of wettability changes. In addition, cores particles solely containing different clay types, such as kaolinite, illite, chlorite and montmorillonite, have been reported to show similar electrostatic behavior with quartz-dominated Berea sandstones $[56,180]$. In several other studies (like $[33,38,116])$, it was reported that sandstone reservoir rocks responded better to low saline brine than outcrop rocks, which demonstrated that 
different sources of sandstone show varying responses to brine-dependent recovery due to different pore geometries and grain structures [168].

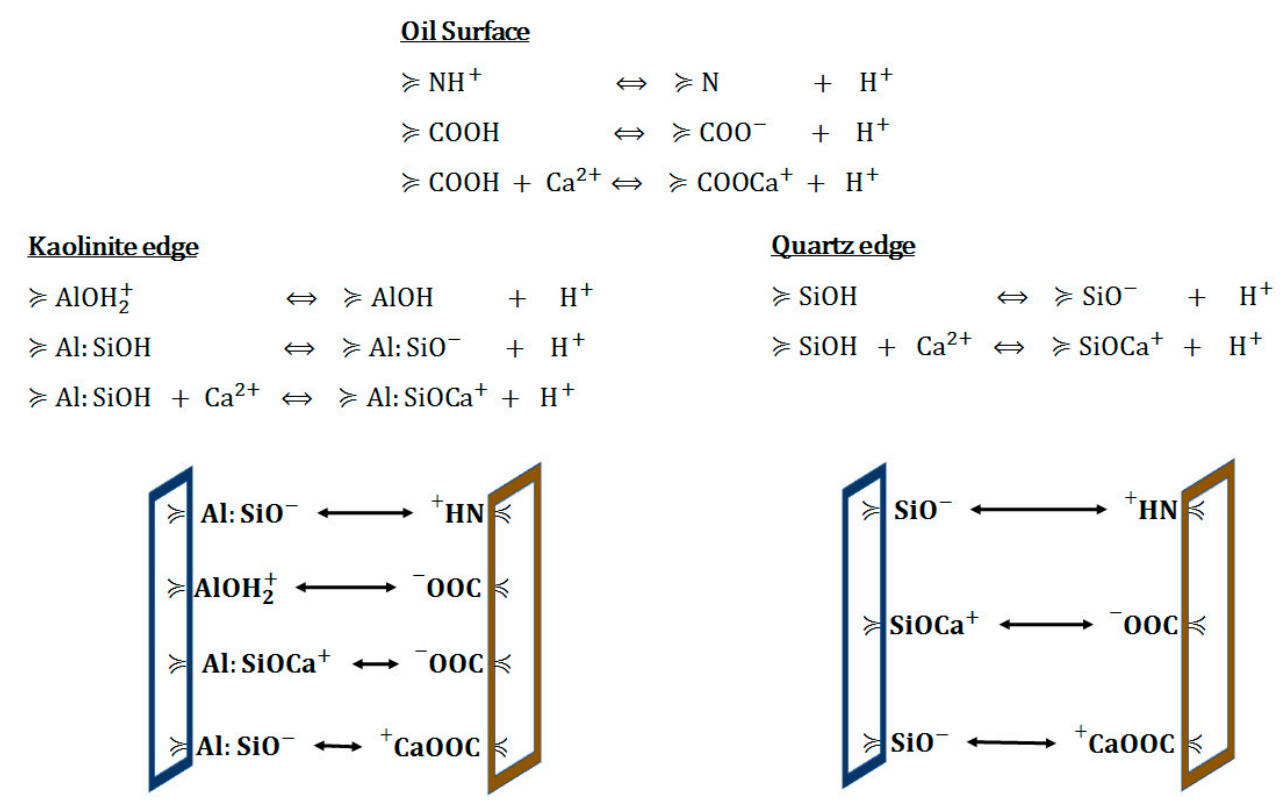

Figure 4. Possible oil-clay electrostatic attraction bridges that can influence oil adhesion onto the clay surface based on surface complexation reactions at the oil surface site (top), kaolinite edge (middle left) and quartz edge (middle right) (adapted from Brady et al. [179]).

\subsubsection{Carbonate Rocks}

On the other hand, carbonate rocks are primarily composed of calcite $\left(\mathrm{CaCO}_{3}\right)$ and dolomite $\left(\mathrm{CaMg}\left(\mathrm{CO}_{3}\right)_{2}\right)$, with a variety of other minerals like anhydrite/gypsum $\left(\mathrm{CaSO}_{4}\right)$, magnesite $\left(\mathrm{MgCO}_{3}\right)$, Aragonite $\left(\mathrm{CaCO}_{3}\right)$, apatite (phosphate source), quartz, siderite $\left(\mathrm{FeCO}_{3}\right)$, evaporite, pyrite, etc. [181,182]. Carbonate rocks often experience different post-depositional chemical/physical changes, which results in corresponding changes in rock properties, such as surface area, reactivity, permeability, porosity, faults, fractures, and wettability. Studies by various authors (like [183-185]) have shown that mechanical properties (such as strength, yield, and bulk modulus) of chalk is weakened (decreased) when flooded with seawater containing $\mathrm{SO}_{4}{ }^{2-}$ ions, which can enhance compaction and cause a minor change in permeability as compared to distilled water and seawater without sulfate. The resulting large-scale heterogeneity often generates complex fluid flow paths, which has been shown to increase oil displacement through ionically-modified brine injection from the matrix blocks by well-connected induced fractures [186], compared with non-connected fractured cores. Meanwhile, it has been shown that the surface area and the reactivity towards PDIs in the injected brine vary for different carbonates. Several parametric studies have demonstrated that chalk (a pure biogenic calcite) is highly reactive to PDIs as their adsorption can change the surface charge of the rock and alter rock wettability $[31,57,59,93,106,158,187-189]$. The degree of sulfate ions adsorption was found to be different depending on the chalk type $[131,183,190]$ and proportional to the surface area of the specific chalk [183]. Further studies by Fathi et al. [28] suggested that NaCl-depleted seawater is more reactive to the chalk surface as its imbibition rate and ultimate oil recovery increased relative to ordinary seawater and further improvement was observed when $\mathrm{NaCl}$-depleted seawater was spiked by sulfate [191], while increasing $\mathrm{NaCl}$ concentration led to decrease in oil recovery. However, limestone, which is less homogeneous than chalk with smaller surface area, has been reported to have a similar affinity towards PDIs, although the reactivity is less than it is for chalk [23,32,34,97]. As for chalk, $\mathrm{NaCl}$-depleted seawater appeared to be an even better wettability modifier in limestone than ordinary seawater [34,39]. 
On the other hand, injection of low saline brine in chalk cores did not result in additional recovery $[28,37,45]$. In the same study, Austad et al. [45] reported oil recovery improvement when limestone cores containing anhydrite was flooded with low saline brine. The study indicated that the improvement in oil recovery recorded by Yousef et al. [47] on limestone core was as a result of anhydrite dissolution that led to in-situ generation of $\mathrm{SO}_{4}{ }^{2-}$ ions. The authors claimed that the presence of anhydrite is essential for the success of brine-dependent recovery in cases where injected brine contains little/no $\mathrm{SO}_{4}{ }^{2-}$ ions. Meanwhile, Romanuka et al. [46] conducted spontaneous imbibition experiments on limestone cores (primarily calcite) and showed that brine dilution contributed to an incremental recovery up to $2-4 \%$ OOIP, whereas $\mathrm{NaCl}$-depleted seawater had no recovery benefit. Zahid et al. [37] also reported a substantial increase in oil recovery with diluted seawater on carbonate cores free of dolomite/anhydrite, and suggested that rather than anhydrite dissolution, calcite mineral rock dissolution leading to fines migration was the plausible mechanism for the incremental recovery. Dolomite core, which predominantly contains dolomite, has been reported to have a similar surface reactivity towards PDIs in the injected brines, however is weaker compared to chalk and limestone cores $[46,99,132,192]$. Shariatpanahi et al. [132] reported that the presence of sulfate ions (either through the injected brine or anhydrite dissolution [46]) is essential to observe oil recovery benefits and the brine salinity was suggested to be low to increase surface reactivity of dolomites to PDIs. The degree of improvement in oil recovery and wettability alteration has been observed to differ based on the mineral composition, grain structure, deposition and crystallographic origin of carbonate rocks [99]. In the study by Mahani et al. [99], it was observed that adhesion between carbonate rocks and oil varies in the following descending order: dolomite $>$ calcite crystal $>$ limestone $>$ chalk for the same type of brine and oil, which signifies that rock surface reactivity is the reverse order (see Figure 5). Likewise, it was reported that limestone showed negative $\zeta$-potential in all tested brines, while dolomite showed more positive $\zeta$-potential, which was related to higher charge density on dolomite, because of the presence of $\mathrm{Mg}^{2+}$ in its crytaline lattice.
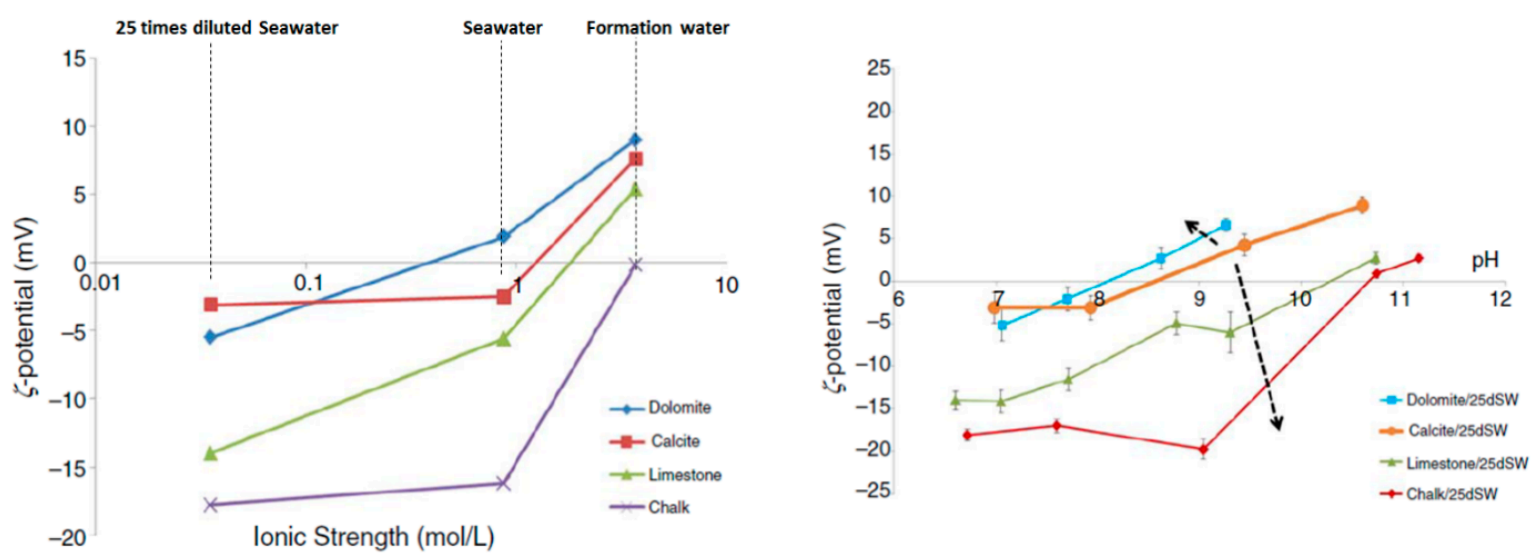

Figure 5. Comparison between $\zeta$-potential of chalk, calcite, limestone and dolomite in different brine salinity (plotted in log-scale) at reservoir $\mathrm{pH}$ of 7 (left) and in 25 times diluted seawater at $\mathrm{pH}$ range 6-11 (right) (reproduced from Mahani et al. [99] with permission).

Additionally, different types of outcrop chalk cores were reported to have a diverse degree of reactivity towards $\mathrm{SO}_{4}{ }^{2-}$ ions with its associated oil recovery benefits due to their mineral depositions and compositional differences [131]. Like outcrop sandstones, outcrop limestones acted completely different from reservoir limestone in wettability alteration studies, which showed that diverse sources of rock could influence the systematic investigation of brine-dependent recovery process. Two outcrop limestones were tested, both showed water-wet conditions and appeared nonreactive towards PDIs as seawater flooding at high temperature couldn't modify the wettability and improve oil recovery [193]. Contrary to outcrop limestones, outcrop dolomite responds to ionically-modified water in the same way as reservoir dolomite cores [132]. In an electrokinetic study by Al Mahrouqi et al. [50], it was 
reported that natural carbonate yielded a more negative $\zeta$-potential than synthetic calcite, due to the presence of impurities (such as clays, organic matter, anhydrite apatite, or quartz), which yield a negative $\zeta$-potential compared to pure calcite. Similarly, it was reported that synthetic calcite and pre-aged calcite rock exhibited positive $\zeta$-potential at a low $\mathrm{pH}$ range and negative potential at a higher $\mathrm{pH}$ (above $\mathrm{pH}$ of 10), which was attributed to positive species (like $\mathrm{Ca}^{2+}$ and $\mathrm{CaHCO}_{3}{ }^{+}$) and negative species (like $\mathrm{CO}_{3}{ }^{2-}$ ) prevalence at the rock surface at lower and high $\mathrm{pH}$ respectively. Meanwhile, natural calcite and post-aged calcite rock exhibited negative $\zeta$-potential, which was attributed to the organic materials adsorption on the calcite surface, giving it the negatively charge surface $[194,195]$.

\subsection{Temperature and Pressure}

Due to the reactive nature of the brine-dependent recovery process, reservoir temperature is a key factor that affects the activation energy required for the chemical reaction at the oil-brine and brine-rock interfaces leading to the wettability alteration process. The influence of temperature can be categorized into two-fold, as it affects rock wettability through the interaction of oil polar organic compounds and the reactivity of ionic species in the brine or sensitivity of the ionic strength with the rock surface. Pressure is mostly identified to impact the oil polar organic compounds interaction with the rock surface due to changes in the solubility of the asphaltenic content of the crude oil. As the reservoir pressure reduces towards bubble point pressure, the asphaltene solubility decreases, resulting in surface precipitation and adsorption of the crude oil onto the rock surface $[119,148]$.

\subsubsection{Sandstone Rocks}

The AN of crude oil is known to be dependent on reservoir temperature, which decreases as the temperature increases because of decarboxylation of the acidic components of the oil. Like the catalytic effect of $\mathrm{CaCO}_{3}$, presence of clay minerals or clay metallic oxides [156,196-198] has been identified to promote the thermal degradation of crude oil but to a lesser extent compared to $\mathrm{CaCO}_{3}$ [156]. The reduction in AN could possibly lead to an increasing base/acid ratio, which has been reported to result in less water-wetness $[119,150]$. There appears to be no temperature limitations to where improvement in oil recovery due to brine-dependent recovery can be observed, though, most studies have been conducted at temperatures below $100{ }^{\circ} \mathrm{C}$. As it relates to initial rock wettability, Jadhunandan and Morrow [11] reported that the rock water-wetness decreased as the aging temperature increased with many other key variables held constant. Zhou et al. [199] recovered less oil for sandstone core plugs aged at $80{ }^{\circ} \mathrm{C}$ compared to $25^{\circ} \mathrm{C}$ and stated that short-term imbibition rates systematically decreased with increase in aging time and temperature. Rezaeidoust et al. [42] suggested that aging temperature had more impact on oil recovery compared to displacement temperature, as they only observed improved oil recovery by aging at $90^{\circ} \mathrm{C}$. It was stated that large hydration energy of $\mathrm{Ca}^{2+}$ and $\mathrm{Mg}^{2+}$ develops as temperature increases, which will increase the reactivity of both ions towards clay mineral surface and cause ion-binding to oil polar compounds. However, displacement temperature has been reported to play a significant role in improving oil recovery; typically as the displacement temperature increases, the rate and extent of imbibition on Berea sandstone increases $[12,86]$. The only exception that showed no temperature effect reported by Tang and Morrow [12] was when refined oil was used in place of crude oil, which was attributed to overall effect of COBR interactions rather than a single rock/brine interaction.

In another study by Agbalaka et al. [121] using low saline (1-2 wt. $\% \mathrm{NaCl}$ ) and high saline ( $4 \mathrm{wt.} \% \mathrm{NaCl}$ ) brines at low to elevated temperatures, additional oil recovery was obtained in both secondary and tertiary modes with reduction in brine salinity (from 4 to $1 \mathrm{wt} . \%$ ) and further increased at elevated temperatures compared to low temperatures. The observed increase in recovery at elevated temperature was initially suspected to be due to additional reduction in fluid viscosity with increase in temperature. However, wettability characterization using the Amott-Harvey wettability index showed an increasing trend as the brine salinity reduces and temperature increases, which indicates increasing rock water-wetness. However, several other studies $[43,118,200]$ have shown an opposite 
temperature-dependence where higher incremental oil recovery was observed for low-intermediate temperatures rather than higher temperatures with the same brine/oil/rock. Aksulu et al. [41] observed that the $\mathrm{pH}$ gradient decreased as temperature increased to further support the claim that the desorption of $\mathrm{Ca}^{2+}$ from the clay mineral surface is an exothermic chemical process [200]. It was suggested that increase in displacement temperature will increase the reactivity of ion-binding divalent cations and cause a proton transfer that will reduce the $\mathrm{pH}$ (which indirectly indicates a decrease in water-wetness) [41]. In the electrokinetic study conducted by Vinogradov and Jackson [201], the $\zeta$-potential of the three different reservoir sandstones in low saline brine $(0.01 \mathrm{M} \mathrm{NaCl})$ was observed to be negative and the negative magnitude decreased (more positive $\zeta$-potential) with increasing temperature, which was accompanied by reduction in $\mathrm{pH}$ for unbuffered experiments. While for high saline brine $(>0.5 \mathrm{M} \mathrm{NaCl})$, the $\zeta$-potential and $\mathrm{pH}$ remained constant; independent of temperature (beyond $0.3 \mathrm{M}$ ionic strength [202,203]). The temperature dependence of $\zeta$-potential was associated with the temperature dependence of $\mathrm{pH}$ as it is well known to control the surface charge of metallic oxides of sandstone rocks. Aside from a decrease in $\mathrm{pH}$ with increasing temperature owed to enhanced dissociation of water molecules, it was hypothesized that ion exchange occurred with a proton from the silanol group being replaced by a $\mathrm{Na}^{+}$ion from the solution [204]. Meanwhile for higher ionic strength, Vinogradov et al. [58] suggested that maximum packing of $\mathrm{Na}^{+}$counterions within the diffuse layer is achieved at $0.3 \mathrm{M}$ and further increase in ionic strength will have no effect on the counterion density, thereby leading to constant $\zeta$-potential.

\subsubsection{Carbonate Rocks}

In contrast to sandstone rocks, the thermal degradation of crude oil is more promoted in the presence of calcite as substantially greater amounts of a lower carbon number hydrocarbon is formed at a high temperature [156]. Over geological time, the thermo-catalytic effect of calcite on the decomposition of carboxylic acids in crude oil will significantly result in reduction in AN as the temperature increases. Because of the affinity of the carboxylic materials to carbonate surfaces compared to other polar materials that are naturally present in crude oil, the AN strongly dictates the wettability state of carbonate rocks, which implies that the water-wetness increases as the temperature increases. This might explain the reason why high temperature carbonate reservoirs appear to be more water-wet compared to low temperature reservoirs, contrarily to most sandstone reservoirs [205]. However, Zhang and Austad [157] argued that the observation is not a temperature effect, rather it is the reduction in carboxylic acids. Typical reservoir examples mentioned by Zhang and Austad [157] in decreasing order of water wetness are: Yates dolomite Texas field $\left(30^{\circ} \mathrm{C}, \mathrm{AN}-1.0 \mathrm{mg} \mathrm{KOH} / \mathrm{g}\right)>$ Valhall chalk North sea field $\left(90^{\circ} \mathrm{C}, \mathrm{AN}-0.3-0.5 \mathrm{mg} \mathrm{KOH} / \mathrm{g}\right)>$ Ekofisk chalk North sea field $\left(130{ }^{\circ} \mathrm{C}\right.$, $\mathrm{AN}-0.1 \mathrm{mg} \mathrm{KOH} / \mathrm{g})$. It was further reported that cores aged at three different temperatures $(40,80$ and $120^{\circ} \mathrm{C}$ ) with similar AN crude oil show insignificant differences in chromatographic wettability test, which suggests that aging temperature have a minor impact on chalk rock wettability, provided the oil-rock-brine system reaches chemical equilibrium during aging [157]. The authors claimed that decarboxylation is a slow process and cannot be achieved in the aging period considered in their experiments. Like observations made in sandstone rocks, aging temperature has been observed to affect the wetting conditions of carbonate surface aged at 25 and $50{ }^{\circ} \mathrm{C}$ [206]. The core aged at $50{ }^{\circ} \mathrm{C}$ was observed to reach an intermediate wetting state earlier compared to the core aged at $25^{\circ} \mathrm{C}$ in a contact angle measurement conducted using a synthetic brine solution $(1 \mathrm{wt} . \% \mathrm{NaCl})$. Another factor where temperature plays a role in brine-dependent recovery is the dependence of the reactivity of brine ionic species on temperature.

A systematic series of studies has been conducted by Austad and colleagues $[27,31,57,93,106,188]$ to investigate the effect of temperature on the activity of PDIs in the injected brine. The reactivity of $\mathrm{SO}_{4}{ }^{2-}$ towards the chalk surface was observed to increase in a chromatographic wettability test due to increased sulfate adsorption as temperature increased from $20-130^{\circ} \mathrm{C}$, with a linear increase between 40 and $100{ }^{\circ} \mathrm{C}$ and drastic increase above $100{ }^{\circ} \mathrm{C}[27,31]$. The authors further support the 
improvement in water-wetness by reporting an increase in oil recovery by spontaneous imbibition as the temperature increases for experiments with the same sulfate concentration in the injected brine. The ultimate oil recovery from spontaneous imbibition of chalk cores at two different temperatures $\left(100\right.$ and $130^{\circ} \mathrm{C}$ ) for a fixed condition (same oil AN, initial water and varying sulfate concentration in seawater) was observed to be smaller at $100{ }^{\circ} \mathrm{C}$ compared to $130{ }^{\circ} \mathrm{C}$. It was stated that further increase in the amount of sulfate in the imbibing brine at $100^{\circ} \mathrm{C}$ could only partly compensate for the significant difference in recovery [188]. Strand et al. [57] investigated the effect of $\mathrm{Ca}^{2+}$ and $\mathrm{SO}_{4}{ }^{2-}$ ions on wettability modification of chalk surfaces at varying temperatures $\left(90\right.$ and $\left.130{ }^{\circ} \mathrm{C}\right)$ and reported increase in both imbibition rate and oil recovery as the temperature increased. The improvement in recovery was further verified through a chromatographic wettability test performed at varying temperature $\left(23-130{ }^{\circ} \mathrm{C}\right)$, where adsorption of $\mathrm{SO}_{4}{ }^{2-}$ and co-adsorption of $\mathrm{Ca}^{2+}$ increased as the temperature increased, while at any given $\mathrm{Ca}^{2+} / \mathrm{SO}_{4}{ }^{2-}$ ratio, sulfate adsorption as well as the front dispersion increases with temperature. It was also reported that beyond $100{ }^{\circ} \mathrm{C}$ the sulfate adsorption reduces as the $\mathrm{Ca}^{2+} / \mathrm{SO}_{4}{ }^{2-}$ ratio increases. The given explanation is that the solubility of $\mathrm{CaSO}_{4}$ drastically reduces above $100{ }^{\circ} \mathrm{C}$, possibly because of a decrease in hydrogen bonding between the sulfate ions and water molecules. Therefore, as the bond breaks, sulfate has the tendency to leave the aqueous phase either by adsorption onto rock or precipitation of $\mathrm{CaSO}_{4}$. With decrease in solubility and increase in $\mathrm{Ca}^{2+}$ ion, sulfate will precipitate above $100^{\circ} \mathrm{C}$. Zhang et al. [93] showed, in a similar study, that increasing $\mathrm{Ca}^{2+}$ concentration increased oil recovery as temperature increased from 70 to 100 ${ }^{\circ} \mathrm{C}$ and further when temperature was increased to $130^{\circ} \mathrm{C}$, however, the impact was reduced and even vanished due to precipitation of $\mathrm{CaSO}_{4}$. The overall theme in these studies $[27,31,57,188]$ is that higher affinity of sulfate observed at higher temperatures results in displacement of the negatively charged carboxylic oil groups on the rock surface, alters the wettability to more water-wetness and increases the degree of the water-wetness. In another study conducted by Zhang et al. (2007), the interplay between $\mathrm{Ca}^{2+}$ and $\mathrm{Mg}^{2+}$ was investigated through the chromatographic wettability technique at different temperatures and reported that affinity of $\mathrm{Ca}^{2+}$ towards the chalk surface was higher compared to $\mathrm{Mg}^{2+}$ at low temperatures. However, $\mathrm{Mg}^{2+}$ strongly adsorbed and even substituted $\mathrm{Ca}^{2+}$ at higher temperatures and the degree of substitution increased with temperature, with $70{ }^{\circ} \mathrm{C}$ appearing as the threshold temperature for $\mathrm{Ca}^{2+} / \mathrm{Mg}^{2+}$ substitution. In addition, spontaneous imbibition experiments showed that adding $\mathrm{Mg}^{2+}$ ions resulted in a higher incremental oil recovery than by adding $\mathrm{Ca}^{2+}$ ions at 100 and $130{ }^{\circ} \mathrm{C}$. The reactivity of $\mathrm{Mg}^{2+}$ observed at $130{ }^{\circ} \mathrm{C}$ significantly surpassed the effect of spiking sulfate in the injected brine with $\mathrm{Ca}^{2+}$. It was then proposed that instead of $\mathrm{Ca}^{2+}$ co-adsorbing with $\mathrm{SO}_{4}{ }^{2-}$ at the chalk surface, $\mathrm{Mg}^{2+}$ becomes active and less hydrated at higher temperature, and displaces $\mathrm{Ca}^{2+}$ to bound to the surface, because $\mathrm{Mg}^{2+}$ has smaller ionic radius and larger hydrated radius compared to $\mathrm{Ca}^{2+}[27,59,62,189]$. An identical temperature-dependent interaction was reported between PDIs and limestone, though the reactivity was less than for chalk surfaces as previously mentioned [34,97].

Another temperature-dependent effect was observed for the non-active salt $(\mathrm{NaCl})$ on oil recovery by Fathi et al. [28] using NaCl-depleted seawater, while maintaining the concentration of PDIs. It was reported that as the elevated temperature increased (from 100-120 ${ }^{\circ} \mathrm{C}$ ), imbibition rate and oil recovery significantly increased for $\mathrm{NaCl}$-depleted seawater compared to when $\mathrm{NaCl}$ was spiked 4 times in the seawater. In a later study, it was reported that spiking sulfate concentration in $\mathrm{NaCl}$-depleted seawater increased oil recovery as the temperature increased $\left(70-120^{\circ} \mathrm{C}\right)$ while spiking Ca ion above $100{ }^{\circ} \mathrm{C}$ did not result in additional recovery [191]. Like the electrokinetic study in sandstones, the measured $\zeta$-potential of intact carbonate rocks in low saline brine environments was reported to increase with temperature; however, the $\mathrm{pH}$ remained constant irrespective of temperature or ionic strength. Instead, the equilibrium concentration of calcium resulting from carbonate dissolution was observed to increase as temperature increased with low saline brine and remained constant with high saline brine, while equilibrium concentration of other PDIs remained constant irrespective of temperature. Hence, temperature dependence of the $\zeta$-potential is correlated to have a Nernstian 
linear relationship with the temperature dependence of the equilibrium calcium concentration (PDI for the calcite surface) [49]. Similarly, Mahani et al. [207] reported that as temperature increases in the range of $25-70{ }^{\circ} \mathrm{C}$ for low saline brine, the oil and rock $\zeta$-potentials shift towards the point of zero potential (either from more positive to less positive values or from more negative to less negative values). This shift with increasing temperature was negligible for higher salinity. The increasing trend of rock $\zeta$-potentials towards a less negative value for low salinity brine was ascribed to more presence of divalent cations adsorbing to the rock surface. Meanwhile, for low saline brine injection that depended on he presence of anhydrite minerals because of little/no sulfate ions in the injected brine, it has been shown that the dissolution of anhydrite decreases with temperature [34,45]. Whereas surface reactivity leading to wettability alteration as well as imbibition rate and ultimate oil recovery increases as temperature increases, which could somewhat be counterbalanced by a lesser amount of sulfate available for adsorption due to reduced dissolution. For this reason, Austad [79] proposed that the optimum temperature window for success of low salinity brine injection is probably between 90-110 ${ }^{\circ} \mathrm{C}$. In addition, Zhang and Sarma [26] studied the effect of lowering brine salinity and spiking $\mathrm{SO}_{4}{ }^{2-}$ ions concentration on wettability alteration and oil recovery of reservoir limestones at varying temperatures $\left(70,90,120^{\circ} \mathrm{C}\right)$. The authors argued that, at $70^{\circ} \mathrm{C}$, lowering brine salinity is more efficient than increasing the $\mathrm{SO}_{4}{ }^{2-}$ ions concentration, while at 90 and $120^{\circ} \mathrm{C}$, reducing brine salinity and increasing $\mathrm{SO}_{4}{ }^{2-}$ concentration resulted in a similar magnitude of wettability alteration and higher oil recovery.

\subsection{Injected Brine Composition and Salinity}

The effect of injected brine salinity and composition on wettability alteration and oil recovery improvement has been studied using both ionically-tuned and diluted versions of formation water or seawater (common injection water sources as shown in Table 1).

\subsubsection{Sandstone Rocks}

Lowering brine salinity was observed to have improved oil recovery benefits by Yildiz and Morrow [14], where it was shown that low saline brine $\left(2 \mathrm{wt} . \% \mathrm{CaCl}_{2}\right)$ gave $5.5 \%$ higher oil recovery than high saline brine ( $4 \mathrm{wt} . \% \mathrm{NaCl}+0.5 \mathrm{wt} . \% \mathrm{CaCl}_{2}$ ) with Berea sandstone core aged in Moutray crude oil. The difference in recovery for Alaskan crude oil was $15 \%$ and imbibition tests further indicated that the high saline brine showed less water-wet conditions than the low saline brine. Tang and Morrow [13] observed improved oil recovery benefits with the injection of 10 and 100 times diluted formation brine. In another study, Tang and Morrow [208] studied the effect of cation valency and their salinity on oil recovery using injected brines containing different cations like monovalent $\left(\mathrm{Na}^{+}\right)$, divalent $\left(\mathrm{Ca}^{2+}\right)$, and trivalent $\left(\mathrm{Al}^{3+}\right)$. It was reported that the rate and extent of imbibition is in the following descending order at relatively high salinities (1 wt. \% solutions): $\mathrm{Na}^{+}>\mathrm{Ca}^{2+}>\mathrm{Al}^{3+}$, while the water-wetness decreased as the cation valency increased. However, the impact of cation valency became less significant at lower salinities, while the waterflood recovery, rate, and extent of imbibition were observed to increase with reduction in salinity. The study suggests that increase in salinity and/or ion valence decreased the Debye length and compressed the electrical double layer, which promoted adsorption of crude oil and decrease water-wetness. In addition, the presence of higher valence cations could promote the adsorption of negatively-charged polar compounds onto the negatively-charged sandstone rock surface by ion-binding, thus decreasing the rock water-wetness, and leading to lower recovery. Improved oil recovery was observed with the dilution of injection brine compared to the injection of higher salinity brines in several other studies (such as $[11,12,116]$ ). Researchers at BP $[24,172,209]$ observed that injection of seawater to displace higher saline formation brine in sandstone cores did not result in improve oil recovery and suggested that improved oil recovery is only observed below injected brine salinities of $5000 \mathrm{ppm}$. An evidence to support this claim ensued when McGuire et al. [21] observed a lack of response to oil recovery when the brine salinity was higher than 7000 ppm in various single-well chemical tracer tests (SWCTT) conducted. 
Based on conclusions made from field trials [21,210], Webb et al. [209] showed that using low salinity brine in the range of 1000-4000 ppm, which was less than $5 \%$ of formation brine salinity, significantly improved secondary and tertiary recoveries compared to higher salinity brines (such as seawater and $5600 \mathrm{ppm}$ brine). Zhang et al. [127] observed that the low salinity brine that was about $5 \%$ formation brine salinity increased secondary and tertiary recovery beyond the recovery obtained for formation brine. Meanwhile, there was a lack of response to injection of $8000 \mathrm{ppm} \mathrm{NaCl}$ brine, which indicated that removal of divalent cations and salinity reduction to this salinity level was not sufficient. Further reduction of $\mathrm{NaCl}$ brine (1500 ppm) resulted in a sharp increase in tertiary recovery and pressure drop, while $4 \%$ additional recovery was obtained when low salinity brine (containing divalent ions) was injected. Cissokho et al. [118] reported a clear threshold in injected brine salinity to be below 2000 and above which no additional oil recovery can be observed.

Subsequent studies have almost all used low salinity brines with concentrations below $5000 \mathrm{ppm}$ (see [32,33,41-43]). However, Ligthelm et al. [32] suggested that there should be a lower threshold for the reduced salinity, because a further reduction in brine salinity can cause the repulsive forces within clay minerals to exceed the binding forces keeping clay particles intact. This can result in detachment and migration of clay minerals as well as formation damage. Hence, optimum injection brine salinity should exist that is low enough to cause wettability alteration and improved recovery, and high enough not to impede fluid flow and reduce oil recovery through formation damage. Meanwhile, Rezaeidoust et al. [124] opined that improved recovery and water-wetness associated with low saline brine injection is not directly related to salinity gradient but rather the concentration gradient of the most active cations $\left(\mathrm{Ca}^{2+}\right.$ and/or $\left.\mathrm{Mg}^{2+}\right)$. A tertiary improved recovery was observed using pure $\mathrm{CaCl}_{2}(25,000 \mathrm{ppm})$ as the formation brine and pure $\mathrm{NaCl}(40,000 \mathrm{ppm})$ of the same ionic strength as the injected brine. It was proposed that reduction in salinity at a given $\mathrm{pH}$ will increase adsorption of organic material onto clay surfaces but with an increase in $\mathrm{pH}$, absorbed active surface cations are desorbed, which will lead to significant desorption of organic material and the clay becoming more water-wet. Jackson and colleagues $[58,203]$ demonstrated that the $\zeta$-potential at quartz surfaces in contact with $\mathrm{NaCl}$ brine increases as the brine salinity increases and becomes constant within experimental error at concentrations of beyond approximately $0.4 \mathrm{M}$. (23,400 ppm). It was argued that the thickness of the double layer at this threshold salinity $(0.47 \mathrm{~nm})$ is comparable to the hydrated radius of $\mathrm{Na}^{+}$ion $(0.358 \mathrm{~nm}$ [62]); further increase in brine salinity will not further decrease the double layer thickness because of the finite size of the dominant ionic species. The effect of multivalent ions was also tested in natural brines (seawater) compared to pure $\mathrm{NaCl}$ brine and the $\zeta$-potential was found to be the same in both sign and magnitude irrespective of brine composition. They concluded that multivalent ions were not high enough in natural brines to cause charge inversion and that double layer expansion will not occur until the brine salinity is reduced below this threshold salinity. A similar trend was presented by Alotaibi et al. [95] and Nasralla and Nasr-El-Din [56], where $\zeta$-potential of sandstone rocks with differing clay contents were observed to decrease as the brine salinity was decreased for all rock types, which suggests a thicker double layer with a lower salinity brine. Divalent cations were also observed to result in less negative $\zeta$-potential than monovalent cations at the same concentration, which became more pronounced at high $\mathrm{pH}$ values $[56,180]$. Increased water surface relaxation and a higher $T_{2}$ water peak relaxation time than bulk oil and fully water-saturated core plug observed from low saline brine (400-3000 ppm) treatment of intact sandstone samples provided by NMR analysis, suggested a wettability change to more water-wetting state by stripping off adsorbed oil from pore surfaces [101,211]. Different atomic scale AFM studies have also suggested a reduction in adhesion of both polar and non-polar oil components to silica and natural quartz surfaces as brine salinity reduces, rendering the surface less oil wet $[54,103,177,212]$. Hilner et al. [54] further stated that adhesion was slightly constant in high saline brine solutions until a threshold value in the range of 5000 to $8000 \mathrm{ppm}$ (Figure 6), below which adhesion decreased as brine salinity decreased, which fits well with observations from core plug experiments and field tests. 

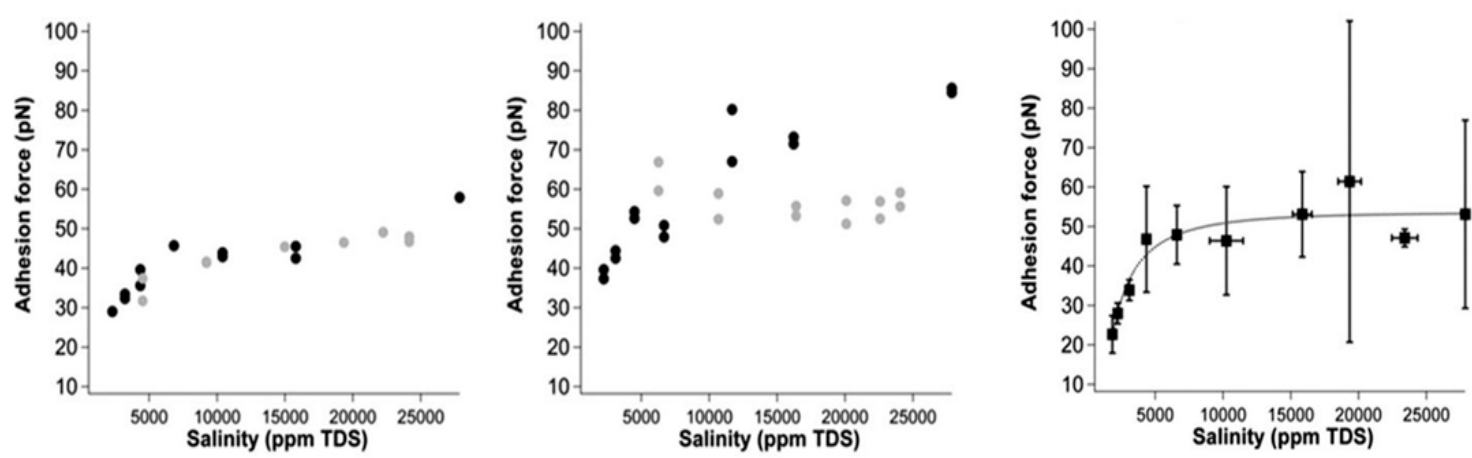

Figure 6. Adhesion force between the tip and the rock surface of data plotted as a function of salinity for Sample 1 (left), sample 2 (middle) and line of fit for all samples (right) (reproduced from Hilner et al. [54]).

\subsubsection{Carbonate Rocks}

In contrast to sandstone rocks, extensive laboratory studies, especially coreflooding and spontaneous imbibition, from carbonate cores have shown that increasing divalent ions (particularly PDIs, see Figure 7) and decreasing monovalent ion $\left(\mathrm{Na}^{+}\right.$and $\left.\mathrm{Cl}^{-}\right)$concentrations in the injected brine lead to an increase in the rate and extent of oil recovery $[27,28,31,57,59,93,187,188]$. The existence of an interdependent interaction among multivalent ions in brine $\left(\mathrm{Ca}^{2+}, \mathrm{Mg}^{2+}, \mathrm{SO}_{4}{ }^{2-}, \mathrm{PO}_{4}{ }^{3-}\right.$ and $\left.\mathrm{BO}_{3}{ }^{3-}\right)$ at the rock-brine interface has been emphasized that can bring the rock-brine interface into a new equilibrium state, thus improving water-wetness and recovery through various interfacial phenomena.

Earlier studies $[31,157,187,190]$ have shown that $\mathrm{SO}_{4}{ }^{2-}$ can act as surface active agents that can lower the surface charge of carbonate surface, facilitate the removal of negatively charged polar components and change the contact angle to more water-wetness and improve oil recovery by spontaneous imbibition. A significant increase in oil recovery was observed as the $\mathrm{SO}_{4}{ }^{2-}$ concentration in injected brine is increased from 0 to 4 times the concentration in ordinary seawater and the affinity of $\mathrm{SO}_{4}{ }^{2-}$ towards chalk surface has been shown to be temperature dependent [31,158]. The impact of sulfate, as a PDI and wettability modifier on increased oil recovery, has been well examined and reported by other researchers (such as $[23,26,32,34,46,97,161,213-215]$ ). In addition, several of these studies have proved that a high $\mathrm{SO}_{4}{ }^{2-}$ concentration did not offer improved recovery; rather an upper limit existed beyond which no improved recovery could be observed [31,94,96,131].

Similarly, $\mathrm{Ca}^{2+}$ and $\mathrm{Mg}^{2+}$ are considered to be active towards the carbonate rock surface [187]. Strand et al. [57] observed that the efficiency of the wettability alteration due to brine-dependent recovery is governed by the relative concentration of $\mathrm{Ca}^{2+}$ and $\mathrm{SO}_{4}{ }^{2-}$ in the injected brine. The authors reported that increasing the $\mathrm{Ca}^{2+} / \mathrm{SO}_{4}{ }^{2-}$ ratio between 0.25 and 3 times the concentration in ordinary seawater led to increased adsorption of $\mathrm{SO}_{4}{ }^{2-}$, but decreased as temperature exceeded $100{ }^{\circ} \mathrm{C}$. Zhang et al. [93] also presented spontaneous imbibition of oil as evidence to show the symbiotic interaction between $\mathrm{Ca}^{2+}$ and $\mathrm{SO}_{4}{ }^{2-}$ and the temperature-dependency of the interaction. Increasing $\mathrm{Ca}^{2+}$ led to strong imbibition and increase in oil recovery, and beyond $100{ }^{\circ} \mathrm{C}$, the recovery is less due to precipitation of $\mathrm{CaSO}_{4}$. According to these studies, $\mathrm{SO}_{4}{ }^{2-}$ adsorbed onto the chalk surface lowers the positive surface charge resulting in lesser electrostatic repulsion. Meanwhile, $\mathrm{Ca}^{2+}$ would gain greater access to approach the surface to balance the electric charge as well as bind to the negatively charged oil acidic groups. This helps to release the oil from the chalk surface. On the other hand, Zhang et al. [59] presented $\zeta$-potential experimental evidence to prove that $\mathrm{Mg}^{2+}$ has the potential to increase positive surface charge like $\mathrm{Ca}^{2+}$ and investigation of the interplay between $\mathrm{Ca}^{2+}$ and $\mathrm{Mg}^{2+}$ through chromatographic test at different temperatures shows that $\mathrm{Ca}^{2+}$ was substituted by $\mathrm{Mg}^{2+}$ at higher temperatures. It was then proposed that instead of $\mathrm{Ca}^{2+}$ co-adsorbing with $\mathrm{SO}_{4}{ }^{2-}$ at the chalk surface, $\mathrm{Mg}^{2+}$ becomes active and less hydrated at higher temperature and displaces $\mathrm{Ca}^{2+}$ bound to the surface. In contact angle measurement, it was shown that $\mathrm{SO}_{4}{ }^{2-}$ and $\mathrm{Mg}^{2+}$ were more efficient in altering wettability and improving oil recovery $[26,89,96,215]$. The significant conclusion from the 
systematic series of studies conducted to investigate impact of PDIs on oil recovery is that none of the PDIs could act alone in improving water-wetness, although in the different combinations, $\mathrm{SO}_{4}{ }^{2-}$ was found to be present in the imbibing fluid [26,31,215].

The significance of polyatomic anions (e.g., phosphate $\left(\mathrm{PO}_{4}{ }^{3-}\right)$ and borate $\left.\left(\mathrm{BO}_{3}{ }^{3-}\right)\right)$ as a possible replacement for sulfate has been investigated due to their higher ion valency to lower surface charge compared to sulfate $\mathrm{SO}_{4}{ }^{2-}$. Researchers at ExxonMobil $[53,216]$ found that replacing $\mathrm{SO}_{4}{ }^{2-}$ in the injected brine by $\mathrm{BO}_{3}{ }^{3-}$ in coreflooding experiments performed on several limestone and dolomite cores in tertiary mode resulted in higher recovery, whereas replacing with $\mathrm{PO}_{4}{ }^{3-}$ gave even higher recovery. Meanwhile, softening the injected brine by depleting $\mathrm{Ca}^{2+}$ and $\mathrm{Mg}^{2+}$ in the formation water also resulted in an increase in recovery due to rock dissolution. In addition, Meng et al. [111] demonstrated that high concentration of $\mathrm{PO}_{4}{ }^{3-}$ in the injected brine can induce larger contact angle alteration of limestone cores to a more water-wet condition, which was more pronounced when the brine was ten times diluted. However, the effect of polyatomic anions has not been further investigated due to the limitation of a higher likelihood of formation of precipitate that could potentially damage the reservoir.

Aside the PDIs, $\mathrm{Na}^{+}$and $\mathrm{Cl}^{-}$have been identified as non-active ions that are indifferent toward carbonate surfaces. Fathi et al. [28] discovered that $\mathrm{NaCl}$-depleted seawater gave a higher imbibition rate and recovery relative to seawater, whilst spiking $\mathrm{NaCl}$ concentration in seawater by 4 times gave a lower recovery. Furthermore, chromatographic tests showed that the water-wet fraction further increased for chalk cores imbibed in $\mathrm{NaCl}$-depleted seawater relative to seawater. In a later study, it was reported that spiking $\mathrm{SO}_{4}{ }^{2-}$ concentration in $\mathrm{NaCl}$-depleted seawater significantly increased recovery and water-wetness, however spiking $\mathrm{Ca}^{2+}$ had no significant effect because the experiments were conducted above $100{ }^{\circ} \mathrm{C}$ [191]. Awolayo and Sarma [39] has also shown that $\mathrm{NaCl}$-depleted seawater alters wettability towards more water-wetness relative to seawater in a contact angle measurement, which was supported by improved tertiary oil recovery in coreflooding experiments on limestone cores. These studies highlighted the impact both $\mathrm{SO}_{4}{ }^{2-}$ and the indifferent ions $\left(\mathrm{Na}^{+}\right.$and $\left.\mathrm{Cl}^{-}\right)$have on the injected brine to modify rock wettability. All charged surfaces in contact with a brine will have an excess of ions close to the surface, which is usually called the double layer. If the double layer consists of a lot of ions not active in the wettability alteration process like $\mathrm{NaCl}$, the access of the active ions, $\mathrm{Ca}^{2+}, \mathrm{Mg}^{2+}$ and $\mathrm{SO}_{4}{ }^{2-}$ to the surface is partly prevented. This approach of depleting $\mathrm{NaCl}$ from seawater results in total brine salinity reduction because of a high concentration of the indifferent ions in most brines. Another approach of reducing total salinity through brine dilution, which failed to work in chalk cores $[28,45,46]$, has shown tremendous positive benefits in a series of experiments with middle-eastern limestone cores containing small amounts of anhydrite conducted by Yousef and colleagues [25,48]. Seawater was diluted up to 100 times and the sequential flooding experiments showed that the highest recovery was achieved by twice diluted seawater, followed by 10 times dilution, whereas 20 and 100 times dilution resulted in little/marginal recovery. The authors reported a total incremental recovery of up to $19 \%$ OOIP and indicated that surface charge alteration was more important than dissolution in the wettability alteration process.

Elsewhere, Austad et al. [45] injected sulfate-free diluted brine into carbonate cores containing anhydrite and reported an incremental recovery up to $5 \%$ OOIP. The authors explained that sulfate was continually generated in-situ because of anhydrite dissolution, which led to the wettability alteration process. Romanuka et al. [46] carried out spontaneous imbibition experiments on different mineralogical carbonate cores with/without evaporites and showed that brine dilution contributed to an additional recovery of up to $20 \%$ OOIP. Zahid et al. [37] conducted another series of experiments on carbonate cores free of dolomite/anhydrite, and observed no incremental recovery at room temperature and reported additional recovery up to $18 \%$ OOIP at $90{ }^{\circ} \mathrm{C}$. They proposed fines migration and rock material dissolution as the plausible mechanisms for wettability alteration. Zhang and Sarma [26] and Chandrasekhar and Mohanty [215] observed that the multi-ion exchange between the active multivalent ions and mineral dissolution was the mechanism responsible for wettability 
alteration when the brine dilution approach was applied to middle-eastern carbonate cores. However, in a few other cases in limestones [39,89], very little or negligible results were observed during brine dilution. Results of lower/decrease in contact angle have also suggested that the wettability of carbonate rocks is altered by either a reduction in the brine salinity and/or increasing PDI concentrations $[26,47,55,95,96,111,215]$.

Nyström et al. [217] carried out an electrokinetic study on the influence of the concentration of monovalent $\left(\mathrm{Na}^{+}\right)$and multivalent $\left(\mathrm{Ca}^{2+}, \mathrm{Ba}^{2+}\right.$ and $\left.\mathrm{La}^{3+}\right)$ cations on calcite particles. It was reported that $\mathrm{Na}^{+}$acted indifferent towards calcite surface, $\mathrm{Ba}^{2+}$ exhibited similar behaviour to that of $\mathrm{Ca}^{2+}$ but of greater magnitude as the $\zeta$-potential increased with concentration, while $\mathrm{La}^{3+}$ exhibited an opposite trend to that of the other divalent cations. In a different study, Jackson and colleagues [50,51] reported that both $\mathrm{Ca}^{2+}$ and $\mathrm{Mg}^{2+}$ exhibited identical behavior, linearly increasing the $\zeta$-potential of intact limestones as their concentrations increased in the different $\mathrm{NaCl}$ brine solutions. While increasing $\mathrm{SO}_{4}{ }^{2-}$ concentration reduced the magnitude of the $\zeta$-potential, the gradient of the linear trend however, is observed to be lower than shown for both $\mathrm{Ca}^{2+}$ and $\mathrm{Mg}^{2+}$. The gradient of the linear trend between $\zeta$-potential and $\mathrm{Ca}^{2+} / \mathrm{SO}_{4}{ }^{2-}$ decreases with increasing brine salinity $(\mathrm{NaCl})$, though at $\mathrm{Ca}^{2+}$ concentration, the $\zeta$-potential becomes less sensitive to increase in brine salinity. The $\zeta$-potential of natural carbonate was observed to linearly increase as the concentrations of indifferent ions $\left(\mathrm{Na}^{+}\right.$and $\left.\mathrm{Cl}^{-}\right)$were increased. It was suggested that the presence of the indifferent ions could change the magnitude, but not the polarity of the $\zeta$-potential [50]. It was shown that diluting seawater and adding $\mathrm{SO}_{4}{ }^{2-}$ to seawater as a way of modifying the injected brine decreases the $\zeta$-potential by double layer expansion and increasing negative charge on the calcite surface, which was correlated to incremental recovery [51]. Kasha et al. [192] observed similar trends for the PDIs with $\zeta$-potential during an electrokinetic study on calcite and dolomite particles, though $\mathrm{Mg}^{2+}$ had a stronger effect on surface charges compared to $\mathrm{Ca}^{2+}$ in high salinity brines and suggested that the point of zero charge of carbonate rocks is not only a function of electrolyte $\mathrm{pH}$ but also PDI concentrations. Yousef et al. [48] demonstrated that $\zeta$-potential of the rock-brine interface decreases as the brine salinity decreases and suggested that $\mathrm{Ca}^{2+}$ ions leave the rock surface in form of mineral dissolution and enter the brine solution to re-establish chemical equilibrium. Jackson et al. [98] correlated improved oil recovery to $\zeta$-potential of rock-brine and oil-brine interfaces using a reservoir limestone core, and different crude oils and brine solutions. The authors concluded that the potential for improved oil recovery by low saline brine injection is increased when both interfaces possess the same polarity ( $\zeta$-potential sign), such that the electrostatic repulsive force generated between the interfaces stabilizes the water film on the rock surface. It was suggested that for a negatively charged oil-water interface, diluting the brine salinity to produce a more negative/less positive rock-brine interface would be successful at improving oil recovery. While for a positively charged oil-water interface, increasing the rock-brine interface surface charge by increasing the PDI cation concentration would increase recovery, which would have been responsible for failure of low saline brine to improve recovery in such cases. 


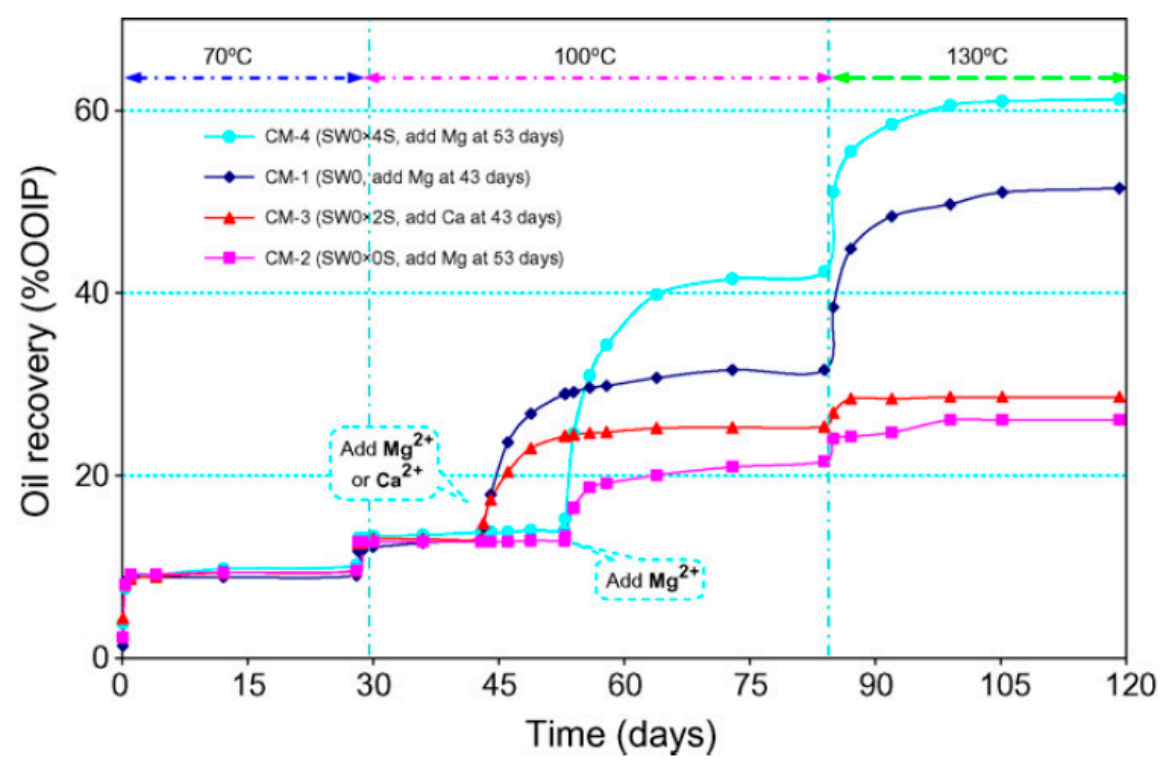

Figure 7. Comparison of spontaneous imbibition rates of PDIs in chalk conducted at 70,100 and $130{ }^{\circ} \mathrm{C}$. Modified seawater without $\mathrm{Ca}^{2+}$ and $\mathrm{Mg}^{2+}$ was initially imbibed and $\mathrm{Mg}^{2+}$ or $\mathrm{Ca}^{2+}$ was later added in a systematic variation of PDI concentrations (reproduced from Zhang et al. [59] with permission).

Mahani et al. [55] investigated the importance of brine composition, salinity and $\mathrm{pH}$ on oil-brine-rock systems on different carbonate rock particles in different brine solutions. They observed positive $\zeta$-potential for formation water, negative for seawater, and more negative for diluted seawater, which increased with increase in $\mathrm{pH}$ in the range 6.5-11. The low saline brine was influenced by a large shift in $\zeta$-potential with $\mathrm{pH}$ because of the presence of fewer concentrations of PDIs compared to the concentration of $\mathrm{H}^{+}$and $\mathrm{OH}^{-}$, which means any changes in later ion concentrations, would strongly impact the EDL and $\zeta$-potential. The changes in rock-brine $\zeta$-potential from positive to more negative was consistent with the observed decrease in contact angle and concluded that these changes are predominantly due to phenomena occurring at the rock-brine interface and to a lesser extent at the oil-brine interface. Meanwhile, the authors further claimed that $\mathrm{pH}$ does not directly control the $\zeta$-potential, but rather equilibrium concentration of $\mathrm{Ca}^{2+}$, because of the established relationship between $\zeta$-potential and concentration of $\mathrm{Ca}^{2+}$.

Other experimental evidence such as NMR has been used to test the hypothesis of improved water-wetness by low saline brine injection. Yousef et al. [25] performed NMR measurements on reservoir limestone cores, before and after low saline brine treatment, and reported a significant shift in $T_{2}$ distribution and surface relaxation by various versions of diluted brines. The influence of pore cleaning was also investigated to solely ascertain the observed shift in $T_{2}$ distribution to brine dilution. An improvement in connectivity among macro and micro pores as a result of rock dissolution was associated with the observed shift. In contrast, in an NMR experiment conducted with different diluted seawaters, Zahid et al. [37] observed no significant changes in surface relaxation and no shift in $\mathrm{T}_{2}$ distribution.

\section{Field Application Studies}

Promising achievements from laboratory studies have been the background for some pilot scale field trials of low salinity waterflooding during the past few years. The encouraging feature of the systematic experimental studies using sandstone and carbonate rocks, as discussed in the previous section, has been reflected in the observations from several near-wellbore tests (like log-inject-log and single well chemical tracer (SWCT)), inter-well scale tests and multi-well field scale, which emphasize on the overall consistency between laboratory and field observations, as summarized in Table 2. 


\subsection{Sandstone Reservoirs}

Over the past decade, the majority of field applications of brine salinity reduction approach have been conducted in sandstone reservoirs. Researchers at BP have been the front-runner, while those from several other oil companies (e.g., Shell, Statoil, Total, and Eni) have conducted field implementation as well. Webb et al. [210] evaluated the impact of low saline brine on recovery using the log-inject-log field test on a giant Middle Eastern clastic reservoir. Multiple passes of pulse neutron capture logs were run to quantify the saturation during each brine injection cycle through a producing well. They injected three different brines in sequence (connate brine-250,000 ppm, intermediate saline brine - 170,000 ppm, low saline brine-3000 ppm and repeated the connate brine injection). There was no significant difference in saturation when intermediate brine was injected over connate brine, which was used to define the baseline residual oil saturation (Sor). However, injection of low saline brine led to $50 \%$ and $10-20 \%$ reduction in Sor for the top and bottom-middle perforations respectively, which agreed with previous laboratory tests. Another BP researcher, McGuire et al. [21] confirmed that favorable laboratory results can be replicated in the field by performing four sets of SWCT tests in Prudhoe Bay and Endicott fields of Alaska North Slope formation. The low saline brine reduced Sor by $8 \%, 4 \%, 4 \%$ and $9 \%$ in these four tests, leading to $8-19 \%$ OOIP incremental recovery. The operational salinity level for improved recovery was reported to be less than $5000 \mathrm{ppm}$ as no benefit was observed during the injection of brine with salinity of $7000 \mathrm{ppm}$. Seccombe et al. [173] further presented detailed analysis of the three SWCT tests conducted in Endicott field validated against wireline log and coreflood data. The reduction in Sor was observed to vary as a function of kaolinite clay fractions (increase from 9 to $17 \%$ as clay fraction increases) and further confirmed the optimum slug size for improved recovery as 0.4 pore volume (PV). Another attempt was made by Seccombe et al. [218] to demonstrate improved oil recovery beyond near wellbore to consider area and vertical sweep effects by conducting inter-well tests using a producer and an injector placed approximately $317 \mathrm{~m}$ apart. It was reported that, after 1.6 PV injection of low saline brine, about $10 \%$ of the total pore volume of the swept area was additionally recovered and the result agreed with increment recovery-clay content relationship established with previous coreflood data and single well tracer tests. Lager et al. [219] reported an inter-well field test conducted in an Alaskan oil field involving one injector and two producers within a constrained well spacing of approximately 366-518 m. It was found out that there was a significant drop in water cut and oil production rate doubled during 12 months of low saline brine injection. However, the oil recovery potential was low as confirmed by prior laboratory studies because the injected brine was considered as non-optimum. The authors further conducted the SWCT test and reported a reduction of Sor by $2 \%$ using non-optimized low saline brine and 10\% using optimized low saline brine [219].

Elsewhere, in the Powder River basin of Wyoming, Robertson [220] published the comparison of three Minnelusa field performances based on historical evidence of unintentional injection of low saline brine. It was reported that the oil recovery trend in historical data appeared to increase as the salinity ratios decreased, which corroborated laboratory corefloods using Berea outcrop material. Similarly, from a large dataset of waterflooding in Wyoming fields available in public records, Thyne et al. [221] published a comprehensive evaluation of historical low saline brine injection in 26 fields and compared with laboratory corefloods. In contrast to Robertson [220], they found no correlation between dilution and oil recovery. It was concluded based on historical field and coreflood data that no benefit was associated with low saline brine injection. Another documented proof of historical low saline brine injection, which was unintentionally implemented in the Omar Field in Syria for a period of ten years starting from 1991, was published by Vledder et al. [222]. Observations made from measurements at 21 wells presented abundant field-scale evidence of improved water-wetness, as evident from the dual steps in water cut development [223]. Low saline brine injection gave an incremental oil recovery of 10-15\% OIIP compared to high salinity water flooding, which showed positive correlation with clay content. These observations were supported by the spontaneous imbibition tests and a single well log-inject-log test in an analogue field (Isba). Mahani et al. [223] also presented further evidence for the positive response observed in Omar field and claimed a strong buoyancy force and high contrast 
between formation and injected water salinity was responsible for the decreased benefits of low saline brine injection in the Sijan field.

For some Norwegian Continental Shelf fields like Snorre, Heidrun, and Gullfaks, laboratory studies and SWCT tests have been carried out over the past few years and more are being considered for a possible pilot. Hegre [224] presents details of a proposed low salinity pilot in Heidrun after laboratory corefloods showed an average of $9 \%$ reduction in Sor as seawater was diluted hundred times. The plan was to inject low saline water (500-3000 ppm) into two wells in the Lower Tilje Formation and observe expected response in three producers. Despite laboratory corefloods only indicating a low potential of $2 \%$ of OOIP by diluted seawater injection by using Snorre cores, a SWCT test was performed and showed no significant reduction in Sor. The explanation was that the clay mineral acted as water-wet because of the buffering effect of the high presence of plagioclase feldspar on the formation water. In addition, the low content of organic acid in the Snorre oil ensured that the reservoir was already close to optimum wetting conditions, such that low saline water could not significantly improve recovery [36]. Furthermore, Abdulla et al. [225] documented two recent SWCT tests conducted in the giant Kuwait Burgan oilfield. The tests were implemented in two reservoir formations with the least clay content and good quality rock. They observed an average of $3 \%$ reduction in Sor and no injectivity problem during injection of low saline brine. Additional tests were planned for other parts of the Burgan field with reservoir rock containing high clay content to further corroborate the established trend of recovery performance with clay content. In the same giant Burgan oilfield, Al-Qattan et al. [226] reported another SWCT tests performed on Wara reservoir considering the radius of investigation of $4.8 \mathrm{~m}$ around the wellbore. They documented that low saline brine injection reduced Sor by $3 \%$ as compared high saline brine injection. Thereafter, a low saline polymer was injected and further reduced Sor by $4 \%$, which was consistent with the laboratory corefloods. Researchers at Eni reportedly conducted a log-inject-log test in the Congo oil field to corroborate the performance of low saline water injection in laboratory experiments, but not much information about the results was published [227]. Instead, Callegaro et al. [20] detailed a SWCT test conducted in a West Africa complex onshore reservoir to evaluate Sor after each injection of seawater, low saline water and surfactant. It was reported that despite high recovery potentials observed during laboratory corefloods, no significant recovery was observed during low saline water injection. The possible explanation for the discrepancy between lab and field tests was because of lower clay content and low Sor obtained after seawater injection, which allowed minimal impact from low saline brine. However, surfactant proved effective by reducing Sor by $6-7 \%$. In another SWCT tests conducted on the giant North Africa oil field, a reduction in Sor in the range of $5-11 \%$ was observed [228].

Another account was given by Zeinijahromi et al. [229] and Zeinijahromi et al. [230] on the historical injection of low saline brine into Zichebashskoe and Bastrykskoye fields in Russia, respectively, to majorly provide pressure maintenance. Little improvement in recovery was observed for both field cases because the low saline brine was injected below the water-oil contact. Meanwhile, Akhmetgareev and Khisamov [231] evaluated a historical injection of low saline water sourced from the nearest Karma river in the Pervomaiskoye oil field in the Republic of Tatarstan, Russia. They observed that more than one-third of the wells were not potentially effective, which is similar to conclusions made by Zeinijahromi et al. [229]. However, wells in the seven pilots evaluated showed that 5-9\% OOIP incremental recovery and reduced water cut, which was ascribed to wettability alteration and formation damage of clay particles. Furthermore, because of the positive response from laboratory tests, other fields have been considered for field trials and implementations including Clair Ridge field in the UK and West Salym field in West Siberia, Russia [232-234].

\subsection{Carbonate Reservoirs}

There are a few field-scale projects in carbonate reservoirs that are reported in the literature. The fractured chalk Ekofisk reservoir, North Sea, has been flooded with seawater since 1987 following a successful waterflood pilot $[17,235]$. Over the first three years, oil production steadily increased 
from 11,130-22,258 $\mathrm{m}^{3} /$ day, with an increasing trend and after ten years, production level reached $46,106 \mathrm{~m}^{3} /$ day. The significant increase in oil rates has been accompanied by a drop in producing Gas-Oil ratio (GOR) and reduced water breakthrough $[18,236]$. About two-thirds of the increase in production was ascribed to seawater injection response and the recent prognosis estimated recovery to be slightly above $50 \%$ of OOIP $[16,79,189,236]$. The tremendous success recorded till date shows the potential for seawater to improve water-wetness of chalk through spontaneous imbibition and viscous displacement. This positive response seen in Ekofisk stimulated interest to investigate the potential of brine-dependent recovery in the fractured chalk Valhall field, North Sea.

A single injector waterflood pilot test was implemented by early 1990 to evaluate the potential of seawater injection and its success recommended the feasibility of an economic waterflood scheme with its associated risks. Sea water injection only began in 2006 and the response revealed a varying performance in different part of the reservoir. Some wells showed no oil production benefit with rapid water breakthrough and increase in water-cut, while others showed increase in oil production, decrease in GOR and reduced water cut $[237,238]$. This regional response was attributed to matrix/fracture dominance on water movement. A systematic study conducted by Webb et al. [213] on Valhall core showed that seawater improved water-wetness and oil recovery significantly compared with formation water. A further comparison between both brine-dependent field applications revealed that seawater injection performed less for Valhall as compared to Ekofisk. The difference in performance was ascribed to temperature and wetting conditions, as the wettability alteration process is temperature-dependent. The deeper Ekofisk field reservoir $\left(130^{\circ} \mathrm{C}\right)$ has a significantly higher reservoir temperature than Valhall $\left(90^{\circ} \mathrm{C}\right)$ [239]. In addition, Ekofisk field is more oil-wet compared to Valhall field as reflected by the acid numbers of their crude oils, about 0.35 and $0.1 \mathrm{mg} \mathrm{KOH} / \mathrm{g}$ for Valhall and Ekofisk, respectively $[189,239]$.

The above listed field projects have majorly explored the ionic composition modification, while the only field application of ionic salinity reduction (low salinity waterflood) was reported in Saudi Arabia Upper Jurassic carbonate reservoirs by Yousef and co-workers [22,47]. Yousef et al. [22] reported two field trials with two single well chemical tracer (SWCT) tests using various dilutions of field seawater. The distance of investigation for the SWCT was considered as up to $6.1 \mathrm{~m}$. around the wellbore. For well A, a slug of seawater and twice diluted seawater was sequentially injected, while for well B, a slug of seawater, twice diluted and ten-times diluted seawater was sequentially injected and after each injection cycle, three different tracers were injected to estimate the residual oil saturation (ROS).

They observed from the two field trials that diluted seawater gave $7 \%$ ROS reduction at well $\mathrm{A}$ beyond conventional seawater injection, while at well B, 3\% reduction in ROS beyond conventional seawater was achieved by twice-diluted seawater and a further $3 \%$ reduction beyond twice-diluted seawater was achieved by ten-times diluted seawater injection. They concluded that the total reductions in ROS from well A and B are comparable and the field trials are in agreement with their previous experimental studies [47]. 
Table 2. Summary of main field implementations of brine-dependent recovery in sandstones and carbonates.

\begin{tabular}{|c|c|c|c|c|}
\hline Authors & Field Attributes & Reservoir Temp. $\left({ }^{\circ} \mathrm{C}\right)$ & Formation I I Injected Brine (ppm) & Benefits \\
\hline \multicolumn{5}{|c|}{ Sandstone reservoirs } \\
\hline Webb et al. [210] & $\begin{array}{c}\text { Giant Middle Eastern clastic } \\
\text { Clay: }<5 \% \\
\text { Oil Viscosity: } 0.46-50 \mathrm{cP}\end{array}$ & 77 & $220,000|| 3000$ & $25-50 \%$ Sor reduction \\
\hline McGuire et al. [21] & $\begin{array}{c}\text { Alaska North Slope Prudhoe Bay field } \\
\text { Oil Viscosity: } 0.8 \mathrm{cP} \\
\text { Distance of Investigation: } 3.9-4.2 \mathrm{~m} \text {, } \\
2.6-2.7 \mathrm{~m} \text {, and } 4.6 \mathrm{~m} \\
\text { Endicott Field Clay: } 7 \%\end{array}$ & $\begin{array}{c}66 \\
103 \\
103 \\
99\end{array}$ & $\begin{array}{c}23,000 \quad|| \mid 3000 \\
23,000 \quad|| \mid 3000 \\
7000|| \mid 2200 \\
28,000 \quad|| 1500\end{array}$ & $\begin{array}{l}8 \% \text { Sor reduction and } 18 \% \text { incremental recovery } \\
4 \% \text { Sor reduction and } 15 \% \text { incremental recovery } \\
4 \% \text { Sor reduction and } 8 \% \text { incremental recovery } \\
9 \% \text { Sor reduction and } 19 \% \text { incremental recovery }\end{array}$ \\
\hline Seccombe et al. [173] & $\begin{array}{l}\text { Endicott Field } \\
\text { Clay: } 7 \% \\
\text { Clay: } 12 \% \\
\text { Clay: } 14 \%\end{array}$ & 99 & 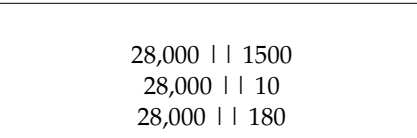 & $\begin{array}{l}9 \% \text { Sor reduction } \\
11 \% \text { Sor reduction } \\
17 \% \text { Sor reduction }\end{array}$ \\
\hline Lager et al. [219] & Alaskan Oil Field & & $16,640|| 2600$ & $2 \%$ Sor reduction \\
\hline Robertson [220] & $\begin{array}{l}\text { Minnelusa field } \\
\text { Oil Viscosity: } 15.2 \mathrm{cP} \\
\text { West Semlek } \\
\text { North Semlek } \\
\text { Moran }\end{array}$ & $\begin{array}{l}62 \\
60 \\
93\end{array}$ & 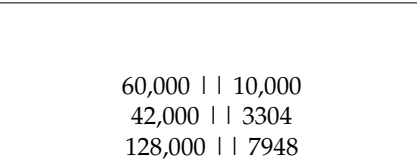 & $\begin{array}{l}27.5 \% \text { Sor reduction } \\
32.5 \% \text { Sor reduction } \\
31.5 \% \text { Sor reduction }\end{array}$ \\
\hline Thyne et al. [221] & Wyoming Minnelusa fields & $68-75$ & $\begin{array}{c}\text { Range }(1134-261,982)|| \text { Range } \\
(300-6000)\end{array}$ & no significant benefit \\
\hline Vledder et al. [222] & $\begin{array}{c}\text { Omar Oil Field (Isba) } \\
\text { Clay: } 0.5-4 \% \\
\text { Oil Viscosity: } 0.3 \mathrm{cP}\end{array}$ & & 90,000 | | 500 & $10-15 \%$ incremental recovery \\
\hline Skrettingland et al. [36] & $\begin{array}{c}\text { Snorre field (Upper Statfjord formation) } \\
\text { Clay: } 10-20 \%\end{array}$ & 90 & 34,020 | | 440 & no significant benefit \\
\hline Abdulla et al. [225] & Burgan Oil field & & 140,000 | I 5000 & $3 \%$ Sor reduction \\
\hline Al-Qattan et al. [226] & $\begin{array}{l}\text { Burgan Oil field (Wara formation) } \\
\text { Distance of Investigation: } 4.6 \mathrm{~m}\end{array}$ & $54-57$ & $148,000|| 692$ & $3 \%$ Sor reduction \\
\hline Callegaro et al. $[20,228]$ & $\begin{array}{c}\text { West African Oil Field } \\
\text { Oil Viscosity: 0.6 cP } \\
\text { Distance of Investigation: } 3.7 \mathrm{~m} \\
\text { North African Brown Field } \\
\text { Oil Viscosity: 6-8 cP } \\
\text { Distance of Investigation: } 4 \mathrm{~m}\end{array}$ & $\begin{array}{l}88 \\
76\end{array}$ & $\begin{array}{c}\text { Range }(27,000-87,000)|| \text { | } 200 \\
39,000 \text { | | } 1000\end{array}$ & $\begin{array}{l}\text { no significant benefit } \\
5-11 \% \text { Sor reduction }\end{array}$ \\
\hline Zeinijahromi et al. $[229,230]$ & $\begin{array}{l}\text { Bastrykskoye } \\
\text { Zichebashskoe }\end{array}$ & 25 & 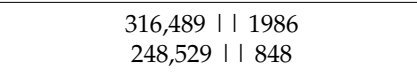 & \\
\hline Akhmetgareev and Khisamov [231] & $\begin{array}{c}\text { Pervomaiskoye } \\
\text { Oil Viscosity: } 5.8 \mathrm{cP}\end{array}$ & & $252,738|| 848$ & $5-9 \%$ incremental recovery \\
\hline
\end{tabular}


Table 2. Cont.

\begin{tabular}{|c|c|c|c|c|}
\hline Authors & Field Attributes & Reservoir Temp. $\left({ }^{\circ} \mathrm{C}\right)$ & Formation I I Injected Brine (ppm) & Benefits \\
\hline \multicolumn{5}{|c|}{ Carbonate reservoirs } \\
\hline Austad [79] & Ekofisk reservoir, North Sea & 130 & 68,050 । | 33,498 & $\begin{array}{l}\text { Ultimate recovery above } 50 \% \text { of OOIP with } \\
\text { two-thirds ascribed to seawater injection }\end{array}$ \\
\hline $\begin{array}{l}\text { Barkved et al. [237], } \\
\text { Griffin et al. [238] }\end{array}$ & Valhall field, North Sea & 90 & & $\begin{array}{l}\text { Increase in oil production, decrease in GOR and } \\
\text { reduced water cut }\end{array}$ \\
\hline Yousef et al. [22] & $\begin{array}{l}\text { Saudi Arabia Upper Jurassic } \\
\text { Oil Viscosity: } 0.691 \mathrm{cP}\end{array}$ & 100 & $\begin{array}{c}57,670 \text { | | } 5767 \\
57,670|||28,835| \mid 5767\end{array}$ & $\begin{array}{l}7 \% \text { Sor reduction } \\
6 \% \text { Sor reduction }\end{array}$ \\
\hline
\end{tabular}




\section{Proposed Underlying Recovery Mechanisms}

Considering the huge research studies, several physicochemical recovery mechanisms have been proposed, while majority of the observed trends attributed the primary cause to wettability modification, either to a more water-wetting or mixed wetting state $[35,94,121,240]$ by varying PDIs and/or decreasing injected brine salinity. There is a lack of consensus on the prevalent mechanism responsible for changing the wettability. This is because of the complex nature of the oil-brine-rock interaction, as well several conflicting observations from various suggested mechanisms. It is quite apparent from these studies that either there are several mechanisms synergistically involved to increase the oil recovery or the right mechanism has not yet been identified. However, the inclination of this research study based on reviewed papers is that the primary cause of improved oil recovery is directly or indirectly linked to the wettability alteration. The different proposed mechanisms appear to establish various similarities and differences in modified water impact on carbonates and sandstones, which is the crude oil adsorption onto positively charged calcite surfaces and negatively charged silica surfaces [44].

\subsection{Proposed Mechanisms in Sandstone Rocks}

\subsubsection{Swelling of Clay and Fines Mobilization}

Early experimental studies have associated improved recovery observed during exposure of sandstone cores to low saline brine or fresh water with swelling of clay and fines migration [7-9,166,241]. Bernard [8] reported higher oil recovery only when accompanied by a high pressure drop (consistent with permeability reduction) with sandstone cores containing swelling clays, e.g., montmorillonite. In addition, Tang and Morrow [13] noticed an improved oil recovery, increase in pressure drop and production of fines when diluted brine was injected into sandstone cores containing kaolinite. It was further reported that firing the cores, which stabilized the fines and increasing $\mathrm{Ca}^{2+}$ content did not improve oil recovery. Then, Tang and Morrow [13] proposed that the crude oil adsorbed onto fines-coated rock surface is mobilized with the detachment of mixed-wet fines during low saline brine injection rendering the mineral more water-wet due to exposure of the water-wet surfaces beneath the detached fines (see Figure 8). Bedrikovetsky and his colleagues [70,74] developed an analytical model based on torques balance and mass balance to describe the relationship between the static equilibrium of clay particles and salinity, which was also used in the study by Akhmetgareev and Khisamov [231]. The torque balance is distorted when the detaching torque of drag and lifting forces exceeds the attaching torque of electrostatic and gravity forces, resulting in fines detachment and migration during the arrival of low saline brine. This hypothesis implies that clay tends to hydrate and swell in a less saline environment. A less-saline solution expands the electrical double layer and destabilizes clay. Clay is also destabilized by divalent cations, because of their ability to lower the electrostatic repulsive force by decreasing the $\zeta$-potential. Thus, in any of these brine solutions, clay swelling, and detachment are triggered, which upon dispersion, flow with water to occupy and block smaller pores or pore throats. When this occurs, the fines are not necessarily produced in the effluents, but they force the injected fluid to redirect its path from invaded areas to upswept areas, thereby resulting in improved microscopic sweep efficiency and improved oil recovery. Relating to plugging of pores, it has been suggested to cause subtle permeability reduction and formation damage, but rather a decrease in relative permeability to water and increase in fractional flow of oil [242-244]. Several research studies have also observed evidence of fines migration associated with improved oil recovery (such as $[20,29,242,243,245-248]$ ), whereas there are several other studies where fines production and/or permeability reduction did not result in improved oil recovery (such as $[43,118]$ ). However, many cases (such as $[24,32,95,116,127,249]$ ) note oil recovery improvement without fines migration, which question the veracity of this mechanism. A possible explanation could be that the working condition varied with mineralogy and lithology (e.g., concentration of swelling clay higher than non-swelling clay) or fines migration with its associated permeability reduction is not always 
linked with the improved recovery observed during low saline brine injection. Another possibility is that the fines released do not appear in the effluent or show substantial increase in pressure drop because released fines could adhere to the oil as pickering emulsion or separately migrate and reattach to other surrounding pore walls downstream $[179,242]$.
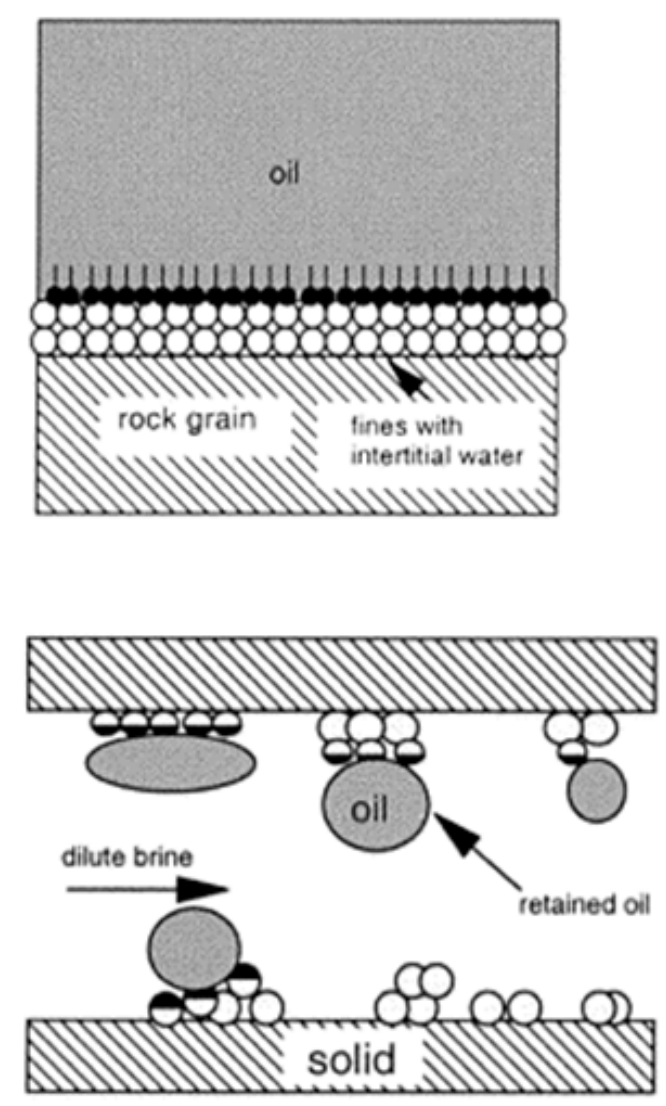
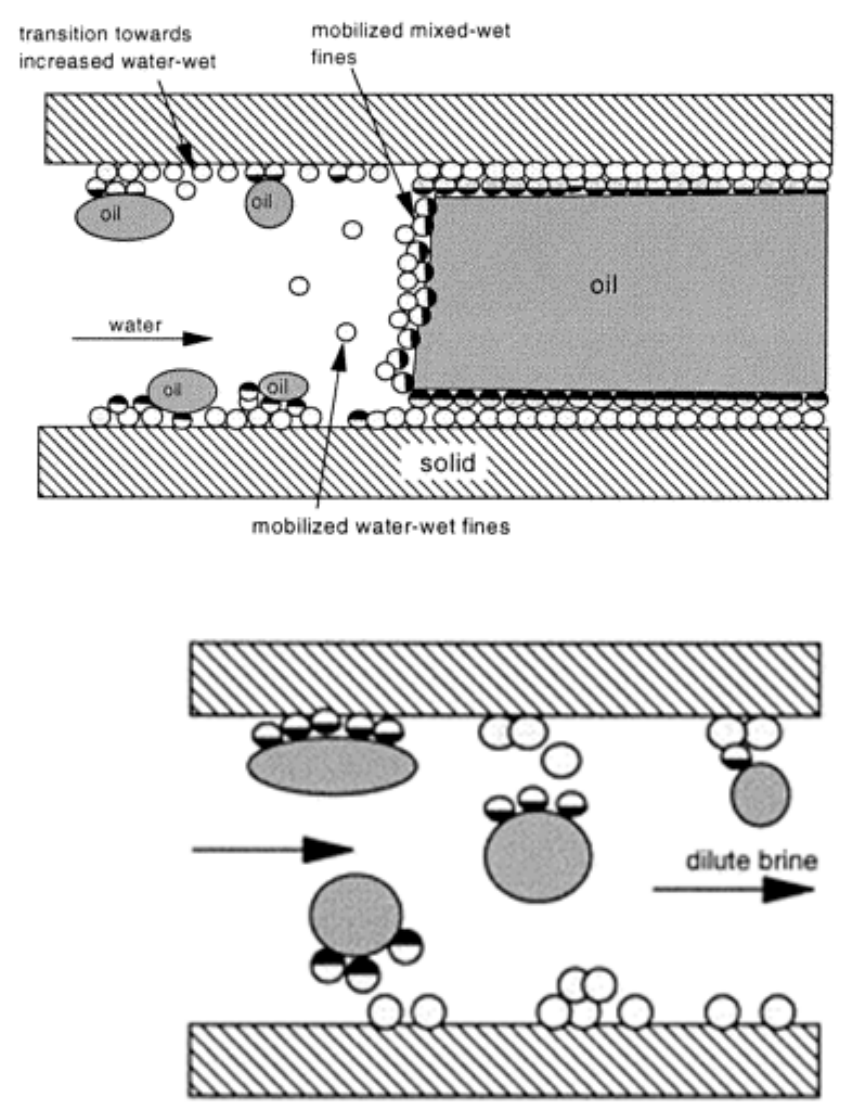

Figure 8. A sketch of proposed wettability alteration by "fines mobilization" in sandstones, showing organic components adsorption to potentially mobile fines forming mixed-wet fines (left upper), stripping of mixed-wet fines during low saline brineflood (right upper), and residual oil mobilization through fines detachment (lower) (reproduced from Tang and Morrow [13] with permission).

\subsection{2. $\mathrm{pH}$ Gradient}

Increase in effluent $\mathrm{pH}$ during low saline brine injection was earlier observed in the study by Tang and Morrow [13], which was attributed to a combination of carbonate dissolution and ion exchange. Carbonate dissolution is a relatively slow process that depends on the carbonate mineral fraction and often results in excess hydroxyl ions $\left(\mathrm{OH}^{-}\right)$in aqueous solution. On the other hand, ion exchange reaction is much faster, occurs between the mineral surface and the brine phase, where cations adsorbed on the mineral surface is exchanged with $\mathrm{H}^{+}$from the aqueous phase, thereby leading to decrease in aqueous $\mathrm{H}^{+}$and an increase in $\mathrm{OH}^{-}(\mathrm{pH})$. Later, McGuire et al. [21] proposed that the increased oil recovery observed in some corefloods experiment is associated with a significant increase in $\mathrm{pH}$, which possibly generate in-situ surfactants from the crude oil. It was suggested that low saline brine flooding shows similar behavior to alkaline flooding, where the organic acids in the crude oil are saponified as they contact the low saline brine and as a result, lower the oil-water interfacial tension, and subsequently increase the capillary number and mobilization of the trapped residual oil. The authors also claimed that reducing the concentration of divalent cations in the injected brine could inhibit the surfactants precipitation encountered in a high saline environment, thereby increasing the efficiency of the in-situ surfactants to increase recovery. The lack of oil recovery response to increased $\mathrm{Ca}^{2+}$ concentration in the injected brine observed by Tang and Morrow [13] was ascribed to sensitivity 
of $\mathrm{Ca}^{2+}$ to promote/inhibit the surfactants precipitation. Similar increase in effluent brine $\mathrm{pH}$ have been observed by several authors $[21,33,52,118,124,250]$, while there are reports showing improved recovery with lack of change in $\mathrm{pH}$ (such as $[24,29,127])$. Several other experimental observations also indicate that higher effluent brine $\mathrm{pH}$ does not always result in increased oil recovery $[43,67,118]$; in such instances the $\mathrm{pH}$ increase was explained to be a resultant combination of calcite dissolution and ion-exchange [67]. However, these conflicting evidences cast doubts on the $\mathrm{pH}$ gradient proposed by McGuire et al. [21]. Even though, reduced oil-brine IFT has been observed for low saline brine, but not to ultra-low values identified with alkaline flooding. While the $\mathrm{pH}$ gradient observed in many successful corefloods is often within 1-3 $\mathrm{pH}$ unit range and achieved at a $\mathrm{pH}$ below 7 , unlike in alkaline flooding where $\mathrm{pH}$ is usually 11 to 13 and needs to be greater than 9 for saponification to occur. The saponification process also requires a high AN, whereas successful waterfloods have been achieved with low AN crude oil and no correlation could be established between the improved recovery and AN (see Figure 2; [24,75]). Similarly, Zhang et al. [127] also noticed a slight rise and drop in effluent $\mathrm{pH}$ during low saline brine injection and found no clear relationship that exists between $\mathrm{pH}$ and oil recovery. Meanwhile, a local $\mathrm{pH}$ increase at the water-clay interface was proposed by Austad et al. [52]. The authors suggested that clay minerals are better cation exchangers due to their large surface area and CEC compared to quartz and are negatively charged in the reservoir natural state (pH 5-6). As shown in Figure 9, at the initial conditions, when clay particles are exposed to high saline brine solution, the high divalent cations in the brine establish a thermodynamic equilibrium with the rock surface to enhance the adsorption of both acidic and basic organic materials onto the clay surface. Austad and colleagues [41,52,124] reported an inverse $\mathrm{pH}$ dependence of adsorption of both acidic and basic materials on clay minerals based on an adsorption test, i.e., at low $\mathrm{pH}$, the adsorption is higher. The moment low saline brine is injected; the existing equilibrium is disrupted causing the adsorbed divalent cations to be substituted at the rock surface. The substitution process is facilitated by the dissociation of the surrounding water molecules into $\mathrm{H}^{+}$and $\mathrm{OH}^{-}$ions. The $\mathrm{H}^{+}$ ions adsorb onto the clay surface because of its higher affinity towards clay compared to other cations and the $\mathrm{OH}^{-}$ions in solution increase the $\mathrm{pH}$ locally near the clay surface, which can also react with the adsorbed acidic/basic materials (acid-base reaction) and release them from the surface. The low salinity condition is reflected in Equation (1) where exchange of the divalent cation, $\mathrm{Ca}^{2+}$ by a higher affinity ion, $\mathrm{H}^{+}$takes place and a reversal of the equation will result in the initial existing equilibrium state of the reservoir:

$$
\text { Clay }-\mathrm{Ca}^{2+}+\mathrm{H}_{2} \mathrm{O} \Leftrightarrow \text { Clay }-\mathrm{H}^{+}+\mathrm{Ca}^{2+}+\mathrm{OH}^{-}
$$

Hence the hypothesis considers that the removal of $\mathrm{Ca}^{2+}$ from the injection brine as a way to reduce brine salinity is favorable because $\mathrm{pH}$ increase becomes more significant. In support of this claim, Rezaeidoust et al. [124] reported an increase in recovery when pure $\mathrm{CaCl}_{2}$ brine was replaced by a similar ionic strength brine (pure $\mathrm{NaCl}$ ) and that a low saline brine of $\mathrm{NaCl}$ (containing a lower affinity cation, $\mathrm{Na}^{+}$) showed largest $\mathrm{pH}$ gradient ( 3 units). This implies that $\mathrm{pH}$ increase depends on the affinity of the injected brine cation, consistent with several studies that showed improved recovery with a diluted $\mathrm{NaCl}$ brine injection, although not all observed the anticipated $\mathrm{pH}$ increase $[32,33,43,245,249]$. Austad and colleagues [41,52] further claim that in a buffered system where improved oil recovery is observed, the effluent $\mathrm{pH}$ might hardly increase, but it does not mean that the desorption of the organic material due to a local $\mathrm{pH}$ increase in the neighbourhood of the clay surface is not taking place. It was quoted that the activity of $\mathrm{H}^{+}$in the bulk solution as described by $\mathrm{pH}$ measurements differs from activity of $\mathrm{H}^{+}$in the neighborhood of water-minerals interface (2-4 $\mathrm{pH}$ units difference). Rather than seeing a local $\mathrm{pH}$ increase as a major effect, Rezaeidoust et al. [44] proposed that organic materials are desorbed from clay surface by a salting-in effect. As it is well known that the solubility of organic compounds in aqueous phase is strongly affected by brine salinity and compositions: adding salts to the brine solution can drastically decrease organic material solubility (salting-out) while the solubility can be increased by removing salts (salting-in). Meanwhile inorganic cations like $\mathrm{Ca}^{2+}, \mathrm{Mg}^{2+}$, and $\mathrm{Na}^{+}$, 
present in the brine can break water structure around organic molecules, and decrease the solubility of organic molecules. The relative strength of these cations to decrease organic material is reflected in the order of their hydration energy. Thus, a reduction in brine salinity below a critical level can increase the solubility of the organic material in aqueous phase. The hypothesis was further verified in a desorption/re-solubilization study of 4-tert-butyl benzoic acid in an aqueous kaolinite suspension that carboxylic acid remained adsorbed in a high saline solution and less adsorbed in a low saline solution. This hypothesis has been largely ignored and remains comparatively under-investigated, probably because it is somehow associated with $\mathrm{pH}$ gradient. Based on these studies, it can be hypothesized that $\mathrm{pH}$ is likely to increase locally but the effect may be offset in the reservoir due to the presence of $\mathrm{pH}$ buffers e.g., $\mathrm{CO}_{2}$. It has also been suggested that clay minerals with high CEC are effective at improving oil recovery, yet Kaolinite, which has lower CEC compared to other clays, is often associated with improved recovery. Several studies have observed improved recovery in the absence of clay minerals, especially quartz/silica, which the proposed local $\mathrm{pH}$ increase mechanism could not explain.

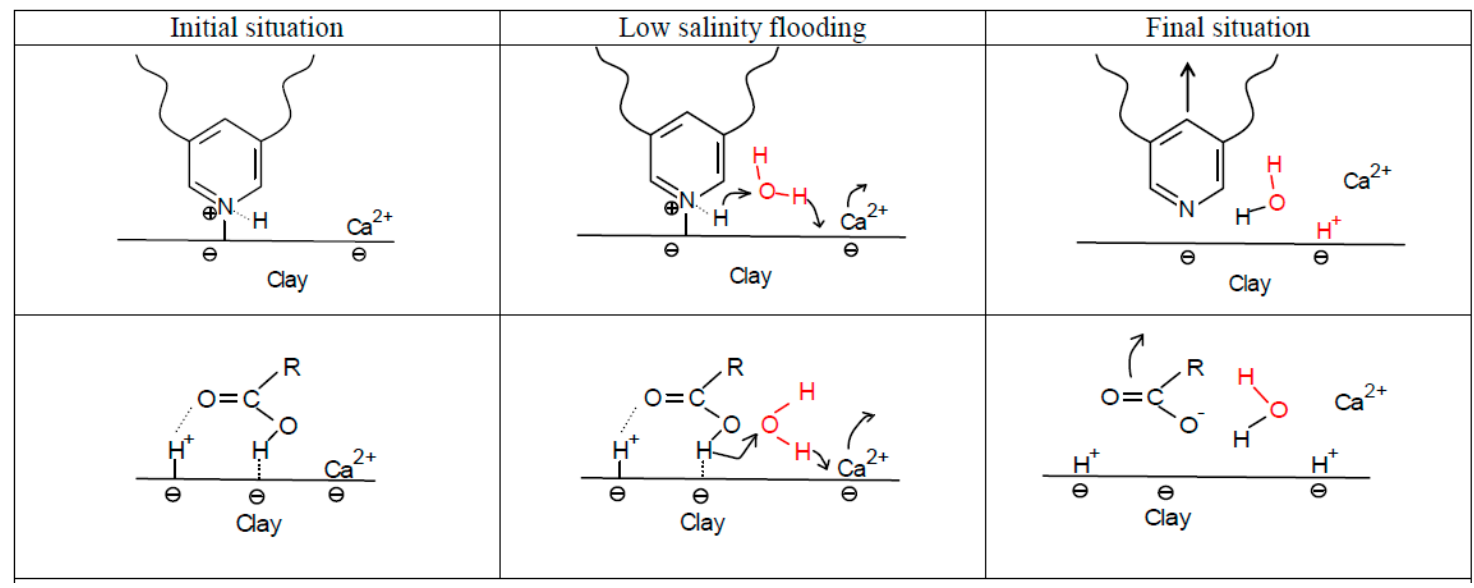

Figure 9. An illustration of proposed mechanism of wettability alteration by " $\mathrm{pH}$ gradient" for basic (upper) and acidic (lower) oil components desorbed from clay mineral surfaces through acid/base-proton transfer, yielding a pH increase (reproduced from Austad et al. [52]).

\subsubsection{Multi-Component Ionic Exchange (MIE)}

Lager et al. [24] suggested that there are different possible interactions, e.g., cation exchange, anion exchange, ligand exchange, protonation, water bridging, cation bridging, hydrogen bonding, van der Waals interaction, by which organic materials can adsorb on the rock based on the various organic functional groups present in the crude oil. The organic material or organo-metallic complexes are often attached to the clay minerals through the most dominant adsorption interactions (see Figure 10) due to the presence of divalent ions ( $\mathrm{Ca}$ and $\mathrm{Mg}$ ) in high saline formation brine, which are removed and replaced during injection of low saline brine by cationic ion exchange of uncomplexed cations at the clay surface. The evidence of MIE came from measured effluent brine composition during low saline brine injection in coreflood experiments and field tests and the authors noticed a reduced multivalent cation (especially $\mathrm{Mg}^{2+}$ ) concentration in the effluent compared to those in the low saline brine $[24,219]$. This hypothesis was validated in another experiment, when all $\mathrm{Ca}^{2+}$ and $\mathrm{Mg}^{2+}$ was removed from the clay mineral surfaces, the low saline $\mathrm{NaCl}$ brine injection yielded no additional recovery compared to the high saline brine and subsequent flooding with low saline brine containing $\mathrm{Ca}^{2+}$ and $\mathrm{Mg}^{2+}$ also yielded no recovery. Meanwhile, an additional 5\% recovery was observed during low saline brine flooding of cores initially containing $\mathrm{Ca}^{2+}$ and $\mathrm{Mg}^{2+}$ ions. The authors suggested that for low saline brine to result in improved recovery, clay minerals must be present alongside $\mathrm{Ca}^{2+}$ and $\mathrm{Mg}^{2+}$ in the initial high saline brine, while either acidic or basic organic components must adsorb to clay mineral surfaces through any of the adsorption interactions. 


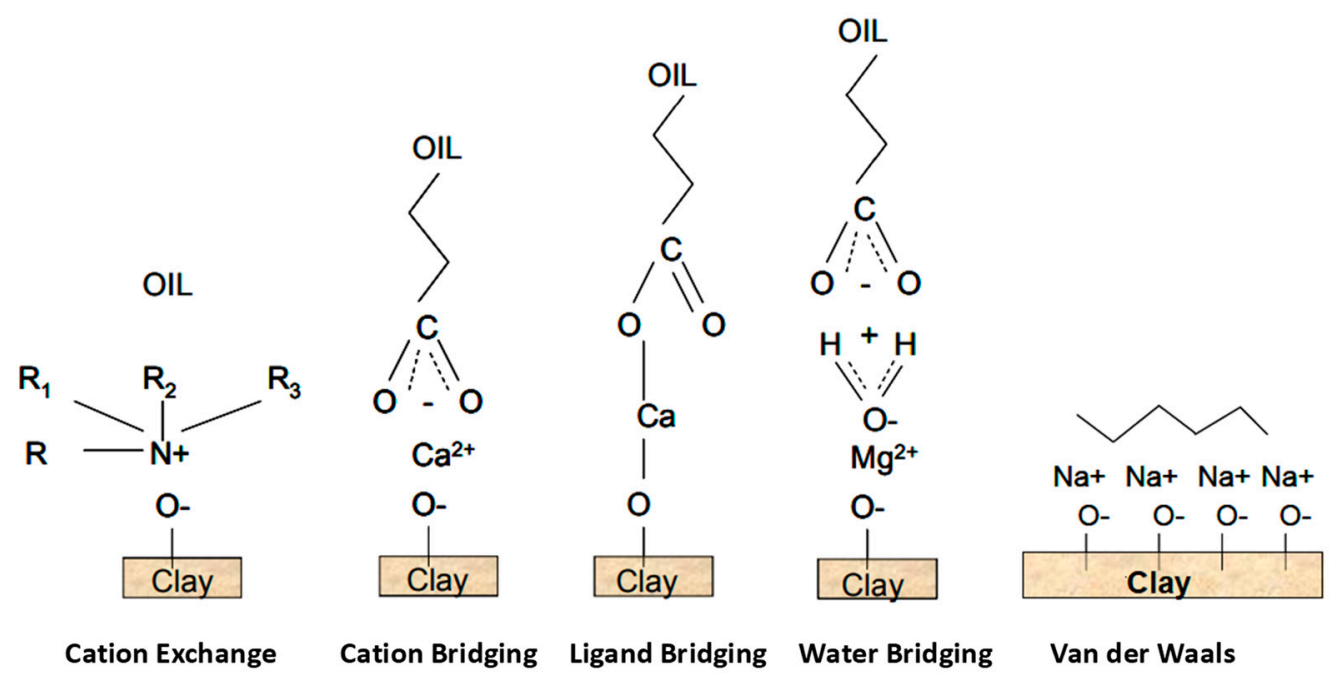

Figure 10. Proposed dominant adsorption interactions between organic oil materials and clay mineral surfaces associated with suggested mechanism for wettability alteration by "MIE" (adapted from Lager et al. [24]).

The authors argued that low saline brine did not improve recovery in the study by Tang and Morrow [13] after the core was acidized and fired as the CEC of the clay minerals was destroyed, which prevented ion exchange. They also claimed that basic organic components are strongly adsorbed which was the reason why no direct correlation exists between the oil acid number and the amount of oil recovered. It was also stated that due to a lack of clay minerals, low saline brine could not seem to work on carbonate reservoirs as earlier predicted. However, a mechanism of similar nature is proposed for wettability modification in carbonates without the need for clay presence, which will be discussed in the subsequent section. The MIE hypothesis was rebutted by Austad et al. [52] that the change in $\mathrm{Mg}^{2+}$ concentration observed by Lager et al. [24] was not necessarily caused by MIE, but by precipitation of $\mathrm{Mg}(\mathrm{OH})_{2}$ as a result of a local $\mathrm{pH}$ increase

Despite this shortcoming, MIE has been well explored and modelled. Alagic and Skauge [245] found that $\mathrm{Mg}^{2+}$ and $\mathrm{Na}^{+}$was less in the effluent during successful low saline $\mathrm{NaCl}$ brine corefloods. They suggested that $\mathrm{Mg}^{2+}$ was retained in aged samples while $\mathrm{Ca}^{2+}$ was eluted, which is consistent with MIE, though more elution of $\mathrm{Ca}^{2+}$ occurred due to calcite dissolution. Nasralla and Nasr-El-Din [56] also showed evidence that cations at the rock surface are leached and replaced by cations from single cation $\left(\mathrm{Ca}^{2+}, \mathrm{Mg}^{2+}\right.$ and $\left.\mathrm{Na}^{+}\right)$brine solutions in dry sandstone cores and injection of $\mathrm{NaCl}$ brine solution yielded higher oil recovery compared to $\mathrm{CaCl}_{2}$ and $\mathrm{MgCl}_{2}$ brine at the same concentration level. Omekeh and colleagues $[67,251]$ observed that $\mathrm{Ca}^{2+}$ was much more eluted compared to the monovalent ion $\left(\mathrm{K}^{+}\right)$in the effluent analysis of a static test conducted by mixing the crushed minerals and low saline brines. They also developed a numerical model that integrated ion-exchange into transport model, which was used to predict different experimental cases on the premise of $\mathrm{Ca}^{2+}$ desorption. $\mathrm{No} \mathrm{Ca}^{2+}$ desorption was observed where low saline brine did not improve recovery for a core saturated with no divalent ions [24,32], no desorption was also observed for cases where divalent ions were initially present but low saline brine did not improve recovery $[36,95]$ and desorption was also observed where divalent ions were initially present and low salinity did improve recovery [95].

Similarly, Fjelde et al. [252] observed that $\mathrm{Mg}^{2+}$ and $\mathrm{Ca}^{2+}$ were retained by the rock while $\mathrm{K}^{+}$was more in the effluent during successful low saline brine injections. They used the model developed by Omekeh et al. [67] and predicted that $\mathrm{Ca}^{2+}$ adsorption during low saline brine injection altered wettability to less water-wet, gave earlier water breakthrough and oil production over a longer period than high saline brine injection. In contrast, Dang et al. [63] proposed that the replacement of Na at the surface by $\mathrm{Ca}$ in low saline brine is the premise for the wettability shift towards water-wetness and improved oil recovery, which predicted the coreflood results of Fjelde et al. [252] and Rivet et al. [40], 
similarly implemented by Kadeethum et al. [253]. The MIE mechanism alone does not explain the numerous studies where the above conditions were not met but improved recovery was still observed.

\subsubsection{Electrical Interactions}

Electrostatic interaction is considered because the rock, brines, and crude oil, all contain charged ions and based on Derjaguin-Landau-Verwey-Overbeek (DLVO) theory, the electrostatic interactions acting on the oil-brine-rock system, comprising of the rock-brine and oil-brine interfaces, leads to the development of the electric double-layer (EDL). An EDL is a structure of ions with two parallel layers of charge, that appears on portions of rock mineral or oil surface that are exposed to brines in the pore space. Close to the charged surface is the stern layer, where counter-ions are attached, and this layer is surrounded by the diffuse layer, composed of co-ions and counter-ions that are not attached and move freely under the influence of thermal motion and electric attraction in the adjacent bulk fluid. The thickness of this EDL, also known as Debye length, is dependent on the electrical charges at rock-brine and oil-brine interfaces (often evaluated by $\zeta$-potential) as a function of $\mathrm{pH}$, brine salinity and ion valency. The concept of electrical double layer expansion (DLE) was suggested by Ligthelm et al. [32] as they argued that MIE was a secondary cause that decreased ionic strength and valency rather than a primary cause to wettability alteration. It was stated that during low saline brine injection, with reduced divalent cations, the EDL at both interfaces expand, resulting in increased electrostatic repulsion between the two interfaces (see Figure 11). When the repulsive force exceeds the binding forces involved in oil adsorption interaction with the clay surface, the water layer thickens and the oil polar components desorb, yielding improved water-wetness and oil recovery. This was verified by conducting a series of corefloods with injection of brines of similar ionic strength, with/without divalent cations and lower salinities. It was observed that oil recovery slightly increased when injecting purely $\mathrm{NaCl}$ brine after flooding brine containing both monovalent and divalent ions with similar ionic strength and a significant increase in recovery was observed when $\mathrm{NaCl}$ brine was diluted 100 times. Similarly, Lee et al. [178] reported a general trend of thicker water layer of both the clay and silica surfaces when the brine salinity is reduced from 0.1 to $0.001 \mathrm{M}$ (i.e., 6000 to $60 \mathrm{ppm}$ ). The authors claimed that there is broad variation in water layer thickness for divalent ions compared to monovalent ions. As $\mathrm{NaCl}$ brine salinity was reduced from 0.1 to $0.001 \mathrm{M}$, the water layer size increased from 10.8 to $11.8 \AA$, while for similar reduction in $\mathrm{MgCl}_{2}$ concentration, the water layer thickness increased from 8.1 to $14.8 \AA$. This suggested that high concentration of divalent cations on sandstone minerals can lead to significantly thinner water layer than monovalent cations and reducing the concentration of divalent cations can further increase water layer thickness of the mineral surface. Nasralla and Nasr-El-Din [249] studied the effect of $\mathrm{pH}$ on low saline brine injection and noticed that reducing the $\mathrm{pH}$ of the low saline brine increases the $\zeta$-potential of both rock-brine and oil-brine interfaces, thereby reducing the EDL expansion prompted by low saline brine, similarly observed by Takahashi and Kovscek [254] and Buckley et al. [255]. They concluded that for low saline brine injection to be successful, the $\mathrm{pH}$ must be high enough to increase the electrostatic repulsion forces between the two interfaces. The $\mathrm{pH}$ gradient theory discussed above also makes a similar prediction. Several other studies have also demonstrated that the $\zeta$-potential at mineral surfaces decreases as the brine salinity reduces $[56,58,203,249,256]$, with $\mathrm{NaCl}$ brine giving lesser $\zeta$-potential reduction than divalent cations brines $[56,256]$ and $\zeta$-potential becomes constant within experimental error at concentrations beyond $0.4 \mathrm{M}(23,400 \mathrm{ppm})[58,203]$.

The disjoining pressure, which is the sum of electrostatic, structural, and Van der Waal forces, and surface complexation models have been used to further support DLE theory. Brady and colleagues [179, 257,258 ] considered that clay surface charge is dictated by sum of clay edge and basal plane charges and in most clay minerals, such as kaolinite, the clay edge is more dominant while basal plane can be non-existent except in cases of impurities. As such, oil adhesion differs between the clay edges and basal planes, where the latter is independent of $\mathrm{pH}$ and cation exchange results from lattice substitution; while the former varies with $\mathrm{pH}$ because of its acid-base functionality. It was predicted that there are 
four attraction bridges that are important for kaolinite-oil adhesion, which involved the linking of kaolinite edges with protonated positively charged nitrogen base groups and with both positively and negatively charged acidic groups respectively produced through $\mathrm{Ca}^{2+}$ binding and deprotonation, as shown in Figure 4. Positive benefits could be observed from low saline brine interaction to generate repulsion for weakened oil adhesion of positively charged oil base groups to kaolinite edges at $\mathrm{pH}<5$ while at higher $\mathrm{pH}$, the electrostatic interaction is controlled by the competition between negatively and positively charged acid groups towards kaolinite edges. The authors suggested that this might explain the insensitivity of the effectiveness of low saline brine injection to oil acid number noted by lager et al. At low acid number, when the carboxylate sites existing at the oil-brine interface are minimal, improved oil recovery can be observed by decreasing the $\left[>\mathrm{Al}_{\mathrm{SiO}}{ }^{-} \Leftrightarrow^{+} \mathrm{HN}<\right]$ attraction bridge, which would result in high $\mathrm{pH}$. Meanwhile, at high acid number, low $\mathrm{Ca}^{2+}$ concentration in the injected brine will reduce $\mathrm{Ca}^{2+}$ coordination to abundant carboxylate and reduce the $\left[>\mathrm{Al}_{\mathrm{SiO}}^{-} \Leftrightarrow^{+} \mathrm{CaOOC}<\right]$ attraction bridge. Moreover, because high $\mathrm{pH}$ will result in the deprotonation and $\mathrm{Ca}^{2+}$ binding of carboxylic groups, low saline brine was predicted to be more effective at switching the oil/kaolinite edge interaction to repulsion in a narrow range of $\mathrm{pH} 5-6$. They proposed that the integration of $\mathrm{pH}$ gradient and DLE to be responsible for wettability alteration during low saline brine injection. Several studies have also shown the disjoining pressure (at small distances, where it is most effective) become more positive as the brine salinity is reduced $[100,179,254,259]$. Positive disjoining pressure indicates repulsion, which increases the thickness of water film and results in increased water-wetness (see Figure 11). Despite many studies attributing improved recovery to DLE, it has also failed to explain why the positive response is not always observed with reduced salinity or ionic strength.

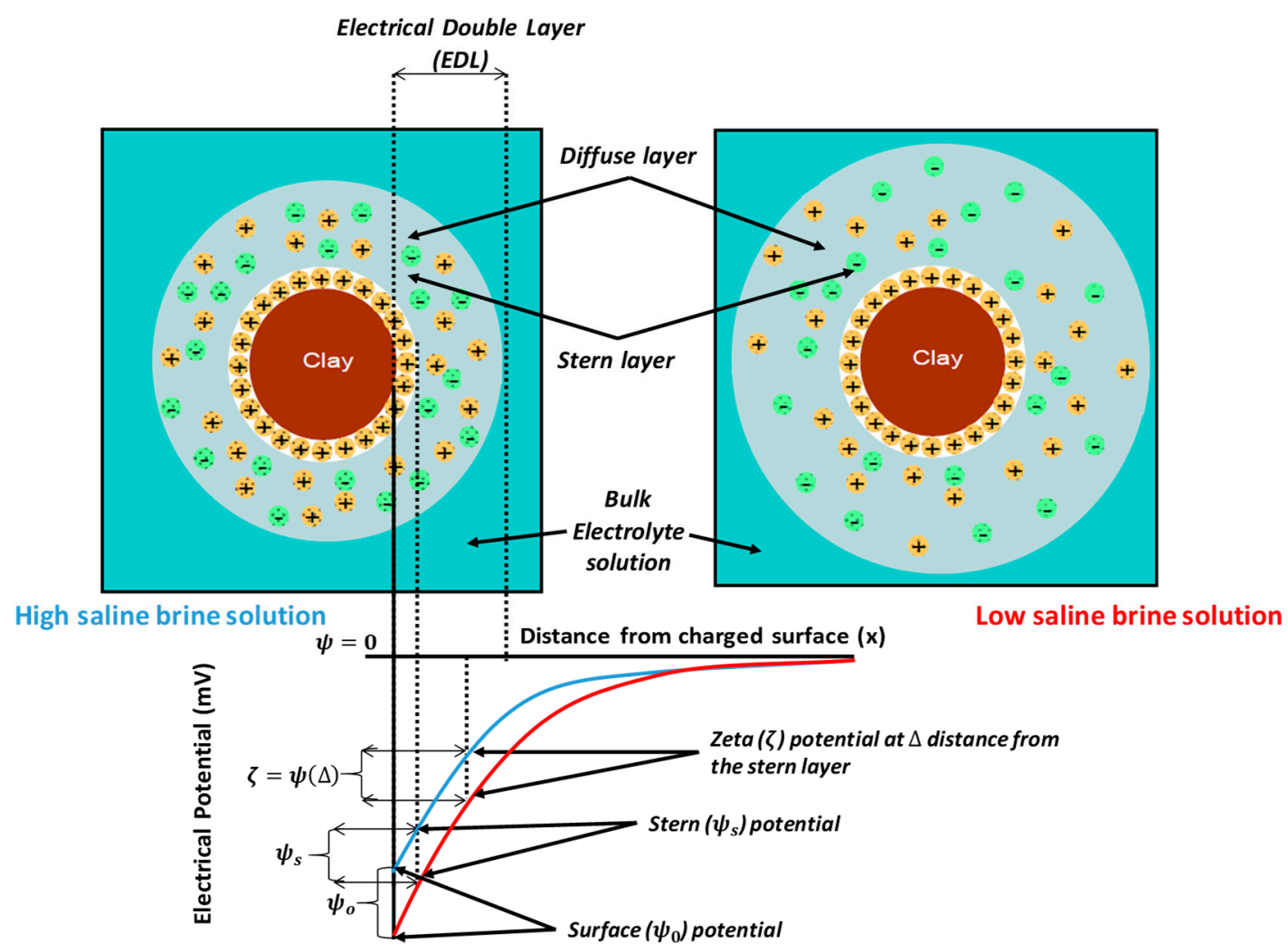

Figure 11. A schematic illustration of the EDL expansion in sandstone reservoirs for original high saline condition (left) and low saline condition (right) with corresponding changes in surface charge distribution shown (bottom). The blue and red lines represent the electrical potential distribution under high saline and low saline brine, respectively (adapted from Awolayo et al. [62]). 


\subsection{Proposed Mechanisms in Carbonate Rocks}

\subsubsection{Rock Dissolution}

The rock dissolution theory postulates that reduced concentration of PDIs (such as $\mathrm{Ca}^{2+}, \mathrm{Mg}^{2+}$ and $\mathrm{SO}_{4}{ }^{2-}$ ) in the injected brine compared to the initial high saline brine disturbed the existing equilibrium and causes dissolution of these PDI source-rock minerals like $\mathrm{CaCO}_{3}, \mathrm{CaMg}\left(\mathrm{CO}_{3}\right)_{2}$ and $\mathrm{CaSO}_{4}$, thereby re-establishing a new equilibrium with the injected brine. During this process, the release of adsorbed polar components accompanies the dissolved minerals, which consequently result in increased water-wetness and improved oil recovery as illustrated in Figure 12. This concept was proposed by Hiorth et al. [65] through geochemical thermodynamic modelling of various experimental studies (such as spontaneous imbibition and electrokinetic tests, see $[57,59,93,188,260]$ ) on chalk that the surface charge dependence of disjoining pressure could not describe the oil recovery improvement observed in relation to pore water chemistry and temperature. They argued that PDI cations will promote oil wetting because they increased the rock surface charge while $\mathrm{SO}_{4}{ }^{2-}$ did not show the strong temperature-dependence that was observed in many studies. Then, they reiterated that due to the calcite surface being thermodynamically unstable, dissolution occurs, and the amount dissolved correlates linearly with the improved production, particularly when the calcite was preferentially dissolved exactly where the oil wets the calcite. In a study with limestone cores, Yousef et al. [25,47] attributed the improved connectivity between micropores and macropores during NMR experiments on low saline brine injection at reservoir conditions to microscopic dissolution of anhydrite. Austad et al. [45] injected sulfate-free diluted brine into limestone cores containing anhydrite and reported an incremental recovery of 5\% OOIP. They explained that sulfate was continually generated in-situ because of anhydrite dissolution, and this led to the wettability alteration process. Several other experimental studies have ascribed the observed improved recovery in carbonates during low saline brine injection to rock dissolutions of different minerals [29,37,53,215].

Austad et al. [261] strongly opposed the calcite dissolution mechanism proposed by Hiorth et al. [65] by questioning the applicability of the geochemical model to calculate the chemical equilibrium between calcite and seawater and the corresponding compositions at the considered temperature range. It was argued that calcite dissolution is contradictory to published experimental results, where it was discussed that an increase in aqueous $\mathrm{Ca}^{2+}$ increases oil recovery and will suppress chalk dissolution due to common ion effect, which means that decreased dissolution increases oil recovery, and then at high temperature there is no increase in oil recovery with increased dissolution.
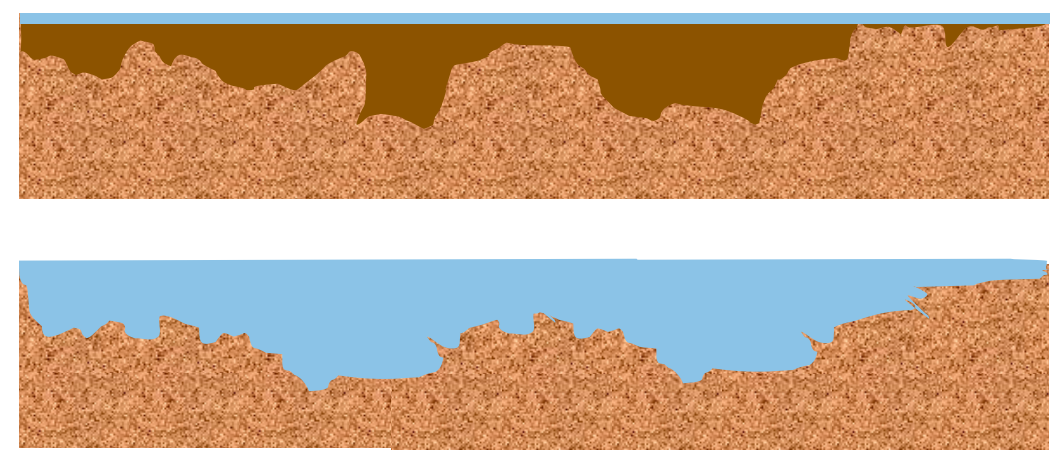

\section{Carbonate rock}

\section{Aqueous brine}

Crude oil

Figure 12. An illustration of the proposed mechanism of wettability alteration by "dissolution" showing an oil-wetting state with oil attachment before dissolution (top) and the water-wetting state after dissolution (bottom) (adapted from Hiorth et al. [65]).

Furthermore, it was argued that wettability alteration does not depend on the bulk mineral dissolution due to buffering of aqueous solution and equilibration at field-scale. This implied mineral dissolution is not considered to be contributing at a reservoir scale, hence ranked as a secondary cause [55,99,262,263]. Despite these studies, Awolayo et al. [181] claimed, by using a geochemical 
model to predict performance history of low saline brine injection into different rock minerals, that the interplay between mineral dissolution and surface charge alteration is vital to improved recovery and their relative contribution depends on brine composition, mineral constituents, and temperature. Aqueous $\mathrm{pH}$ was also reported to be controlled by interaction between injected brine and minerals present, majorly the resultant effect of mineral dissolution and precipitation. The authors concluded that mineral dissolution/precipitation cannot be exempted in modelling low saline brine injection at both core and field scale as it affects the concentrations of the PDIs available to adsorb.

\subsubsection{Surface Ion Exchange}

The pristine structure of carbonate mineral surfaces is composed of metal ions (such as $\mathrm{Ca}^{2+}$, $\mathrm{Mg}^{2+}$, etc.) coordinated to oxygen atoms from carbon atoms (such as $\mathrm{CO}_{3}{ }^{2-}$ ). Because of the reactive nature of the carbonate mineral surface, the surface is hydrated by the dissociation of chemisorbed water molecules resulting in a surface composed of hydroxylated cationic sites and protonated anionic sites, which are stabilized by the dissociated hydroxyl ions $\left(\mathrm{OH}^{-}\right)$and protons $\left(\mathrm{H}^{+}\right)$respectively. The stabilization of the surface site depends on the brine composition as well as the $\mathrm{pH}$. At low $\mathrm{pH}$ below $6-8$, the excess $\mathrm{H}^{+}$ions and probable dissolution will make the positively charged cationic sites dominate and the overall surface positively charged. Meanwhile at a high enough $\mathrm{pH}$, excess $\mathrm{OH}^{-}$ ions will change the surface to more negative charge. In representative reservoir conditions, carbonate rock surface is positively charged in the $\mathrm{pH}$ range (6.5-7.5) of the surrounding high saline formation brine (consisting low concentration of negatively charged ions like $\mathrm{CO}_{3}{ }^{2-}$ and $\mathrm{SO}_{4}{ }^{2-}$ and high amount of positively charged $\mathrm{Ca}^{2+}$ ) while the polar components of oil have a predominantly negative surface charge, resulting in a high bonding energy between polar carboxylic materials and carbonates [97].

The adsorption of the negatively charged carboxylic component of crude oil onto the mineral surface causes a change in the rock wettability (preferentially oil/mixed-wet). Under the influence of modified brine with more PDIs, $\mathrm{SO}_{4}{ }^{2-}$ competes with the polar component, and adsorb onto the carbonate rock surface, lowering the rock surface charge. This creates an electrostatic repulsion and causes the bond between the rock-brine interface and oil-brine interface to rupture. Then, $\mathrm{Ca}^{2+}$ ions are co-adsorbed to the rock surface and its excess concentration at the site bind to the negatively charged carboxylic groups in oil and release the oil in the form of $\mathrm{Ca}^{2+}$-carboxylate complexes, resulting in improved water-wetness and oil recovery (Figure 13). This mechanism is analogous to the MIE described for sandstones in the previous section, except this mechanism revolves around the adsorption of the active ions unto the rock surface resulting in release of the attached oil and was first proposed by Austad and colleagues in different carbonate rocks $[27,31,44,57,59,93,97,188,189]$ and several others have presented evidence to support this mechanism $[215,264]$. As discussed earlier, temperature seems to influence the activity of these PDIs. At higher temperature (above $100{ }^{\circ} \mathrm{C}$ ), $\mathrm{Mg}^{2+}$ has higher activity and could substitute $\mathrm{Ca}^{2+}$ at the rock surface and cause the oil to be released as $\mathrm{Ca}^{2+}$-complexes. This mechanism has also been linked with rock dissolution as sufficient $\mathrm{SO}_{4}{ }^{2-}$ is produced by dissolution of anhydrite while $\mathrm{Mg}^{2+}$ is produced by dolomite dissolution. Similarly, this mechanism is somewhat related to DLE as will be discussed below. 


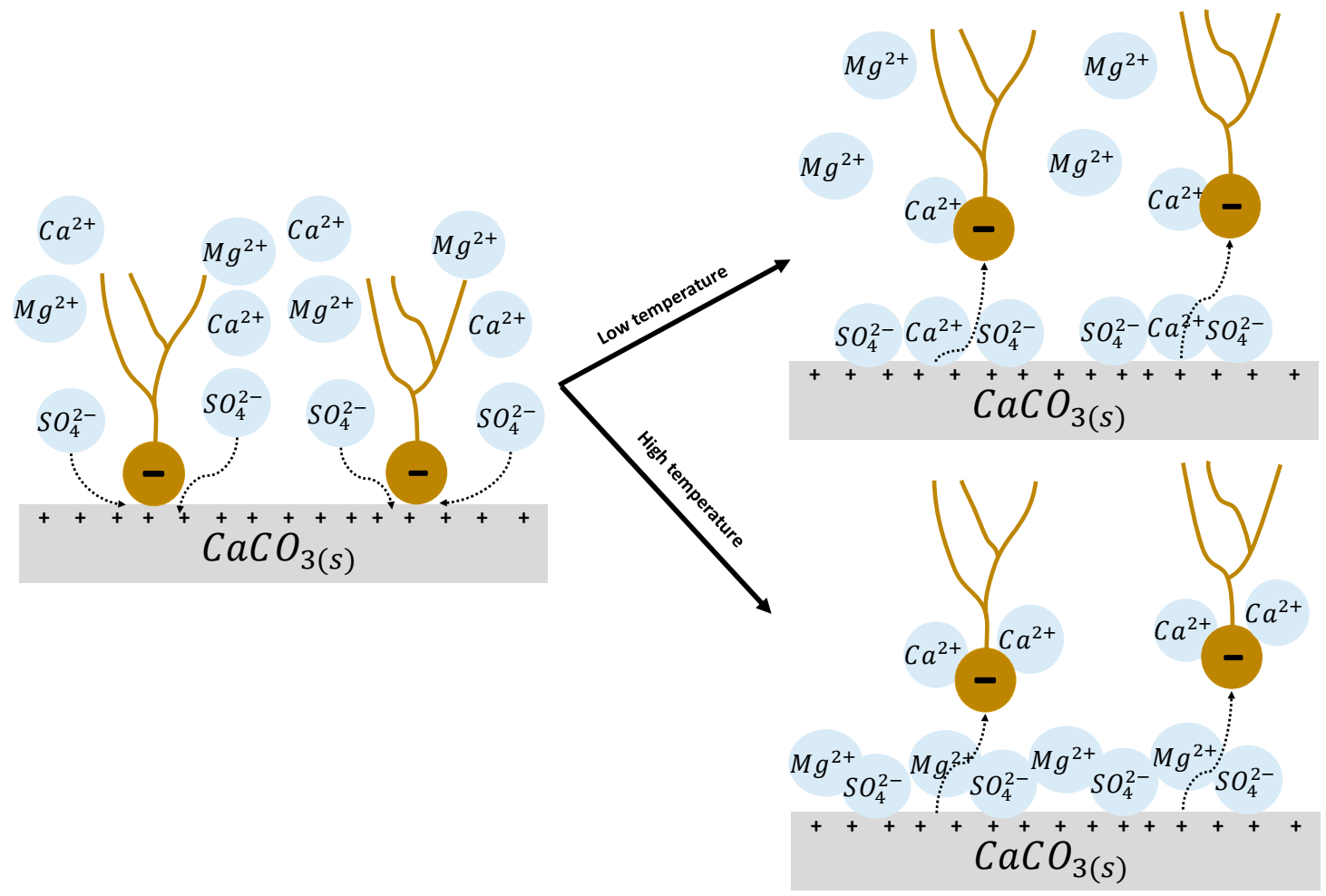

Figure 13. An illustration of the proposed mechanism of wettability alteration by "MIE" in carbonate reservoirs showing the polar oil component displacement from the carbonate rock surface through PDIs competition. Original state (left), Low temperature state (right upper) and High temperature state above $100{ }^{\circ} \mathrm{C}$ (left lower) (adapted from Zhang et al. [59]).

\subsubsection{Electrical Interaction-DLE}

This is like the DLE mechanism described in the previous section for sandstone reservoirs. EDL expansion increases the electrostatic repulsion between rock-brine and oil-brine interfaces, resulting in higher and/or positive disjoining pressure, creating a thicker and more stable water film layer and resulting in more water-wet conditions (see Figure 11). Many authors $[23,47,99,181,265]$ describe this as "surface charge alteration" mechanism, which involves altering the rock surface charge to create more electrostatic repulsive forces between the two interfaces and alter rock wettability toward water-wetness. Monovalent ions consisting of $\mathrm{Na}^{+}$and $\mathrm{Cl}^{-}$have been considered as non-reactive towards the rock surface, which implies that they do not partake in the interaction at the carbonate surface within the stern layer but are very sensitive in the outer diffuse layer and they might regulate the admittance of the PDIs onto the rock surface $[28,34,191]$. At the initial reservoir conditions, the high saline formation brine contains relatively lower PDIs compared to the high concentration of $\mathrm{NaCl}$, which implies that the initial positive charge at the rock-brine interface is maintained and much of $\mathrm{Na}^{+}$ and $\mathrm{Cl}^{-}$are retained at the diffuse layer. This will hinder the PDIs from interacting with the surface of the rock and electrostatic attraction (low/negative disjoining pressure) between the two interfaces and thinning of the water film layer. A significant change to the water chemistry will create much better access through the double layer and enable the PDIs to attach specifically in the stern layer or via the intermolecular coordination of water molecules, altering the surface charge at the interface. $\mathrm{NaCl}$-depleted brine has been shown to reduce the concentration of non-active ions in this layer so that the active ions could enter easily to the surface (Figure 14). In this context, rock-surface charge is reduced or even reversed towards negative from its initial condition of positive charge $[107,266]$. Such interaction can release adsorbed oil acidic components from the surface sites because of the more stable water film layer that is developed due to lesser attraction (higher disjoining pressure) 
between the two interfaces. This was first proposed in chalk by Fathi and colleagues $[28,191]$ and later in limestones [34,39].

In addition, Yousef et al. [25] associated wettability changes to surface charge alteration in combination with rock dissolution through electrokinetic and NMR analysis. NMR showed fast surface relaxation and $\zeta$-potential shifted towards more negative with successive dilution of seawater. Alroudhan et al. [51] also observed a shift towards more negative when injected brine was diluted or $\mathrm{SO}_{4}{ }^{2-}$ was added to the injected brine. They confirmed that both cases could improve oil recovery by altering surface charge and expanding the EDL. Similarly, Mahani et al. [55] conducted ל-potential and contact angle measurements on different carbonate rocks and stated that the observed wettability changes and improved recovery is primarily driven by surface-charge alteration due to electrostatic interactions between crude oil and rock. Moreover, the phenomena are predominantly occurring at the rock-brine interface. In place of sorption of $\mathrm{SO}_{4}{ }^{2-}$ to the rock surface, Brady and Thyne [267] suggested, based on work of Goldberg and Forster [268] that maximum boron sorption to calcite occurs at a $\mathrm{pH}$ of 9.5, that $\mathrm{BO}_{4}{ }^{3-}$ can coordinate with calcite positive surface site $\left[>\mathrm{CaOH}_{2}{ }^{+}\right]$, locally decrease the charge to decrease oil adhesion through an electrostatic attraction bridge and thicken the water film layer. In the same way, $\mathrm{PO}_{4}{ }^{3-}$ can also link and reduce oil adhesion, which was observed by $\mathrm{S} \varnothing$ et al. [269]. At relatively low concentrations, $\mathrm{PO}_{4}{ }^{3-}$ can electrostatically sorb to calcite surfaces to convert the positively charged surface sites into neutral/negative, whereas at high concentration, it can precipitate as calcium phosphate. These studies further acknowledge the improved recovery observed and water wetness using $\mathrm{PO}_{4}{ }^{3-}$ and $\mathrm{BO}_{4}{ }^{3-}$ by various researchers and their likelihood to precipitate at higher concentrations $[53,111,216]$.
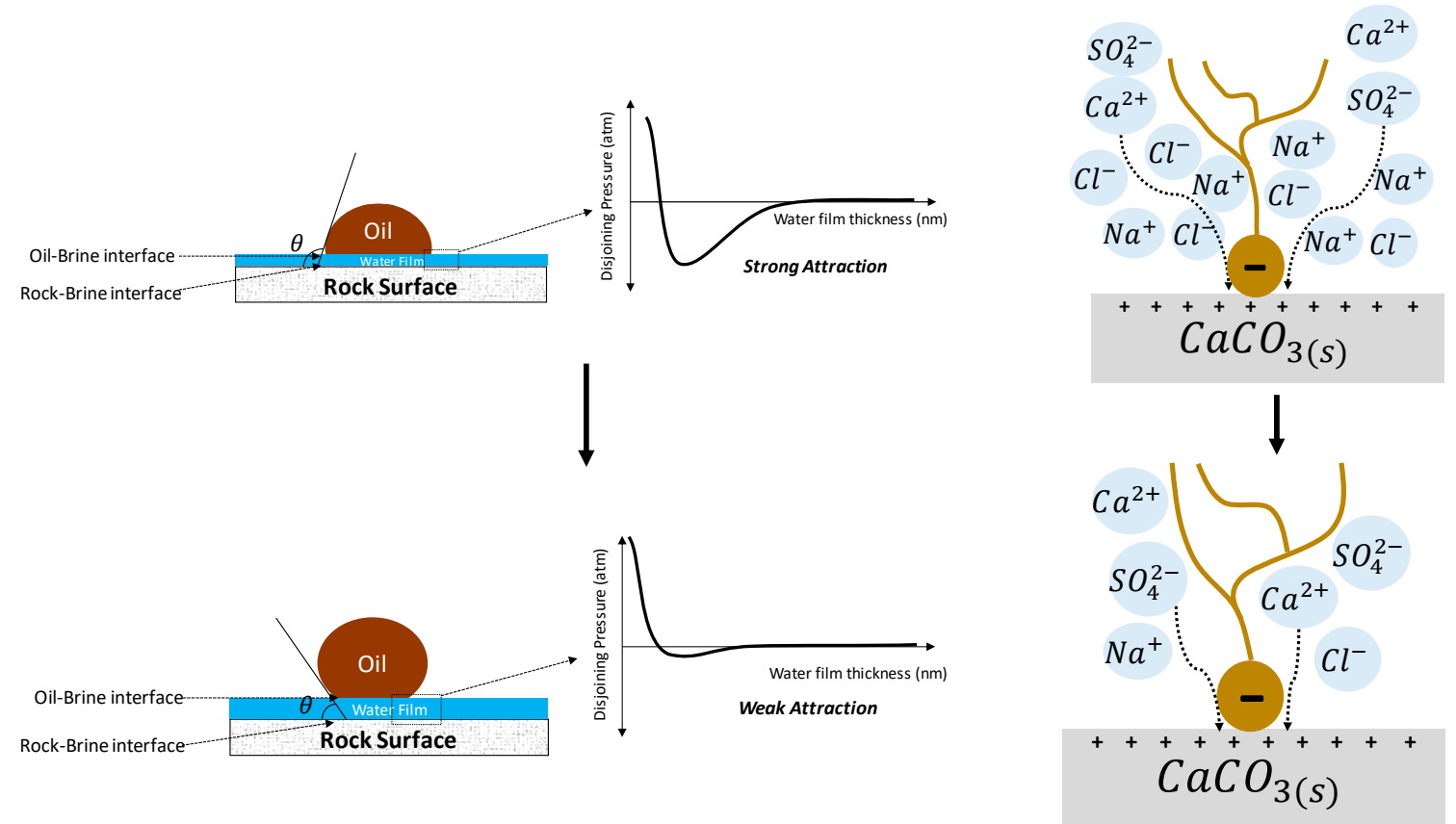

Figure 14. An illustration of the proposed mechanism for wettability alteration by "DLE" in oil-brine-carbonate rock system with DLVO disjoining pressure showing transition from an oil wetting state (left upper) with crowded double layer-filled non-active ions (right upper) to water wetting state (left lower) with double layer depleted non-active ions (right lower) (adapted from Fathi et al. [28], Awolayo et al. [62]).

A combination of all these mechanisms are often believed to be involved in improving oil production, because during the injection of low saline brine/ ion-modified brine, the thermodynamic equilibrium existing among the ion species dissolved in the water film layer, ion species adsorbed on the rock surface and the ion species that forms the rock matrix is disturbed. This triggers a reaction 
involving connate-waterflood mixing, dissolution/precipitation, sorption and surface ion exchange, while trying to establish a new equilibrium state, and favourably cause the rock-brine interface to become less positively charged and repel the negatively charged oil-brine interface.

\section{Modeling of Brine-Dependent Recovery}

Reliable optimization of any recovery process requires the availability of a predictive tool, which is a necessity to understand completely the principal mechanisms driving the recovery process. For such a tool to be developed to simulate the recovery process, the mechanisms at play need to be well grasped. However, despite various inconsistencies in the process mechanisms, several attempts have been made to model this process and outlined below are the relevant works done thus far. The phenomena of fluid flow during brine-dependent recovery process are often mathematically described by a partial differential equation (PDE) or a system of several PDEs, with associated boundary and initial conditions. The PDE describing process can be solved either analytically or numerically. Majorly, the PDE solution is linked to the observed improved recovery by considering the influence of capillary forces as a driver for wettability alteration, particularly, an increase in flow oil functions (e.g., relative permeability, capillary pressure and residual oil saturation and a corresponding decrease in water flow functions, are used to calculate the flow of each individual phase. The methodologies and application of analytical and numerical approaches that are often made in modeling the brine-dependent recovery process are summarized below.

\subsection{Analytical Approach}

Most of the recent modeling efforts have attempted to capture the brine-dependent recovery process through numerical approximations, and to the best of our knowledge, very few studies have explored the application of analytical solutions. This is because analytical solutions are often applied to many practical problems of fluid flow, with certain simplifying conditions, involving insufficient experimental data that could justify the use of a numerical model. Besides, analytical solutions can guide in the design of experiments and benchmark the numerical models. In addition, the practical advantage of analytical solutions lies in the fact that they offer quick estimation, improve interpretations and are useful in conducting sensitivity analysis and computations of different displacement behavior for different injection brine salinity and compositions.

Lemon et al. [270] captured the fine migration effects and permeability reduction by providing a simple analytical induced-fines migration model to justify improved oil production associated with low saline brine injection. The authors implemented a modified particle-detachment model, which considered maximum retention function as related to the ratio of detaching and attaching torques, into the quasi-2D Dietz model for waterflooding in a layered-cake reservoir and was validated using single flow laboratory coreflooding experiments. They suggested that fines migration effects on oil recovery are more pronounced with increased viscosity ratio and reservoir heterogeneity. Zeinijahromi et al. [70] opined that this model considered single-phase environment with mobilization caused by increase in flow velocity and extended the model to capture 3D modeling of fines-assisted waterflooding by introducing two-phase flow equations with fines lifting and migration in the aqueous phase and fines size-exclusion. The fines lifting is caused by water salinity changes and the alterations in particle equilibrium by changes in both fluid velocity and salinity were captured, resulting in reduction of relative permeability to water. The model typically involved integrating fines migration and permeability reduction into two-phase black-oil model and was used to model fines-assisted waterflooding in two heterogenous formations. It was highlighted that induced-fines migration was more effective in improving sweep efficiency for large-scale heterogeneity with highly correlated flow paths. This model has been applied to interpreting and predicting fines-assisted waterflooding in many oil fields (such as Pervomaiskoye, Zichebashskoe, and Bastrykskoye fields) in Russia [229-231]. On the other hand, Borazjani et al. [74] extended this model by simultaneously accounting for wettability alteration and fines mobilization, migration, and straining, solved by using splitting procedure for 
hyperbolic systems. It was proposed that wettability alteration reduces residual oil and increased oil displacement from the swept area, while induced-fines migration with permeability reduction in the swept area decreased water flux and diverts the injected brine to unswept zones. The collective effects were observed to improve oil recovery much more than their individual effects.

Venkatraman et al. [69] used the hyperbolic theory of conservation laws to develop analytical solutions to the Riemann problem to explain the displacement process observed during fluid flow and cation exchange reactions between flowing aqueous phase and sandstone solid phase. The analytical solutions were used to predict effluent profiles of specific cases of three heterovalent cations $\left(\mathrm{Na}^{+}, \mathrm{Ca}^{2+}\right.$ and $\left.\mathrm{Mg}^{2+}\right)$ and an anion $\left(\mathrm{Cl}^{-}\right)$for any constant initial and injection brine composition by using mass equilibrium action laws, charge conservation equation and the cation exchange capacity equation. The number and nature of shocks or rarefaction waves in the displacement as well as when they occur was predicted to a reasonable accuracy, which becomes increasingly complex as the number of cations in the system increases. The theoretical predictions compared well with experimental data available at both the laboratory scale and the field scale and showed reasonable agreement with numerical model predictions, developed using finite differences. Awolayo and Sarma [73] derived an analytical expression based on the advection-reaction-dispersion equation (ARDE) theory for 1-D single-phase flow, which considered a linear adsorption (retardation) to capture changes between ions in aqueous phase and stationary solid phase in terms of sorption and surface complexation reactions. The model was used to replicate histories of effluent ions from single-phase experiments and the reactivity of PDIs towards carbonate rock surface was emphasized. The authors also predicted the breakthrough composition of different ions during oil-brine displacement experiments and stated that the wettability change was observed with a high retardation for PDIs, which resulted in improved oil recovery. Various researchers have created a theoretical model based on DLVO theory of surface forces to estimate the rock surface wettability through the stability of the water film layer separating the rock and oil phase. The theoretical model evaluates the stability of the film by calculating disjoining pressure isotherm and interaction potential that influences the water film thickness and the energy barrier needed to be overcome to rupture the water film [62,100,179,207,214,259,271,272]. Alshakhs and Kovscek [214] further estimated contact angle from the disjoining pressure and compared with that from contact angle measurements.

\subsection{Numerical Approach}

As discussed above, analytical solutions are often difficult to obtain because of several complexities that might be encountered during many practical applications of fluid flow in porous media. The shapes of the reservoir boundaries might be irregular, the dependent variables in the governing equations, initial and boundary conditions might be space-variant and non-uniformly distributed, while the sink/source term in the governing equations might be a non-analytic function. Hence, numerical technique provides a convenient, flexible, and sophisticated tool for solving fluid flow problems in complex realistic situations as it is the case for brine-dependent recovery, which combines multiple mechanisms. These mechanisms include processes such as convection, advection, diffusion/dispersion, sorption (adsorption/ion-exchange), surface complexation, mineral reactions, zero/first order production, and decay. The widely used numerical modeling method for brine-dependent recovery is based on black-oil and compositional reservoir simulation with or without coupling either of these two types of models: the surface sorption models (SSMs) and surface complexation models (SCMs). The SSM captures sorption reactions like adsorption, ion-exchange, where the electrical interaction is integrated into the equilibrium constants for the reactions and SCM captures similar surface reactions, except the sorption process depends on the interaction surface charges that are simultaneously calculated with the surface species. 


\subsubsection{Sandstone Rocks}

Jerauld et al. [66] made the earliest attempt to model brine-dependent recovery process in sandstone reservoir through the adoption of the existing waterflood model. They implemented fractional flow theory to describe the process and treated salt as a single-lumped component in the aqueous phase. The relative permeability and capillary pressure was considered a function of salinity, such that wettability alteration was initiated through interpolation between two relative permeability and capillary pressure sets (one at water-wet and the other at oil-wet set) within the salinity thresholds. The residual oil saturation was also made a linear function of salinity, which is used in calculating the interpolating parameter as expressed in the Equations (2)-(5). They were successful in simulating coreflood experiments as well as other single-well tests:

$$
k_{r l}=\omega k_{r l}{ }^{H S}\left(S_{w n}\right)+(1-\omega) k_{r l}{ }^{L S}\left(S_{w n}\right)
$$

where $k_{r l}$ is the relative permeability to phase $l$ (dimensionless), $n$ is an exponent (dimensionless), which has a value of 0 for current set, HS for high salinity set and LS for low salinity set, $\omega$ is the interpolation parameter (dimensionless) and $S_{w n}$ is the normalized water saturation (dimensionless):

$$
P_{\text {cow }}=\omega P_{\text {cow }}{ }^{H S}\left(S_{w n}\right)+(1-\omega) P_{\text {cow }}{ }^{L S}\left(S_{w n}\right)
$$

where $P_{\text {cow }}$ is the oil-water capillary pressure (Pa).

$$
\omega=\frac{S_{o r}-S_{o r}{ }^{L S}}{S_{o r} H S-S_{o r} L S}
$$

where $S_{o r}$ is the residual oil saturation to waterflood (dimensionless):

$$
S_{w n}=\frac{S_{w}-S_{w i}}{1-S_{o r}-S_{w i}}
$$

where $S_{w}$ is the water saturation (dimensionless) and $S_{w i}$ is the irreducible water saturation (dimensionless). Tripathi and Mohanty [273] extended Jerauld et al. [66]'s work to studying the flow instability related to wettability alteration using a 1-D Buckley-Leveret analytical model excluding effect of capillary pressure. They identified two saturation shocks for the considered low saline waterflood case, one of which was associated with adverse mobility. This was supported by viscous fingering theory and 2-D numerical simulation. Wu and Bai [274] tried to model the process in both porous and fractured reservoirs. They treated salt as a pseudo component in the aqueous phase, which was subjected to advection and diffusion, as well as adsorption on mineral surface. Similar to Jerauld et al. [66], their model expressed the dependency of relative permeability, capillary pressure and residual oil saturation on salinity. The residual oil saturation and contact angle was interpolated between two sets of residual oil saturation and contact angle data using the total salt concentration as shown in Equations (6) and (7), which was used to evaluate only the oil relative permeability and capillary pressure respectively (Equations (2) and (3)). They simulated a hypothetical case to compare the low saline waterflood with conventional waterflood:

$$
\begin{aligned}
& S_{o r}\left(X_{c}\right)=S_{o r}{ }^{L S}+\frac{X_{c}-X_{c}{ }^{L S}}{X_{c}{ }^{L S}-X_{c} H S}\left(S_{o r}{ }^{L S}-S_{o r}{ }^{H S}\right) \\
& \theta\left(X_{c}\right)=\theta^{L S}+\frac{X_{c}-X_{c}{ }^{L S}}{X_{c}{ }^{L S}-X_{c}^{H S}}\left(\theta^{L S}-\theta^{H S}\right)
\end{aligned}
$$

where $X_{c}$ is the salt mass fraction in the aqueous phase (dimensionless) and $\theta$ is the contact angle. $\mathrm{Al}$-adasani et al. [240] extended $\mathrm{Wu}$ and Bai [274]'s work by generating different correlations for residual oil saturation, contact angle and IFT as a function of salt concentration. These correlations 
were used to evaluate the oil relative permeability, water relative permeability, and capillary pressure. They successfully simulated a series of experimental data and concluded that the increase in oil relative permeability because of wettability change was the core element of the modeling approach. However, at weakly water-wet conditions, improved recovery is controlled by low capillary pressure. Omekeh et al. [275] was the first to construct a more comprehensive model that takes into consideration the geochemical interpretation of low saline waterflood process in sandstones. They formulated a Buckley-Leveret two-phase model that accounted for MIE as the sole explanation for wettability alteration. The MIE was expressed using Gapon convention where cations are involved in a fast exchange process with the negative clay surface (Equation (8)). They proposed modeling the transition between two relative permeability sets by using a weighting function which considered the amount of divalent cations $\left(\mathrm{Ca}^{2+}\right.$ and $\left.\mathrm{Mg}^{2+}\right)$ desorbed from mineral surface (Equation (9)). The model was successfully used to do several sensitivity checks on Berea sandstone cores using brines with different ion compositions. They observed sensitivity of the desorption fronts speed to the injected brine composition and oil recovery to the composition of the formation water relative to the injected brine composition. They later coupled mineral dissolution into the model [67]. They obtained a good agreement between the model and experimental recovery and effluent concentration from a reported North Sea coreflood experiment:

$$
\begin{gathered}
1 / 2 \mathrm{Ca}^{2+}+\mathrm{Na}-\mathrm{X} \rightleftarrows \mathrm{Na}^{+}+\mathrm{Ca}_{1 / 2}-\mathrm{X} \\
1 / 2 \mathrm{Mg}^{2+}+\mathrm{Na}-\mathrm{X} \rightleftarrows \mathrm{Na}^{+}+\mathrm{Mg}_{1 / 2}-\mathrm{X} \\
\omega\left(\beta_{C a}, \beta_{M g}\right)=\frac{1}{1+r\left[\max \left(\beta_{C a, 0}-\beta_{C a}, 0\right)+\max \left(\beta_{M g, 0}-\beta_{M g}, 0\right)\right]}
\end{gathered}
$$

where $r$ is a constant that determines the shape of the adsorption curve (dimensionless), $\beta_{C a, 0}$ and $\beta_{\mathrm{Mg}, 0}$ are the adsorbed $\mathrm{Ca}^{2+}$ and $\mathrm{Mg}^{2+}$ concentration (dimensionless), respectively, at the initial time, and $\beta_{\mathrm{Ca}}$ and $\beta_{\mathrm{Mg}}$ are the adsorbed $\mathrm{Ca}^{2+}$ and $\mathrm{Mg}^{2+}$ concentration (dimensionless), respectively, at the current time. Similarly, Dang et al. [63] used GEM CMG, a compositional simulator of Computer Modeling Group, to simulate low saline brine injection in sandstones by constructing a comprehensive multi-phase multi-component geochemical model. In their work, the multi-ion exchange was expressed using Gaines-Thomas convention as highlighted in Equation (10). They modeled the transition between the two-relative permeability sets as a function of equivalent $\mathrm{Ca}^{2+}$ fraction on the mineral surface, which was contrary to Omekeh et al. [275]'s viewpoint with regards to recovery mechanism in sandstones. However, wettability alteration was captured as they successfully simulated coreflood experiments conducted on cores from North Sea and Texas reservoirs [40,252]. They validated the model by obtaining good agreement between experimental and model effluent ion concentrations, effluent $\mathrm{pH}$ and recovery. Besides, they extended the model to capture the combination of brine-dependent recovery and $\mathrm{CO}_{2}$ flood [276]. They observed that such combination is a very promising recovery technique that promoted the synergy between the two processes in ensuring capillary force is fully captured via wettability and IFT alteration:

$$
\begin{gathered}
\mathrm{Na}^{+}+1 / 2 \mathrm{Ca}-\mathrm{X}_{2} \rightleftarrows 1 / 2 \mathrm{Ca}^{2+}+\mathrm{Na}-\mathrm{X} \\
\mathrm{Na}^{2+}+1 / 2 \mathrm{Mg}-\mathrm{X}_{2} \rightleftarrows 1 / 2 \mathrm{Mg}^{2+}+\mathrm{Na}-\mathrm{X}
\end{gathered}
$$

Korrani et al. [277] coupled a geochemical package and compositional simulator to obtain an integrated tool in UTCOMP-IPHREEQC capable of executing a geochemical-based modeling of complex processes like low saline brine injection, alkaline-surfactant-polymer (ASP) flooding and formation damage with sensitivity to hydrocarbon interactions. They modeled the transition from oil-wet to water-wet region by considering different interpolation parameters, like total ionic strength (Equation (11)) and ion exchange through organometallic components surface complexation (Equation 
(12)). The model was then used in matching histories of produced ions as well as the oil recovery of coreflood experiments and the Endicott field trial conducted by BP [219]:

$$
\begin{gathered}
\omega=\frac{T I S_{\max }-T I S}{T I S_{\max }-T_{\min }} \\
\omega=\frac{\zeta_{\max }-\zeta}{\zeta_{\max }-\zeta_{\min }}
\end{gathered}
$$

where TIS is the total ionic strength ( $\mathrm{mol} / \mathrm{L}$ ) and $\zeta$ is the fraction of surface organometallic complexes (dimensionless). Brady et al. $[179,257,258]$ constructed a batch SCM for sandstones having two surface charge sites; namely, clay edge and basal plane. Meanwhile the charges at these sites are controlled by $\mathrm{pH}$-dependent protonation/deprotonation reactions at the clay edge and heterovalent substitution in the lattice of the basal plane. Four electrostatic attraction bridges, as shown in figure, were identified as important in modifying rock wettability. At $\mathrm{pH}<5.5,\left[>\mathrm{Al}: \mathrm{SiO}^{-} \Leftrightarrow^{+} \mathrm{HN}<\right]$ and $\left[>\mathrm{AlOH}_{2}{ }^{+} \Leftrightarrow^{-} \mathrm{OOC}<\right]$ attraction bridges are dominant while at higher $\mathrm{pH},\left[>\mathrm{Al}^{-\mathrm{SiO}^{-}} \Leftrightarrow^{+} \mathrm{CaOOC}<\right]$ attraction bridge dominates while $\left[>\mathrm{Al}: \mathrm{SiOCa}^{+} \Leftrightarrow^{-} \mathrm{OOC}<\right]$ attraction bridge only important at $\mathrm{pH}>8$. The authors showed that low $\mathrm{Ca}^{2+}$ injected brine and low saline brine can both decrease $\left[>\mathrm{Al}: \mathrm{SiO}^{-} \Leftrightarrow^{+} \mathrm{CaOOC}<\right]$ attraction bridge at higher $\mathrm{pH}$ and explained that at low acid numbers, low saline brine can decrease, $\left[>\mathrm{Al}: \mathrm{SiO}^{-} \Leftrightarrow^{+} \mathrm{HN}<\right]$ and $\left[>\mathrm{AlOH}_{2}{ }^{+} \Leftrightarrow^{-} \mathrm{OOC}<\right]$ attraction bridges, resulting in improved recovery [257]. It was also identified that, for kaolinite-containing sandstones, an increase in $\mathrm{Ca}^{2+}$ will decrease oil adhesion by filling the exchange basal plane sites $\mathrm{Ca}^{2+}$ and increase oil adhesion by increasing $\left[{ }^{+} \mathrm{CaOOC}<\right]$ species at the kaolinite edge site. They revealed that the ratio of edge to basal plane exposure is critical to determining the mechanism of oil adhesion to kaolinite-containing sandstones [258]. The bond product sum (BPS) of oil interaction with kaolinite edge, which is the sum of the four electrostatic attraction bridges, was also suggested to be a simple means to estimate mutual electrostatic adhesion between the surface charges of oil and kaolinite edge sites [179]. The BPS would equal to zero with no likelihood of electrostatic adhesion when both oil and mineral surfaces only contain negatively charged species, resulting in water-wetness. While the BPS would be high when both oil and mineral surfaces contain oppositely charged species and the potential for electrostatic adhesion would be high. This was used to interpret why the Snorre field (BN $=1.1$ and $A N=0.02 \mathrm{mg}$ $\mathrm{KOH} / \mathrm{g}$ oil) showed very little positive response to low saline brine [36].

Elakneswaran et al. [278] further extend Brady et al.'s work by coupling SCMs and mineral dissolution/precipitation and showed that mineral equilibrium showed a notable positive effect on oil desorption and improved oil recovery. They also emphasized that $\mathrm{pH}, \mathrm{Ca}^{2+}$ and $\mathrm{Mg}^{2+}$ significantly influenced electrostatic interaction at both rock-brine and oil-brine interfaces and oil desorption increased with dilution of injected brines. Erzuah et al. [279] compares BPS from Brady et al. [179]'s SCMs work with flotation techniques in the presence of high saline formation brine and showed that the presence of divalent cations increased oil adhesion through cation bridging to kaolinite and quartz surfaces, reflected by the high BPS through $\left[>\mathrm{Al}: \mathrm{SiO}^{-} \Leftrightarrow^{+} \mathrm{CaOOC}<\right]$ and $\left[>\mathrm{Al}_{\mathrm{SiO}} \mathrm{S}^{-} \Leftrightarrow^{+} \mathrm{MgOOC}<\right]$ bridges, and high concentration of oil-wet particles from flotation tests. In addition, Lima et al. [280] developed a pore scale model by coupling SCM with the generalized Poisson-Boltzmann equation to compute local disjoining pressures and contact angle and their dependence on brine salinity and $\mathrm{pH}$. The contact angle was then incorporated in Brook Corey's formula to obtain the relative permeability functions for various low saline brine injection scenarios. Meanwhile, Korrani and Jerauld [281] showed that BPS failed to predict wettability change as instead of decreasing, it increased as wettability moves towards more water-wet state, and suggested that stability number (SN), which is a dimensionless group for ratio of electrostatic to van der Waals force, gave a better prediction of coreflood experiments and the Endicott field trial conducted by BP [219]. 


\subsubsection{Carbonate Rocks}

Similar to modeling attempts in sandstones, there has been quite a few modeling studies conducted on carbonate rocks. Hiorth et al. [65] was the first to attempt to develop a model to better understand the published experimental results, especially in chalk formations. They coupled bulk aqueous, $\mathrm{SCM}$ with two sites $\left(>\mathrm{Ca}^{+}\right.$and $\left.>\mathrm{CO}_{3}{ }^{-}\right)$and mineral reactions in a geochemical model, calculated the surface speciation, charge, and potential with temperature and tried to calculate the water film stability and oil wettability, the result of which was compared with spontaneous imbibition experiments on Stevns Klint outcrop chalk. They found that the negatively charged surface promotes water-wetness, while the positively charged surface promotes oil-wetness. They reported that the experimental observation could not be fully explained by surface potential changes and only calcite dissolution could account for the improved recovery. They concluded that the unstable equilibrium that resulted in calcite dissolution has a strong dependence on temperature and $\mathrm{pH}$ conditions. Yu et al. [282] presented a 1-D two phase model to simulate a smart waterflood spontaneous imbibition tests conducted on core plugs from Stevns Klint Chalk formation. They considered a wettability alteration (WA) agent (sulfate ions) as the second component in the aqueous phase, which was used along with the adsorption isotherm to imitate the transition between the two-relative permeability and capillary pressure sets representing the oil-wetting and water-wetting state (Equation (13)). The model accounted for molecular diffusion, capillary force, gravity and adsorption. However, it did not capture the influence of WA agent adsorption on rock permeability and porosity. A reasonable match was achieved between the model and experimental results. They placed emphasis on dynamic and fixed wettability alteration, with the dynamic alteration depending on the salt concentration to capture the gradual transition period and gave a better match:

$$
\omega(c)=\frac{a^{*}-a(c)}{a^{*}}, a^{*}=\frac{a_{1}}{a_{2}}, a(c)=\frac{a_{1} c}{1+a_{2} c}
$$

where $c$ is the concentration of WA agent, $a(c)$ is the adsorption isotherm, $a^{*}$ is the asymptotic limit of $a(c), a_{1}$ and $a_{2}$ are constants to calculate adsorption isotherm. Evje et al. [283] constructed a 1-D model to describe water-rock interactions by coupling convection-diffusion equations with geochemical (equilibrium and non-equilibrium) reaction equations relevant for chalk weakening effects essential to carbonate reservoirs. The model's result agreed with experimental profiles for measured effluent concentrations when solution of $\mathrm{MgCl}_{2}$ was injected into a chalk core initially saturated with pure water at an elevated temperature of $130^{\circ} \mathrm{C}$. Mineral non-equilibrium reactions in the form of $\mathrm{MgCO}_{3}$ precipitation and $\mathrm{CaCO}_{3}$ dissolution were the main components of the water-rock interactions used in matching. Similarly, Evje and Hiorth [64] proposed a 1-D mathematical two phase model coupled with geochemical reaction equations for a modified brine flood spontaneous imbibition (SI) experiment conducted on chalk core plugs. Dynamic wettability alteration was introduced by using changes in mineral composition (Equation (14)) as interpolating parameters between two sets of flow functions relating to oil-wet and water-wet conditions. The effects of varying temperature, sulfate and magnesium ion concentrations observed in SI experiments by Zhang et al. [59] were simulated, but not reproduced. They envisaged that mineral dissolution detaches the oil attached to oil-wet sites and gradually shifts rock wetness in a water-wet direction, which favors improved oil mobilization:

$$
\omega(\rho)=\frac{1}{1+r\left[\max \left(\rho_{0}-\rho, 0\right)\right]}
$$

where, $\rho$ is the concentration of the mineral and $\rho_{0}$ is the initial concentration. Andersen et al. [61] extended the model developed for chalk by accounting for transport effects like advection, dispersion, soluble hydrocarbon components, aqueous complexation, cation exchange and mineral alteration. The geochemical model was used to reproduce the measured effluent of flooding experiments performed at $130{ }^{\circ} \mathrm{C}$. In another work, Andersen and Evje [284] developed a two-phase geochemical model to 
interpret possible chemical mechanisms responsible for brine-dependent oil recovery observed in the variation of sulfate and calcium ions at $70{ }^{\circ} \mathrm{C}$ in chalk formation $[59,188]$. They incorporated ion exchange processes that account for sulfate adsorption to the free site at the surface (Equation (15)) and modeled the transition from oil-wet to water-wet region by considering different interpolation parameters like sulfate adsorption, calcite dissolution and anhydrite precipitation. A similar weighting function (Equation (16)) as used by Evje et al. [283] was used for the transition between the sets of flow functions representing oil-wet and water-wet curves, except that adsorption of sulfate was incorporated to increase CEC. They concluded that only sulfate adsorption, coupled with surface calcium activity, was responsible for the observed experimental results at $70{ }^{\circ} \mathrm{C}$ :

$$
\begin{gathered}
1 / 2 \mathrm{SO}_{4}{ }^{2-}+\mathrm{Y}^{+} \rightleftarrows 1 / 2 \mathrm{SO}_{4}-\mathrm{Y}_{2} \\
\omega\left(c_{s o}, \beta_{C a}\right)=0.5-\frac{1}{\pi} \tan ^{-1}\left(10 \frac{a\left(c_{s o}, \beta_{C a}\right)}{a_{\max }}-4.5\right)
\end{gathered}
$$

Al-Shalabi et al. [285] developed a two-phase flow model using UTCHEM, chemical compositional flow simulator developed at The University of Texas at Austin, to study the mechanisms responsible for brine dilution in carbonate reservoirs through data matching. They attempted to simulate injection of sea water and its different dilutions in experimental studies conducted by Yousef et al. [47]. They used different scaling parameters to account for wettability alteration by interpolating between the two sets of relative permeabilities and residual oil saturation. They concluded that simulation was quite sensitive to transition between the two sets of oil flow functions. In another work, Al-Shalabi et al. [60] used empirical correlation between contact angle and salinity as the interpolating parameter to tune residual oil saturation and reported that contact angles gave a better option. Then curve fitting using contact angle was used to obtain the oil relative permeability and Corey exponent. The model was used to obtain a good match on coreflood experiments [48,215]. Al-Shalabi et al. [286] built a geochemical model using Gibbs free energy to correlate residual oil saturation and oil flow function and compared results from UTCHEM and PHREEQC (a geochemical module from the United States Geological Survey) to emphasize the effect of the activity coefficient. The same experimental studies were matched with emphasis on the dominant mechanism for wettability alteration as surface charge alteration and anhydrite dissolution [287]. However, it is essential to state that empirical correlation is only valid under the given experimental conditions and non-predictive under different conditions.

Korrani et al. [288] also extended the usage of their integrated UTCOMP-IPHREEQC to simulate observations made during brine dilution experiments by Chandrasekhar and Mohanty [215]. The authors used the amount of calcite dissolved as the transition between oil and water-wet flow functions coupled with implicitly included surface complexation reactions. The model gave a good match of oil recovery, $\mathrm{pH}$ and breakthrough curves and emphasized that calcite dissolution and surface reactions are mandatory to capture improved oil recovery. Nevertheless, there was high computation time due to the coupled simulator. Brady et al. [258,267] constructed another batch SCM for carbonates and stated that the carbonate surface charge is largely controlled by sorption of $\mathrm{Ca}^{2+}$ and $\mathrm{CO}_{3}{ }^{2-}$, rather than $\mathrm{pH}$. The authors used the calculated surface speciation to consider the individual coordination between calcite and oil at $25-130{ }^{\circ} \mathrm{C}$. They identified several possible electrostatic attraction bridges: at higher $\mathrm{pH}$ are $\left[>\mathrm{CaOH}_{2}{ }^{+} \Leftrightarrow-\mathrm{OOC}<\right]$, $\left[>\mathrm{CO}_{3} \mathrm{Ca}^{+} \Leftrightarrow^{-} \mathrm{OOC}<\right],\left[>\mathrm{CO}_{3}{ }^{-} \Leftrightarrow^{+} \mathrm{CaOOC}<\right],\left[>\mathrm{CaSO}_{4}{ }^{-} \Leftrightarrow^{+} \mathrm{CaOOC}<\right],\left[>\mathrm{CaCO}_{3}{ }^{-} \Leftrightarrow^{+} \mathrm{CaOOC}<\right]$, and at low $\mathrm{pH}$ are $\left[>\mathrm{CO}_{3}{ }^{-} \Leftrightarrow^{+} \mathrm{HN}<\right],\left[>\mathrm{CaSO}_{4}{ }^{-} \Leftrightarrow^{+} \mathrm{HN}<\right]$, and $\left[>\mathrm{CaCO}_{3}{ }^{-} \Leftrightarrow^{+} \mathrm{HN}<\right]$. The strongest oil-calcite attraction bridge at reservoir $\mathrm{pH}$ is considered as $\left[>\mathrm{CaOH}_{2}{ }^{+} \Leftrightarrow^{-} \mathrm{OOC}<\right]$, which can be reduced by increasing $\mathrm{Ca}^{2+}$ and /or $\mathrm{Mg}^{2+}$ (which could reverse the charge of $\left[<\mathrm{COO}^{-}\right]$specie), and/or increasing $\mathrm{SO}_{4}{ }^{2-}$, which can coordinate with $\left[>\mathrm{CaOH}_{2}{ }^{+}\right]$and eliminate the positive charge to produce a negative surface. The model was used to predict the injection of various versions of diluted brines used in the experimental study by Yousef et al. [47] on limestone rocks. The authors claimed that the decreased 
salinity decreased the oil-calcite BPS, which resulted in reduced oil adhesion and increased oil recovery, however diminishing returns was observed beyond ten times dilution.

Qiao et al. [68] developed a multiphase multicomponent reactive transport model that captured the SCMs of surface reactions among carboxylic groups, cations, and sulfate. The model was used to interpret the oil recovery from the spontaneous imbibition experiment conducted on chalk by using brine with selective removal of non-active ions [28]. The water-wetting fractions, controlled by the proportion of the carboxylic group desorbed from the surface sites, were used as the interpolating parameter to transit between the two sets of capillary pressure, relative permeability, and residual oil saturations. The model showed good consistency with experimental observations and through sensitivity studies, they concluded that ion species, ionic strength and parameters, like oil acidity, reaction equilibrium constants, total surface sites and diffusion coefficient, play such a key role in the wettability alteration mechanisms. They extended the model by including limestone mineral dissolution/precipitation reactions [289]. They introduced changes in surface potential in the equilibrium constant calculations. The model was consistent with experimental observations using brine dilution approach on limestone $[45,47,97]$ and chalk outcrop [28].

Mahani et al. [99] developed a batch SCM to elucidate and correlate $\zeta$-potential results under varying brine salinity (synthetic seawater, with 25 and 100 times dilution) and $\mathrm{pH}$ conditions. They made changes to the reaction of $\mathrm{SO}_{4}{ }^{-}$with the calcite sites to match the $\zeta$-potential results and observed that $\zeta$-potential increased with $\mathrm{pH}$, which was caused by formation of surface species coordinating with the PDIs. Brine dilution was observed to lead to more negative surface charge due to the resultant effect of increase in concentration of negatively charged species, decrease in positively charged species concentration and formation of neutral species. As the surface charge is modified, the wetting condition is influenced towards improved water-wetness. Eftekhari et al. [290] developed a SCM reactive transport model to derive the reaction equilibrium constant for natural carbonates by using a non-linear optimization technique to fit the model with $\zeta$-potential and single-phase breakthrough curves data on intact chalk cores. The authors used the tuned model to suggest a correlation existing between the remaining oil in several imbibition tests on chalk and $\left[>\mathrm{CaOH}_{2}{ }^{+} \Leftrightarrow^{-} \mathrm{OOC}<\right]$, which was estimated using equilibrium constants analogous to aqueous acid-base reactions. Awolayo et al. [62] developed a reactive transport model in GEM CMG considering adsorption and ion exchange and obtained temperature-dependent equilibrium constants for the two reactions by fitting with the single-phase breakthrough curves of different ions, temperature and intact carbonate minerals. The optimized model was used to simulate oil recovery and breakthrough curves from different experiments. In another study, the contribution of dissolution and precipitation of different minerals as they contribute to the distribution of PDIs available for surface sorption were captured and simulated. The fraction of the free surface sites that could adhere to oil, was observed to reduce as the brine salinity reduced and sulfate concentration in injected water increased, which was used to transit between two sets of flow functions [181,272].

\section{Injection Water Issues and Remediation}

In most published literature, it is evident that the properties of the formation fluids vary depending on on different parameters, including mineral digenesis, its pressure and temperature history and the other complex alterations experienced as reservoir fluid flow and mix over geological time [291]. As a result, typical formation water is highly saline and enriched in divalent ions. Sandstone formation water often contain an abundance of barium $\left[\mathrm{Ba}^{2+}\right]$ and strontium $\left[\mathrm{Sr}^{2+}\right]$ cations, while carbonate and calcite-cemented sandstone formations usually contains a substantial amount of calcium $\left[\mathrm{Ca}^{2+}\right]$ and magnesium $\left[\mathrm{Mg}^{2+}\right]$ cations [292]. Seawater is also rich in ions (higher $\mathrm{SO}_{4}{ }^{2-}$ than in formation fluids) that form from marine sediments and water evaporation. These two fluids are the major sources of water injected (diluted seawater or formation water) during brine-dependent recovery, and the mixing of both incompatible fluids can result in precipitation/scaling. The precipitate/scale arises when the natural state of the reservoir fluid system is disturbed to the extent that the solubility limits of 
some of its components are exceeded. As such, calcium sulfate (anhydrite) precipitates in carbonate and calcite-cemented sandstone formations [293] and barium sulfate (barite) and strontium sulfate (Celestine) precipitates can be readily formed in sandstone formations. The scale precipitation of these minerals has a complicated dependency on variables like temperature and pressure. For instance, calcium carbonate scales, the most common oil field scale, precipitate because of pressure changes while sodium chloride (halite) scale forms similarly from highly saline brines encountering large temperature drops. The scale formed at near-wellbore region or in the reservoir cause plugging/flow restrictions, resulting in a porosity and permeability reduction and could reduce the waterflood scheme effectiveness, when formed close to an injection well. Those formed at near-wellbore are easily removed through acidizing while those formed in the formation are difficult to remove. Meanwhile, scales formed in the production tubing lower the production rate by reducing the flowing area and increasing the pipe surface roughness [292]. Romanuka et al. [46] proposed that injecting brine, with high amount of surface-interacting ions (like $\mathrm{SO}_{4}{ }^{2-}, \mathrm{PO}_{4}{ }^{3-}$, and $\mathrm{BO}_{3}{ }^{3-}$ ) into a formation containing divalent cations such as $\mathrm{Ba}^{2+}$ and $\mathrm{Sr}^{2+}$, will increase the tendency for scale precipitation in the production lines, at near-wellbore region or in the reservoir.

Another major issue is the presence of sulfate-reducing bacteria (SRB), which feeds on sulfate sources to oxidize organic materials to hydrogen sulfide $\left(\mathrm{H}_{2} \mathrm{~S}\right)$ in the form of anaerobic respiration. The produced $\mathrm{H}_{2} \mathrm{~S}$ is highly toxic and corrosive, which can cause severe handling and safety problems in oilfield operations at a very low concentration. The produced $\mathrm{H}_{2} \mathrm{~S}$ is also slightly soluble in both oil and water phase that can turn sweet oil into sour oil, which is expensive to refine. Fine migration and mechanic compaction are other issues encountered during brine-dependent recovery, which are because of weakened rock structure. Clay swelling has been reported to be associated with brine dependent recovery in sandstone reservoir, which resulted in fines production and/or reduction in permeability or increase in pressure drop. Meanwhile, mechanical compaction has been mostly observed in chalk reservoirs, which is because of reduced mechanical strength of the chalk. This is caused by the replacement of $\mathrm{Ca}^{2+}$ at the biogenic chalk surface by $\mathrm{Mg}^{2+}$ in the injected water through chemical substitution at elevated temperatures. After water breakthrough, another environmental issue might be the content of the produced water, which will include an added cost for treating the water. The produced water from reservoir undergoing brine dependent recovery process will contain low concentration of potential determining ions because of their adsorption to the rock. Hence, injecting an appropriate mixture of this produced water and freshly prepared-injection water has been proposed to also triggers wettability alteration and better recovery [294].

Even though these issues exist, success reported in various brine dependent recovery projects conducted in many fields (notably Alaska and North Sea) for years did not account for much encounter with precipitation/scaling, souring and fines production, except compaction which was prevalent in North Sea Chalk reservoirs. Various authors have highlighted optimum sulfate concentration to avoid precipitation of sulfate scales. Furthermore, in any waterflood project, the choice of water treatment method is a key factor that significantly affects the project success. Treatment and reinjection of produced brines has been reported to be possibly cheaper than its transportation and disposal [295-297]. Desalination is the water treatment process readily used to remove selected dissolved ions in water to provide safe drinking water and treated injection water for improving oil recovery. There are two main methods for water treatment/desalination: thermal-based, which involves heating the feed water and collecting the condensed vapor from the distillation column and membrane-based, which involves applying pressure to force the water feed through the member, thereby leaving the selective salts. Membrane-based methods are often preferred over the thermal methods due to space limitation and energy requirements [298]. The two widely used membrane-based desalination methods are nanofiltration (NF) and reverse osmosis (RO), which are often used as either standalone or hybrid configuration. During the nanofiltration process, the divalent ions are selectively removed, decreasing water hardness, and leading to monovalent-ion rich effluent water (permeate stream) and divalent ion-rich rejected water (retentate stream). Meanwhile, in the reverse osmosis process, both monovalent 
and divalent ions are selectively removed to reduce the permeate stream water salinity. Essentially the permeate stream water from $\mathrm{RO}$ is fresh with negligible amounts of salt and this is possible because RO has a much tighter pore size than NF.

Several published patents [299-303] have been proposed that the desired water quality can be generated through the blending of the effluent permeate streams from the different NF/RO application (standalone, hybrid configuration either parallel or series and plurality) schemes to satisfy brine-dependent recovery requirements in sandstone reservoirs. As such, Yousef and Ayirala [304] proposed a desalination optimization technique based on a parallel configuration of NF/RO that blends both the permeate and retentate water streams to cover the entire range of ionic salinity and composition appropriate for both sandstone and carbonate rocks, which also considered the minimization/prevention of clay swelling, reservoir souring, corrosion and aerobic bacterial issues. The authors emphasized that the availability of these multiple water streams provides the flexibility of customizing the desired ionic content and salinity not just for brine-dependent recovery process but also as a good preconditioner for hybrid-EOR applications such as miscible gas flood, carbonated waterflood, polymer flood, ASP flood, and as boiler feed water in thermal floods. Meanwhile, Ayirala and Yousef [305] recently reviewed different chemical extraction and desalination technologies and reported that current desalination technology has limitations to treat high saline water and produced water. They claimed that no current proven commercial technology can selectively remove specific ions in one step to optimally meet the desired water requirement, but a combination of all current technologies. Forward osmosis and membrane distillation are reported to offer cost-effective potential alternatives to reverse osmosis with the availability of low-grade waste heat and well suited to treat very high salinity water. Dynamic vapour recompression and Carrier-Gas extraction are identified as well suited to treat high saline water and hyper-saline produced water from oil and gas production for zero liquid discharge. This is critically important in locations where disposal facilities are not available, which can become an effective water management strategy during field implementation by converting the produced water into the desired water quality for reinjection. However, the two technologies are reportedly not cost-effective for water desalination and their footprints and energy requirements are not well defined as they are still in the development stage. The comparison of the features and capability of all current and emerging water desalination technology are given in Table 3. 
Table 3. Summary of technology selection criteria, key attributes and capabilities of both current and emerging water treatment technologies (adapted from Ayirala and Yousef [305]).

\begin{tabular}{|c|c|c|c|c|c|c|}
\hline \multirow{2}{*}{$\begin{array}{l}\text { Water Treatment } \\
\text { Process }\end{array}$} & \multirow{2}{*}{$\begin{array}{l}\text { Desalination } \\
\text { Methods }\end{array}$} & \multirow{2}{*}{$\begin{array}{l}\text { Technology } \\
\text { Maturity }\end{array}$} & \multirow{2}{*}{$\begin{array}{l}\text { Selective Ion } \\
\text { Removal }\end{array}$} & \multicolumn{2}{|c|}{ Treatment Capability } & \multirow{2}{*}{ Comparable Features } \\
\hline & & & & High Saline Water & Produced Water & \\
\hline Nanofiltration & Membrane-based & High & Yes & No & No & $\begin{array}{l}\text { - Water recovery efficiency of } 90-99 \% \\
\text { - } \quad \text { Low open pores leading to higher flux } \\
\text { - }{ }^{2} \text { pressure and energy consumption over RO }\end{array}$ \\
\hline Reverse Osmosis & Membrane-based & High & No & No & No & $\begin{array}{l}\text { - Minimal footprint and energy requirement } \\
\text { - Cost effective as its widely used with water recovery efficiency greater } \\
\text { than } 99 \%\end{array}$ \\
\hline $\begin{array}{l}\text { Chemical } \\
\text { Precipitation }\end{array}$ & Pretreatment & Medium-High & Yes & No & No & $\begin{array}{l}\text { - Remove scaling and fouling in desalination pretreatment } \\
\text { Upfront chemical costs and additional facility requirements for sludge } \\
\text { handling and disposal }\end{array}$ \\
\hline Salt Extraction & Pretreatment & Low & Maybe & Yes & Maybe & $\begin{array}{l}\text { - No scaling and lower energy requirements } \\
\text { - Details on cost and chemical solvents not well known }\end{array}$ \\
\hline Forward Osmosis & Membrane-based & Low-Medium & No & Yes & Yes & $\begin{array}{l}\text { - } \quad \text { Lower energy requirements } \\
\text { - Cost-effective compared to widely-used desalination method } \\
\text { Can treat high-saline water }\end{array}$ \\
\hline $\begin{array}{l}\text { Membrane } \\
\text { Distillation }\end{array}$ & $\begin{array}{l}\text { Combo Membrane \& } \\
\text { Thermal-based }\end{array}$ & Medium & No & Yes & No & $\begin{array}{l}\text { - } \quad \text { Cost-effective compared to widely-used desalination method } \\
\text { - } \quad \text { Can treat high-saline water } \\
\text { Low-grade waste heat requirements }\end{array}$ \\
\hline $\begin{array}{l}\text { Carrier-Gas } \\
\text { Extraction }\end{array}$ & $\begin{array}{l}\text { Humidification/ } \\
\text { Dehumidification }\end{array}$ & Medium & No & Yes & Yes & $\begin{array}{l}\text { - } \quad \text { Provide zero liquid discharge solution up to } 85-90 \% \text { water recoveries } \\
\text { - } \quad \text { Treating both high saline water and produced water } \\
\text { - } \quad \text { Costs, footprints and energy requirements not well-defined }\end{array}$ \\
\hline $\begin{array}{l}\text { Dynamic Vapor } \\
\text { Recompression }\end{array}$ & Thermal-based & Medium & Maybe & Yes & Yes & $\begin{array}{l}\text { - } \quad \text { Minimal pretreatment and no scaling } \\
\text { - } \quad \text { Provide zero liquid discharge solution up to } 97 \% \text { water recoveries } \\
\text { - } \quad \text { Non-cost-effective compared to widely-used waser } \\
\text { - Costs, footprints andion method } \\
\text { anergy requirements not well-defined }\end{array}$ \\
\hline
\end{tabular}




\section{Discussion}

In this work, a comprehensive review on systematic investigation of brine-dependent recovery through all level of investigations of oil-brine-rock systems was presented. From laboratory and field scale studies, brine-dependent recovery has resulted in substantial improvement in recovery, though the magnitude observed at field scale is minimal compared to that observed in laboratory experiments. It takes less injection water volume to achieve considerably incremental recovery in field scale than in laboratory, which makes the application of the process more enticing. The improvement in recovery was shown to vary depending on brine content (connate and injected), rock mineralogy, oil type and structure, and temperature. Wettability alteration is widely accepted as the consequence of the brine-dependent recovery process, while no consensus exists on the probable cause/mechanism, which might be due to experiments conducted and reported at varying conditions. Despite these challenges, analytical and numerical models have been utilized to further interpret and predict the process performance.

Based on this review, the established opinion is that petroleum rock wettability can be modified towards a more water-wetting state, irrespective of temperature, depending on rock type. For carbonate rocks, it can be inferred that the injected brine should contain PDIs, depleted in $\mathrm{NaCl}$, and wettability alteration is much more effective at high temperatures. There is however a limit to which increasing the $\mathrm{SO}_{4}{ }^{2-}$ concentration with increasing temperature can improve oil recovery; as high $\mathrm{SO}_{4}{ }^{2-}$ concentrations at high temperature can result in $\mathrm{CaSO}_{4}$ precipitation and oil recovery reduction. Aside chalk cores, $\mathrm{SO}_{4}{ }^{2-}$ and $\mathrm{Mg}^{2+}$ can be generated in-situ due to dissolution of anhydrite and dolomite leading to improved oil recovery, which depends on the injected brine content and reservoir rock temperature. The concentration of these PDIs in the formation water is also critical to observing improved oil recovery, which implies that concentration of PDIs plays a more significant role, compared to brine salinity reduction. Meanwhile, both reduction in brine salinity and modifying the composition of heterovalent ions in sandstone rocks seems equally important as both cases have led to significant improvement in oil recovery. There is an optimum salinity limit that is low enough to improve oil recovery and high enough not to impede fluid flow and reduce oil recovery through reservoir/wellbore plugging. Because sandstone rocks attached identically to both acidic and basic components of the oil, temperature seems not to play such a vital role as compared to carbonate rocks. Overall, the composition of the formation water needs to be critically examined before designing the injected brine content to prevent chances of reservoir/wellbore damage and maximize oil production.

The effect of different minerals on the performance of brine-dependent recovery has been well investigated in carbonate rocks with high degree of repeatability and the observed trend is that the presence of different kind of minerals helps the two approaches of ionic strength and composition modification performs better through in-situ generation of PDIs. Meanwhile, various inconsistencies and contradictions observed with sandstone rocks due to the varying degree of mineralogy and clay contents indicate that more controlled experiments need to be conducted. The current trend observed from this review is that improved oil recovery can be observed in the presence or absence of clay minerals, but lesser in the absence of clay minerals. This remains an area of further investigation as many mechanisms proposed for improved recovery only considered oil adhesion through clay minerals. Many of the studies quantified polar oil components using AN and BN, which might not be able to give a robust description for type and structure of polar oil components contributing to increased oil adhesion. Beyond, AN and BN, a combination of oil compositional characteristics (such as the G-AB parameters [148]) should be further investigated to give a qualitative indication of the extent to which low saline brine can alter wettability.

Observations from a molecular study conducted through electrokinetic analysis shows varying degree of $\zeta$-potential values because many of these studies were conducted using mineral particles of varying sizes. The impact of particle size distribution has not been explored, which could potentially affect the $\zeta$-potential values. In addition, there has been contrast shown between $\zeta$-potential obtained from using intact rock cores and mineral particles suspension, and different measurement techniques 
(like electrophoretic mobility and streaming potential measurement), which is due to the differences in the relative position of the shear plane between natural porous media and particle suspension to the charged mineral surface [51]. These differences can result in contradicting predictions in understanding the process mechanism and influence the reliability of the interpretation of the molecular-scale investigation at the larger scale. This implies that more controlled experiments need to be conducted using intact cores or uniform particle size should be maintained and the position of the shear plane should be considered during the interpretation to compare with that from intact cores. Likewise, further understanding of wettability alteration mechanisms through MIE can be achieved by more robust interpretation and measurements of chemical composition of injected and effluent brines. In addition, most areas of investigation have not been well explored, more detailed and controlled experiments carried out at all scale of investigation will help clarify many of the contradictions facing the current state of understanding and predicting the process efficiency.

The analytical models developed hitherto have only considered a few mechanisms, which have been successfully utilized in describing the improvement in oil recovery. Improving on the development of the analytical models can be quite difficult, because of the complexity of the process mechanisms, however, it will be interesting to develop semi-analytical models that can combine various mechanisms and help in conducting faster sensitivity and screening of the recovery process. The bulk of the numerical black-oil models used salinity-dependent flow functions, while some of the compositional models used empirical correlations. Meanwhile, the complex interaction has been well predicted by the geochemical models using both surface sorption and complexation approaches, which allows the investigation of rock mineralogical contents, brine compositions and polar oil materials, which are significant in electrostatic interactions at both rock-brine and oil-brine interfaces. However, if DLE is to be accepted as the cause of wettability alteration, then SCM would be the ultimate approach at generating a numerical model to predict the process performance at all level of investigation. Another area for further investigation will be to obtain thermodynamic parameters describing the surface sorption and complexation models for natural rocks and their temperature dependency, instead of the current practise of applying aqueous thermodynamic parameters. It is also critical that the premise through which wettability alteration occurs as reflected by the interpolation parameters used in simulation is identified with a high confidence level before being considered in modeling to avoid contradictions.

This recovery process has more advantage than other chemical EOR methods in terms of operating costs, field implementation and environmental assessment, even though it might recover comparably less additional oil. There is currently no commercially proven desalination technology that can selectively remove specific ions in one step, but a combination of all current technologies. However, the emerging technologies have the tendencies to overcome this barrier when they become fully developed. Meanwhile, modification of the injected brine composition (like adding more PDIs) can be more expensive than brine dilution. The recovery benefits from both approaches can further outweigh any potential damages that could be caused to the reservoir or near-wellbore region. Additionally, low saline brine can serve as a preconditioner for other EOR methods, as most of the injected chemical/gas performs better in a low saline brine environment.

\section{Concluding Remarks}

In this paper, a comprehensive review on various published systematic research and industry efforts on brine-dependent recovery process has been presented. This review outlines an integrative overview of laboratory and field observations, descriptions of underlying mechanisms and their validity, the complexity of the oil-brine-rock interactions, modeling attempts, and comparison between sandstone and carbonate rocks. The discussion covers how different techniques have been exploited to interpret and predict the process efficiency, while highlighting various contradictions posed. The following conclusions are drawn from this study: 
- Brine-dependent recovery process has resulted in substantial improvement in oil recovery from laboratory to field scale studies, though the magnitude observed at the field scale is minimal compared to that observed in laboratory experiments.

- The improvement in recovery varies depending on brine content (connate and injected), rock mineralogy, oil type and structure, and temperature.

- Wettability alteration is the resultant effect of the recovery process, while the probable cause/mechanism is a combination of many proposed mechanisms.

- For a brine-dependent recovery process to be effective in carbonate rocks, the injected brine should contain PDIs depleted in $\mathrm{NaCl}$, the rock should contain PDI-sourced minerals, and temperature should be high. For sandstone rocks, on the other hand, there is no temperature limitation but the optimum salinity of the injected brine should be less than $5000 \mathrm{ppm}$ with modified heterovalent ion concentration.

- Various analytical and numerical models have been utilized to further interpret and predict the process performance, however, geochemical models comprising of surface sorption and complexation appear to give comparably better interpretation and prediction.

- Brine-dependent recovery process is a relatively inexpensive and environmental friendly process, particularly because of various emerging cost-effective water treatment technologies.

- Finally, the comparison between brine-dependent recovery process in sandstone and carbonate reservoir highlighted in this review potentially serves to highlight the need for relevant studies for the particular type of candidate reservoirs.

- The areas that need further investigations are identified, and they include crude oil characterization beyond the current $\mathrm{AN}$ and $\mathrm{BN}$ characterization, effect of varying degree of mineralogy in sandstone rocks, development of semi-analytical models, generating the thermodynamic parameters to describe the surface sorption and complexation reactions for natural rocks

Funding: This research received no external funding.

Acknowledgments: The first author, who is a Killam Laureates and Vanier Scholar, acknowledges financial assistance from the Vanier CGS administered by the Government of Canada and Killam Trusts administered through the University of Calgary.

Conflicts of Interest: The authors declare no conflicts of interest.

\section{References}

1. Green, D.W.; Willhite, G.P. Enhanced Oil Recovery; Henry, L., Ed.; Doherty Memorial Fund of AIME, Society of Petroleum Engineers: Richardson, TX, USA, 1998.

2. Alvarado, V.; Manrique, E. Enhanced oil recovery: An update review. Energies 2010, 3, 1529-1575. [CrossRef]

3. Rod, S. Quantification of uncertainty in recovery efficiency predictions: Lessons learned from 250 mature carbonate fields. In Proceedings of the SPE Annual Technical Conference and Exhibition, Denver, CO, USA, 5-8 October 2003.

4. Sheng, J. Enhanced Oil Recovery Field Case Studies; Gulf Professional Publishing: Houston, TX, USA, 2013.

5. Muggeridge, A.; Cockin, A.; Webb, K.; Frampton, H.; Collins, I.; Moulds, T.; Salino, P. Recovery rates, enhanced oil recovery and technological limits. Phil. Trans. R. Soc. A 2014, 372, 20120320. [CrossRef] [PubMed]

6. Kokal, S.; Al-Kaabi, A. Enhanced Oil Recovery: Challenges \& Opportunities. Available online: https://www. world-petroleum.org/docs/docs/publications/2010yearbook/P64-69_Kokal-Al_Kaabi.pdf (accessed on 20 July 2018).

7. Baptist, O.C.; Sweeney, S. The effect of clays on the permeability of reservoir sands to waters of different saline contents. Clay Clay Miner. 1954, 3, 505-515. [CrossRef]

8. Bernard, G. Effect of floodwater salinity on recovery of oil from cores containing clays. In Proceedings of the SPE California Regional Meeting, Los Angeles, CA, USA, 26-27 October 1967. 
9. Martin, J. The Effects of Clay on the Displacement of Heavy Oil by Water. In Proceedings of the Venezuelan Annual Meeting, Caracas, Venezuela, 14-16 October 1959.

10. Jadhunandan, P.P. Effects of Brine Composition, Crude Oil, and Aging Conditions on Wettability and Oil Recovery; Department of Petroleum Engineering, New Mexico Institute of Mining \& Technology: Socorro, NM, USA, 1990.

11. Jadhunandan, P.P.; Morrow, N.R. Effect of wettability on waterflood recovery for crude-oil/brine/rock systems. SPE Reserv. Eval. Eng. 1995, 10, 40-46. [CrossRef]

12. Tang, G.Q.; Morrow, N.R. Salinity, temperature, oil composition, and oil recovery by waterflooding. SPE Reserv. Eval. Eng. 1997, 12, 269-276. [CrossRef]

13. Tang, G.Q.; Morrow, N.R. Influence of brine composition and fines migration on crude oil/brine/rock interactions and oil recovery. J. Pet. Sci. Eng. 1999, 24, 99-111. [CrossRef]

14. Yildiz, H.O.; Morrow, N.R. Effect of brine composition on recovery of Moutray crude oil by waterflooding. J. Pet. Sci. Eng. 1996, 14, 159-168. [CrossRef]

15. Zhou, X.; Morrow, N.R.; Ma, S. Interrelationship of wettability, initial water saturation, aging time, and oil recovery by spontaneous imbibition and waterflooding. SPE J. 2000, 5, 199-207. [CrossRef]

16. Sulak, R. Ekofisk field: The first 20 years. J. Pet. Technol. 1991, 43, 1265-1271. [CrossRef]

17. Sylte, J.; Hallenbeck, L.; Thomas, L. Ekofisk formation pilot waterflood. In Proceedings of the SPE Annual Technical Conference and Exhibition, Houston, TX, USA, 2-5 October 1988.

18. Hallenbeck, L.; Sylte, J.; Ebbs, D.; Thomas, L. Implementation of the Ekofisk field waterflood. SPE Form. Eval. 1991, 6, 284-290. [CrossRef]

19. Hermansen, H.; Thomas, L.; Sylte, J.; Aasboe, B. Twenty five years of Ekofisk reservoir management. In Proceedings of the SPE Annual Technical Conference and Exhibition, San Antonio, TX, USA, 5-8 October 1997.

20. Callegaro, C.; Masserano, F.; Bartosek, M.; Buscaglia, R.; Visintin, R.; Hartvig, S.K.; Huseby, O.K. Single Well Chemical Tracer Tests to Assess Low Salinity Water and Surfactant EOR Processes in West Africa. In Proceedings of the International Petroleum Technology Conference, Kuala Lumpur, Malaysia, 10-12 December 2014.

21. McGuire, P.; Chatham, J.; Paskvan, F.; Sommer, D.; Carini, F. Low Salinity Oil Recovery: An Exciting New EOR Opportunity for Alaska's North Slope. In Proceedings of the SPE Western Regional Meeting, Irvine, CA, USA, 30 March-1 April 2005.

22. Yousef, A.; Liu, J.; Blanchard, G.; Al-Saleh, S.; Al-Zahrani, T.; Al-Zahrani, R.; Tammar, H.; Al-Mulhim, N. Smart Waterflooding: Industry's First Field Test in Carbonate Reservoirs. In Proceedings of the SPE Annual Technical Conference and Exhibition, San Antonio, TX, USA, 8-10 October 2012.

23. Awolayo, A.N.; Sarma, H.K.; AlSumaiti, A.M. An Experimental Investigation into the Impact of Sulfate Ions in Smart Water to Improve Oil Recovery in Carbonate Reservoirs. Transp. Porous Media 2015, 111, 649-668. [CrossRef]

24. Lager, A.; Webb, K.J.; Black, C.J.J.; Singleton, M.; Sorbie, K.S. Low salinity oil recovery-An experimental investigation 1. Petrophysics 2008, 49. Available online: https:/ / www.onepetro.org/journal-paper/SPWLA2008-v49n1a2 (accessed on 20 August 2018).

25. Yousef, A.A.; Al-Saleh, S.H.; Al-Kaabi, A.; Al-Jawfi, M.S. Laboratory investigation of the impact of injection-water salinity and ionic content on oil recovery from carbonate reservoirs. SPE Reserv. Eval. Eng. 2011, 14, 578-593. [CrossRef]

26. Zhang, Y.; Sarma, H. Improving Waterflood Recovery Efficiency in Carbonate Reservoirs through Salinity Variations and Ionic Exchanges: A Promising Low-Cost "Smart-Waterflood" Approach. In Proceedings of the Abu Dhabi International Petroleum Conference and Exhibition, Abu Dhabi, UAE, 11-14 November 2012.

27. Austad, T.; Strand, S.; Høgnesen, E.J.; Zhang, P. Seawater as IOR fluid in fractured chalk. In Proceedings of the SPE International Symposium on Oilfield Chemistry, The Woodlands, TX, USA, 2-4 February 2005.

28. Fathi, S.J.; Austad, T.; Strand, S. "Smart Water" as a Wettability Modifier in Chalk: The Effect of Salinity and Ionic Composition. Energy Fuels 2010, 24, 2514-2519. [CrossRef]

29. Pu, H.; Xie, X.; Yin, P.; Morrow, N.R. Low-salinity waterflooding and mineral dissolution. In Proceedings of the SPE Annual Technical Conference and Exhibition, Florence, Italy, 19-22 September 2010. 
30. Alameri, W.; Teklu, T.W.; Graves, R.M.; Kazemi, H.; AlSumaiti, A.M. Wettability alteration during low-salinity waterflooding in carbonate reservoir cores. In Proceedings of the SPE Asia Pacific Oil \& Gas Conference and Exhibition, Adelaide, Australia, 14-16 October 2014.

31. Høgnesen, E.; Strand, S.; Austad, T. Waterflooding of preferential oil-wet carbonates: Oil recovery related to reservoir temperature and brine composition. In Proceedings of the SPE Europec/EAGE Annual Conference, Madrid, Spain, 13-16 June 2005.

32. Ligthelm, D.; Gronsveld, J.; Hofman, J.; Brussee, N.; Marcelis, F.; van der Linde, H. Novel Waterflooding Strategy By Manipulation Of Injection Brine Composition. In Proceedings of the EUROPEC/EAGE Conference and Exhibition, Amsterdam, The Netherlands, 8-11 June 2009.

33. Loahardjo, N.; Xie, X.; Yin, P.; Morrow, N.R. Low salinity waterflooding of a reservoir rock. In Proceedings of the International Symposium of the Society of Core Analysts, Calgary, AB, Canada, 10-12 September 2007.

34. Shariatpanahi, S.F.; Strand, S.; Austad, T. Evaluation of water-based enhanced oil recovery (EOR) by wettability alteration in a low-permeable fractured limestone oil reservoir. Energy Fuels 2010, 24, 5997-6008. [CrossRef]

35. Sharma, M.M.; Filoco, P.R. Effect of Brine Salinity and Crude-Oil Properties on Oil Recovery and Residual Saturations. SPE J. 2000, 5, 293-300. [CrossRef]

36. Skrettingland, K.; Holt, T.; Tweheyo, M.T.; Skjevrak, I. Snorre Low-Salinity-Water Injection-Coreflooding Experiments and Single-Well Field Pilot. SPE Reserv. Eval. Eng. 2011, 14, 182-192. [CrossRef]

37. Zahid, A.; Shapiro, A.; Skauge, A. Experimental studies of low salinity water flooding in carbonate reservoirs: A new promising approach. In Proceedings of the SPE EOR Conference at Oil and Gas West Asia, Muscat, Oman, 16-18 April 2012.

38. Winoto, W.; Loahardjo, N.; Xie, S.; Yin, P.; Morrow, N. Secondary and Tertiary Recovery of Crude Oil from Outcrop and Reservoir Rocks by Low Salinity Waterflooding. In Proceedings of the SPE Improved Oil Recovery Symposium, Tulsa, OK, USA, 14-18 April 2012.

39. Awolayo, A.N.; Sarma, H.K. Impact of Multi-ion Interactions on Oil Mobilization by Smart Waterflooding in Carbonate Reservoirs. J. Pet. Environ. Biotechnol. 2016, 7, 1-8. [CrossRef]

40. Rivet, S.; Lake, L.W.; Pope, G.A. A coreflood investigation of low-salinity enhanced oil recovery. In Proceedings of the SPE Annual Technical Conference and Exhibition, Florence, Italy, 19-22 September 2010.

41. Aksulu, H.; Håmsø, D.; Strand, S.; Puntervold, T.; Austad, T. Evaluation of low-salinity enhanced oil recovery effects in sandstone: Effects of the temperature and pH gradient. Energy Fuels 2012, 26, 3497-3503. [CrossRef]

42. Rezaeidoust, A.; Puntervold, T.; Austad, T. A Discussion of the Low-Salinity EOR Potential for a North Sea Sandstone Field. In Proceedings of the SPE Annual Technical Conference and Exhibition, Florence, Italy, 19-22 September 2010; p. 12.

43. Boussour, S.; Cissokho, M.; Cordier, P.; Bertin, H.J.; Hamon, G. Oil Recovery by Low-Salinity Brine Injection: Laboratory Results on Outcrop and Reservoir Cores. In Proceedings of the SPE Annual Technical Conference and Exhibition, New Orleans, LA, USA, 4-7 October 2009; p. 12.

44. RezaeiDoust, A.; Puntervold, T.; Strand, S.; Austad, T. Smart water as wettability modifier in carbonate and sandstone: A discussion of similarities/differences in the chemical mechanisms. Energy Fuels 2009, 23, 4479-4485. [CrossRef]

45. Austad, T.; Shariatpanahi, S.; Strand, S.; Black, C.J.J.; Webb, K.J. Conditions for a Low-Salinity Enhanced Oil Recovery (EOR) Effect in Carbonate Oil Reservoirs. Energy Fuels 2011, 26, 569-575. [CrossRef]

46. Romanuka, J.; Hofman, J.; Ligthelm, D.; Suijkerbuijk, B.; Marcelis, F.; Oedai, S.; Brussee, N.; van der Linde, H.; Aksulu, H.; Austad, T. Low Salinity EOR in Carbonates. In Proceedings of the SPE Improved Oil Recovery Symposium, Tulsa, OK, USA, 14-18 April 2012.

47. Yousef, A.; Al-Saleh, S.; Al-Kaabi, A.; Al-Jawfi, M. Laboratory investigation of novel oil recovery method for carbonate reservoirs. In Proceedings of the Canadian Unconventional Resources and International Petroleum Conference, Calgary, AB, Canada, 19-21 October 2010.

48. Yousef, A.; Al-Saleh, S.; Al-Jawfi, M. Improved/Enhanced Oil Recovery from Carbonate Reservoirs by Tuning Injection Water Salinity and Ionic Content. In Proceedings of the SPE Improved Oil Recovery Symposium, Tulsa, OK, USA, 14-18 April 2012.

49. Al Mahrouqi, D.; Vinogradov, J.; Jackson, M.D. Temperature dependence of the zeta potential in intact natural carbonates. Geophys. Res. Lett. 2016, 43. [CrossRef] 
50. Al Mahrouqi, D.; Vinogradov, J.; Jackson, M.D. Zeta potential of artificial and natural calcite in aqueous solution. Adv. Colloid Interface Sci. 2016, 240, 60-76. [CrossRef] [PubMed]

51. Alroudhan, A.; Vinogradov, J.; Jackson, M. Zeta potential of intact natural limestone: Impact of potential-determining ions $\mathrm{Ca}^{2+}, \mathrm{Mg}^{2+}$ and $\mathrm{SO}_{4}{ }^{2-}$. Colloids Surf. A Physicochem. Eng. Asp. 2016, 493, 83-98. [CrossRef]

52. Austad, T.; RezaeiDoust, A.; Puntervold, T. Chemical mechanism of low salinity water flooding in sandstone reservoirs. In Proceedings of the SPE improved oil recovery symposium, Tulsa, OK, USA, 24-28 April 2010.

53. Gupta, R.; Smith, P., Jr.; Willingham, T.; Lo Cascia, M.; Shyeh, J.; Harris, C. Enhanced Waterflood for Middle East Carbonate Cores-Impact of Injection Water Composition. In Proceedings of the SPE Middle East Oil and Gas Show and Conference, Manama, Bahrain, 25-28 September 2011.

54. Hilner, E.; Andersson, M.P.; Hassenkam, T.; Matthiesen, J.; Salino, P.; Stipp, S.L.S. The effect of ionic strength on oil adhesion in sandstone-the search for the low salinity mechanism. Sci. Rep. 2015, 5, 9933. [CrossRef] [PubMed]

55. Mahani, H.; Keya, A.L.; Berg, S.; Bartels, W.-B.; Nasralla, R.; Rossen, W.R. Insights into the mechanism of wettability alteration by low-salinity flooding (LSF) in carbonates. Energy Fuels 2015, 29, 1352-1367. [CrossRef]

56. Nasralla, R.A.; Nasr-El-Din, H.A. Impact of Electrical Surface Charges and Cation Exchange on Oil Recovery by Low Salinity Water. In Proceedings of the SPE Asia Pacific Oil and Gas Conference and Exhibition, Jakarta, Indonesia, 20-22 September 2011.

57. Strand, S.; Høgnesen, E.J.; Austad, T. Wettability alteration of carbonates-Effects of potential determining ions $\left(\mathrm{Ca}^{2+}\right.$ and $\left.\mathrm{SO}_{4}{ }^{2-}\right)$ and temperature. Colloids Surf. A Physicochem. Eng. Asp. 2006, 275, 1-10. [CrossRef]

58. Vinogradov, J.; Jaafar, M.; Jackson, M. Measurement of streaming potential coupling coefficient in sandstones saturated with natural and artificial brines at high salinity. J. Geophys. Res. Solid Earth 2010, 115. [CrossRef]

59. Zhang, P.; Tweheyo, M.T.; Austad, T. Wettability alteration and improved oil recovery by spontaneous imbibition of seawater into chalk: Impact of the potential determining ions $\mathrm{Ca}^{2+}, \mathrm{Mg}^{2+}$, and $\mathrm{SO}_{4}{ }^{2-}$. Colloids Surf. A Physicochem. Eng. Asp. 2007, 301, 199-208. [CrossRef]

60. Al-Shalabi, E.W.; Sepehrnoori, K.; Delshad, M.; Pope, G. A Novel Method To Model Low-Salinity-Water Injection in Carbonate Oil Reservoirs. SPE J. 2014, 20, 1-154. [CrossRef]

61. Andersen, P.Ø.; Evje, S.; Madland, M.V.; Hiorth, A. A geochemical model for interpretation of chalk core flooding experiments. Chem. Eng. Sci. 2012, 84, 218-241. [CrossRef]

62. Awolayo, A.N.; Sarma, H.K.; Nghiem, L.X. Modeling the characteristic thermodynamic interplay between potential determining ions during brine-dependent recovery process in carbonate rocks. Fuel 2018, 224, 701-717. [CrossRef]

63. Dang, C.T.Q.; Nghiem, L.X.; Chen, Z.J.; Nguyen, Q.P. Modeling Low Salinity Waterflooding: Ion Exchange, Geochemistry and Wettability Alteration. In Proceedings of the SPE Annual Technical Conference and Exhibition, New Orleans, LA, USA, 30 September-2 October 2013.

64. Evje, S.; Hiorth, A. A mathematical model for dynamic wettability alteration controlled by water-rock chemistry. Netw. Heterog. Media 2010, 5, 217-256. [CrossRef]

65. Hiorth, A.; Cathles, L.; Madland, M. The impact of pore water chemistry on carbonate surface charge and oil wettability. Transp. Porous Media 2010, 85, 1-21. [CrossRef]

66. Jerauld, G.R.; Webb, K.J.; Lin, C.-Y.; Seccombe, J.C. Modeling low-salinity waterflooding. SPE Reserv. Eval. Eng. 2008, 11. [CrossRef]

67. Omekeh, A.V.; Friis, H.A.; Fjelde, I.; Evje, S. Modeling of Ion-Exchange and Solubility in Low Salinity Water Flooding. In Proceedings of the SPE Improved Oil Recovery Symposium, Tulsa, OK, USA, 14-18 April 2012.

68. Qiao, C.; Li, L.; Johns, R.T.; Xu, J. A Mechanistic Model for Wettability Alteration by Chemically Tuned Waterflooding in Carbonate Reservoirs. SPE J. 2015, 20, 767-783. [CrossRef]

69. Venkatraman, A.; Hesse, M.A.; Lake, L.W.; Johns, R.T. Analytical solutions for flow in porous media with multicomponent cation exchange reactions. Water Resour. Res. 2014, 50, 5831-5847. [CrossRef]

70. Zeinijahromi, A.; Nguyen, T.K.P.; Bedrikovetsky, P. Mathematical Model for Fines-Migration-Assisted Waterflooding With Induced Formation Damage. SPE J. 2013, 18, 518-533. [CrossRef]

71. Adegbite, J.O.; Al-Shalabi, E.W.; Ghosh, B. Geochemical modeling of engineered water injection effect on oil recovery from carbonate cores. J. Pet. Sci. Eng. 2018, 170, 696-711. [CrossRef] 
72. Chandrasekhar, S.; Sharma, H.; Mohanty, K.K. Dependence of wettability on brine composition in high temperature carbonate rocks. Fuel 2018, 225, 573-587. [CrossRef]

73. Awolayo, A.N.; Sarma, H.K. An analytical solution to interpret active ion transport during chemically-tuned waterflooding process in high-temperature carbonate rocks. Can. J. Chem. Eng. 2018. [CrossRef]

74. Borazjani, S.; Behr, A.; Genolet, L.; Van Der Net, A.; Bedrikovetsky, P. Effects of fines migration on low-salinity waterflooding: Analytical modelling. Transp. Porous Media 2017, 116, 213-249. [CrossRef]

75. Jackson, M.D.; Vinogradov, J.; Hamon, G.; Chamerois, M. Evidence, mechanisms and improved understanding of controlled salinity waterflooding part 1: Sandstones. Fuel 2016, 185, 772-793. [CrossRef]

76. Sohal, M.A.; Thyne, G.; Søgaard, E.G. Review of recovery mechanisms of ionically modified waterflood in carbonate reservoirs. Energy Fuels 2016, 30, 1904-1914. [CrossRef]

77. Sheng, J. Critical review of low-salinity waterflooding. J. Pet. Sci. Eng. 2014, 120, 216-224. [CrossRef]

78. Al-Shalabi, E.W.; Sepehrnoori, K. A comprehensive review of low salinity/engineered water injections and their applications in sandstone and carbonate rocks. J. Pet. Sci. Eng. 2016, 139, 137-161. [CrossRef]

79. Austad, T. Water-Based EOR in Carbonates and Sandstones: New Chemical Understanding of the EOR Potential Using "Smart Water". In Enhanced Oil Recovery Field Case Studies, 1st ed.; Sheng, J., Ed.; Gulf Professional Publishing Elsevier: Waltham, MA, USA, 2013; pp. 301-335.

80. Purswani, P.; Tawfik, M.S.; Karpyn, Z.T. Factors and mechanisms governing wettability alteration by chemically tuned waterflooding: A review. Energy Fuels 2017, 31, 7734-7745. [CrossRef]

81. Afekare, D.A.; Radonjic, M. From mineral surfaces and coreflood experiments to reservoir implementations: Comprehensive review of low-salinity water flooding (LSWF). Energy Fuels 2017, 31, 13043-13062. [CrossRef]

82. Myint, P.C.; Firoozabadi, A. Thin liquid films in improved oil recovery from low-salinity brine. Curr. Opin. Colloid Interface Sci. 2015, 20, 105-114. [CrossRef]

83. Derkani, M.H.; Fletcher, A.J.; Abdallah, W.; Sauerer, B.; Anderson, J.; Zhang, Z.J. Low Salinity Waterflooding in Carbonate Reservoirs: Review of Interfacial Mechanisms. Colloids Interfaces 2018, 2, 20. [CrossRef]

84. Buckley, S.E.; Leverett, M. Mechanism of fluid displacement in sands. Trans. AIME 1942, 146, 107-116. [CrossRef]

85. Welge, H.J. A simplified method for computing oil recovery by gas or water drive. J. Pet. Technol. 1952, 4, 91-98. [CrossRef]

86. Morrow, N.R.; Tang, G.-Q.; Valat, M.; Xie, X. Prospects of improved oil recovery related to wettability and brine composition. J. Pet. Sci. Eng. 1998, 20, 267-276. [CrossRef]

87. Morrow, N.R. Wettability and Its Effect on Oil Recovery. J. Pet. Technol. 1990, 42, 1-476. [CrossRef]

88. Masalmeh, S.K. Impact of capillary forces on residual oil saturation and flooding experiments for mixed to oil-wet carbonate reservoirs. In Proceedings of the Society of Core Analysts, Aberdeen, Scotland, UK, 27-30 August 2012.

89. Shehata, A.M.; Alotaibi, M.B.; Nasr-El-Din, H.A. Waterflooding in carbonate reservoirs: Does the salinity matter? SPE Reserv. Eval. Eng. 2014, 17, 304-313. [CrossRef]

90. Al Harrasi, A.; Al-maamari, R.S.; Masalmeh, S.K. Laboratory investigation of low salinity waterflooding for carbonate reservoirs. In Proceedings of the Abu Dhabi International Petroleum Conference and Exhibition, Abu Dhabi, UAE, 11-14 November 2012.

91. Standnes, D.C.; Austad, T. Wettability alteration in chalk: 1. Preparation of core material and oil properties. J. Pet. Sci. Eng. 2000, 28, 111-121. [CrossRef]

92. Xie, X.; Morrow, N.R. Oil recovery by spontaneous imbibition from weakly water-wet rocks. Petrophysics 2001, 42.

93. Zhang, P.; Tweheyo, M.T.; Austad, T. Wettability alteration and improved oil recovery in chalk: The effect of calcium in the presence of sulfate. Energy Fuels 2006, 20, 2056-2062. [CrossRef]

94. Al-Attar, H.H.; Mahmoud, M.Y.; Zekri, A.Y.; Almehaideb, R.; Ghannam, M. Low-salinity flooding in a selected carbonate reservoir: Experimental approach. J. Pet. Explor. Prod. Technol. 2013, 3, 139-149. [CrossRef]

95. Alotaibi, M.B.; Azmy, R.; Nasr-El-Din, H.A. A comprehensive EOR study using low salinity water in sandstone reservoirs. In Proceedings of the SPE Improved Oil Recovery Symposium, Tulsa, OK, USA, 24-28 April 2010. 
96. Awolayo, A.N.; Sarma, H.K.; Al-sumaiti, A.M. A Laboratory Study of Ionic Effect of Smart Water for Enhancing Oil Recovery in Carbonate Reservoirs. In Proceedings of the SPE EOR Conference at Oil and Gas West Asia, Muscat, Oman, 31 March-2 April 2014.

97. Strand, S.; Austad, T.; Puntervold, T.; Høgnesen, E.J.; Olsen, M.; Barstad, S.M.F. "Smart Water" for Oil Recovery from Fractured Limestone: A Preliminary Study. Energy Fuels 2008, 22, 3126-3133. [CrossRef]

98. Jackson, M.D.; Al-Mahrouqi, D.; Vinogradov, J. Zeta potential in oil-water-carbonate systems and its impact on oil recovery during controlled salinity water-flooding. Sci. Rep. 2016, 6, 37363. [CrossRef] [PubMed]

99. Mahani, H.; Keya, A.L.; Berg, S.; Nasralla, R. Electrokinetics of carbonate/brine interface in low-salinity waterflooding: Effect of brine salinity, composition, rock type, and $\mathrm{pH}$ on $\zeta$-potential and a surface-complexation model. SPE J. 2017, 22, 53-68. [CrossRef]

100. Xie, Q.; Liu, Y.; Wu, J.; Liu, Q. Ions tuning water flooding experiments and interpretation by thermodynamics of wettability. J. Pet. Sci. Eng. 2014, 124, 350-358. [CrossRef]

101. Chen, Q.; Mercer, D.; Webb, K. NMR study on pore occupancy and wettability modification during low salinity waterflooding. In Proceedings of the 2010 International Symposium of Core Analysts, Halifax, NS, Canada, 4-7 October 2010; p. 12.

102. Looyestijn, W.J.; Hofman, J. Wettability-Index Determination by Nuclear Magnetic Resonance. SPE Reserv. Eval. Eng. 2006, 9, 146-153. [CrossRef]

103. Hassenkam, T.; Mitchell, A.C.; Pedersen, C.S.; Skovbjerg, L.; Bovet, N.; Stipp, S.L.S. The low salinity effect observed on sandstone model surfaces. Colloids Surfaces A Physicochem. Eng. Asp. 2012, 403, 79-86. [CrossRef]

104. Lebedeva, E.; Senden, T.J.; Knackstedt, M.; Morrow, N. Improved Oil Recovery from Tensleep Sandstone-Studies of Brine-Rock Interactions by Micro-CT and AFM. In Proceedings of the IOR 2009-15th European Symposium on Improved Oil Recovery, Paris, France, 27-29 April 2009.

105. Sarma, H.K. SPE Training Course on Chemical Enhanced Oil Recovery Methods; Unpublished: Kuala Lumpur, Malaysia, 2015.

106. Strand, S.; Standnes, D.C.; Austad, T. New wettability test for chalk based on chromatographic separation of $\mathrm{SCN}^{-}$and $\mathrm{SO}_{4}{ }^{2-}$. J. Pet. Sci. Eng. 2006, 52, 187-197. [CrossRef]

107. Anderson, W. Wettability literature survey-part 1: Rock/oil/brine interactions and the effects of core handling on wettability. J. Pet. Technol. 1986, 38, 1125-1144. [CrossRef]

108. Ding, H.; Rahman, S. Experimental and theoretical study of wettability alteration during low salinity water flooding-an state of the art review. Colloids Surf. A Physicochem. Eng. Asp. 2017, 520, 622-639. [CrossRef]

109. Israelachvili, J.N. Intermolecular and Surface Forces: Revised, 3rd ed.; Academic Press: New York, NY, USA, 2011.

110. Okasha, T.M.; Alshiwaish, A. Effect of brine salinity on interfacial tension in Arab-D carbonate reservoir, Saudi Arabia. In Proceedings of the SPE Middle East Oil and Gas Show and Conference, Manama, Bahrain, 15-18 March 2009.

111. Meng, W.; Haroun, M.R.; Sarma, H.K.; Adeoye, J.T.; Aras, P.; Punjabi, S.; Rahman, M.M.; Al Kobaisi, M. A Novel Approach of Using Phosphate-spiked Smart Brines to Alter Wettability in Mixed Oil-wet Carbonate Reservoirs. In Proceedings of the Abu Dhabi International Petroleum Exhibition and Conference, Abu Dhabi, UAE, 9-12 November 2015.

112. Lashkarbolooki, M.; Ayatollahi, S.; Riazi, M. Effect of salinity, resin, and asphaltene on the surface properties of acidic crude oil/smart water/rock system. Energy Fuels 2014, 28, 6820-6829. [CrossRef]

113. Shariatpanahi, S.F.; Strand, S.; Austad, T. Initial wetting properties of carbonate oil reservoirs: Effect of the temperature and presence of sulfate in formation water. Energy Fuels 2011, 25, 3021-3028. [CrossRef]

114. Suijkerbuijk, B.; Hofman, J.; Ligthelm, D.; Romanuka, J.; Brussee, N.; van der Linde, H.; Marcelis, F. Fundamental investigations into wettability and low salinity flooding by parameter isolation. In Proceedings of the SPE Improved Oil Recovery Symposium, Tulsa, OK, USA, 14-18 April 2012.

115. Lindlof, J.C.; Stoffer, K.G. A Case Study of Seawater Injection Incompatibility. SPE J. 1983, 35, 1256-1262. [CrossRef]

116. Zhang, Y.; Morrow, N. Comparison of secondary and tertiary recovery with change in injection brine composition for crude-oil/sandstone combinations. In Proceedings of the SPE/DOE Symposium on Improved Oil Recovery, Tulsa, OK, USA, 22-26 April 2006.

117. Shehata, A.M.; Nasr-El-Din, H.A. Laboratory Investigations To Determine the Effect of Connate-Water Composition on Low-Salinity Waterflooding in Sandstone Reservoirs. SPE Reserv. Eval. Eng. 2017, 20, 59-76. [CrossRef] 
118. Cissokho, M.; Bertin, H.; Boussour, S.; Cordier, P.; Hamon, G. Low salinity oil recovery on clayey sandstone: Experimental study. Petrophysics 2010, 51. Available online: https:/ /www.onepetro.org/journal-paper/ SPWLA-2010-v51n5a2 (accessed on 2 September 2018).

119. Buckley, J.S.; Liu, Y.; Monsterleet, S. Mechanisms of wetting alteration by crude oils. SPE J. 1998, 3, 54-61. [CrossRef]

120. Fjelde, I.; Omekeh, A.V.; Sokama-Neuyam, Y.A. Low salinity water flooding: Effect of crude oil composition. In Proceedings of the SPE Improved Oil Recovery Symposium, Tulsa, OK, USA, 12-16 April 2014.

121. Agbalaka, C.C.; Dandekar, A.Y.; Patil, S.L.; Khataniar, S.; Hemsath, J.R. Coreflooding studies to evaluate the impact of salinity and wettability on oil recovery efficiency. Transp. Porous Media 2009, 76, 77-94. [CrossRef]

122. Li, Y. Oil recovery by low salinity water injection into a reservoir: A new study of tertiary oil recovery mechanism. Transp. Porous Media 2011, 90, 333-362. [CrossRef]

123. Gamage, P.H.S.; Thyne, G.D. Comparison of oil recovery by low salinity waterflooding in secondary and tertiary recovery modes. In Proceedings of the SPE Annual Technical Conference and Exhibition, Denver, CO, USA, 30 October-2 November 2011.

124. RezaeiDoust, A.; Puntervold, T.; Austad, T. Chemical Verification of the EOR Mechanism by Using Low Saline/Smart Water in Sandstone. Energy Fuels 2011, 25, 2151-2162. [CrossRef]

125. Burgos, W.D.; Pisutpaisal, N.; Mazzarese, M.C.; Chorover, J. Adsorption of quinoline to kaolinite and montmorillonite. Environ. Eng. Sci. 2002, 19, 59-68. [CrossRef]

126. Madsen, L.; Ida, L. Adsorption of carboxylic acids on reservoir minerals from organic and aqueous phase. SPE Reserv. Eval. Eng. 1998, 1, 47-51. [CrossRef]

127. Zhang, Y.; Xie, X.; Morrow, N. Waterflood performance by injection of brine with different salinity for reservoir cores. In Proceedings of the SPE Annual Technical Conference and Exhibition, Anaheim, CA, USA, 11-14 November 2007.

128. Viksund, B.G.; Morrow, N.R.; Ma, S.; Wang, W.; Graue, A. Initial water saturation and oil recovery from chalk and sandstone by spontaneous imbibition. In Proceedings of the International Symposium of Society of Core Analysts, The Hague, The Netherlands, 26-30 August 1998.

129. Puntervold, T.; Strand, S.; Austad, T. Water flooding of carbonate reservoirs: Effects of a model base and natural crude oil bases on chalk wettability. Energy Fuels 2007, 21, 1606-1616. [CrossRef]

130. Puntervold, T.; Strand, S.; Austad, T. New method to prepare outcrop chalk cores for wettability and oil recovery studies at low initial water saturation. Energy Fuels 2007, 21, 3425-3430. [CrossRef]

131. Fernø, M.A.; Grønsdal, R.; Åsheim, J.; Nyheim, A.; Berge, M.; Graue, A. Use of sulfate for water based enhanced oil recovery during spontaneous imbibition in chalk. Energy Fuels 2011, 25, 1697-1706. [CrossRef]

132. Shariatpanahi, S.F.; Hopkins, P.; Aksulu, H.; Strand, S.; Puntervold, T.; Austad, T. Water based EOR by wettability alteration in dolomite. Energy Fuels 2016, 30, 180-187. [CrossRef]

133. Dubey, S.T.; Doe, P.H. Base number and wetting properties of crude oils. SPE Reserv. Eval. Eng. 1993, 8, 195-200. [CrossRef]

134. Denekas, M.O.; Mattax, C.C.; Davis, G.T. Effects of Crude Oil Components on Rock Wettability. PE Trans. AIME 1959, 216, 330-333.

135. Cuiec, L. Rock/Crude-Oil Interactions and Wettability: An Attempt To Understand Their Interrelation. In Proceedings of the SPE Annual Technical Conference and Exhibition, Houston, TX, USA, 16-19 September 1984.

136. Ehrlich, R. Wettability alteration during displacement of oil by water from petroleum reservoir rock. In Proceedings of the 48th National Colloid Symposium ACS preprints, Austin, TX, USA, 24-26 June 1974.

137. Block, A.; Simms, B.B. Desorption and exchange of adsorbed octadecylamine and stearic acid on steel and glass. J. Colloid Interface Sci. 1967, 25, 514-518. [CrossRef]

138. Strassner, J.E. Effect of $\mathrm{pH}$ on interfacial films and stability of crude oil-water emulsions. J. Pet. Technol. 1968, 20, 303-312. [CrossRef]

139. McCaffery, F.G.; Mungan, N. Contact angle and interfacial tension studies of some hydrocarbon-water-solid systems. J. Can. Pet. Technol. 1970, 9. [CrossRef]

140. Marsden, S.S.; Nikias, P.A. The Wettability of the Bradford Sand. Prod. Mon. 1962, 26, 2-5.

141. Basu, S.; Sharma, M.M. Investigating the role of crude-oil components on wettability alteration using atomic force microscopy. In Proceedings of the International Symposium on Oilfield Chemistry, Houston, TX, USA, 18-21 February 1997. 
142. Dubey, S.; Waxman, M. Asphaltene adsorption and desorption from mineral surfaces. SPE Reserv. Eval. Eng. 1991, 6, 389-395. [CrossRef]

143. Akhlaq, M.S.; Kessel, D.; Dornow, W. Separation and chemical characterization of wetting crude oil compounds. J. Colloid Interface Sci. 1996, 180, 309-314. [CrossRef]

144. Czarnecka, E.; Gillott, J. Formation and characterization of clay complexes with bitumen from Athabasca oil sand. Clays Clay Miner. 1980, 28, 197-203. [CrossRef]

145. Collins, S.H.; Melrose, J.C. Adsorption of asphaltenes and water on reservoir rock minerals. In Proceedings of the SPE Oilfield and Geothermal Chemistry Symposium, Denver, CO, USA, 1-3 June 1983.

146. Johansen, R.T.; Dunning, H.N. Relative Wetting Tendencies of Crude Oils by Capillarimetric Method; Bureau of Mines, Bartlesville Petroleum Research Center: Bartlesville, OK, USA, 1961.

147. Buckley, J.S.; Wang, J. Crude oil and asphaltene characterization for prediction of wetting alteration. J. Pet. Sci. Eng. 2002, 33, 195-202. [CrossRef]

148. Buckley, J.S.; Liu, Y. Some mechanisms of crude oil/brine/solid interactions. J. Pet. Sci. Eng. 1998, 20, 155-160. [CrossRef]

149. Buckley, J.S.; Liu, Y.; Xie, X.; Morrow, N.R. Asphaltenes and crude oil wetting-the effect of oil composition. SPE J. 1997, 2, 107-119. [CrossRef]

150. Skauge, A.; Standal, S.; Boe, S.O.; Skauge, T.; Blokhus, A.M. Effects of Organic Acids and Bases, and Oil Composition on Wettability. In Proceedings of the SPE Annual Technical Conference and Exhibition, Houston, TX, USA, 3-6 October 1999.

151. Hoeiland, S.; Barth, T.; Blokhus, A.M.; Skauge, A. The effect of crude oil acid fractions on wettability as studied by interfacial tension and contact angles. J. Pet. Sci. Eng. 2001, 30, 91-103. [CrossRef]

152. Mwangi, P.; Brady, P.V.; Radonjic, M.; Thyne, G. The effect of organic acids on wettability of sandstone and carbonate rocks. J. Pet. Sci. Eng. 2018, 165, 428-435. [CrossRef]

153. Lowe, A.C.; Phillips, M.C.; Riddiford, A.C. On the wetting of carbonate surfaces by oil and water. J. Can. Pet. Technol. 1973, 12. [CrossRef]

154. Benner, F.C.; Bartel, F.E. The effect of polar impurities upon capillary and surface phenomena in petroleum production. In Proceedings of the Drilling and production practice, New York, NY, USA, 1 January 1941.

155. Morrow, N.R.; Cram, P.J.; McCaffery, F.G. Displacement Studies in Dolomite With Wettability Control by Octanoic Acid. Soc. Pet. Eng. J. 1973, 13, 221-232. [CrossRef]

156. Shimoyama, A.; Johns, W.D. Formation of alkanes from fatty acids in the presence of $\mathrm{CaCO}_{3}$. Geochim. Cosmochim. Acta 1972, 36, 87-91. [CrossRef]

157. Zhang, P.; Austad, T. The relative effects of acid number and temperature on chalk wettability. In Proceedings of the SPE International Symposium on Oilfield Chemistry, The Woodlands, TX, USA, 2-4 February 2005.

158. Zhang, P.; Austad, T. Waterflooding in chalk: Relationship between oil recovery, new wettability index, brine composition and cationic wettability modifier. In Proceedings of the SPE Europec/EAGE Annual Conference, Madrid, Spain, 13-16 June 2005; p. 7.

159. Thomas, M.M.; Clouse, J.A.; Longo, J.M. Adsorption of organic compounds on carbonate minerals: 1 . Model compounds and their influence on mineral wettability. Chem. Geol. 1993, 109, 201-213. [CrossRef]

160. Mwangi, P.; Thyne, G.; Rao, D. Extensive Experimental Wettability Study in Sandstone and Carbonate-Oil-Brine Systems: Part 1-Screening Tool Development. In Proceedings of the International Symposium of the Society of Core Analysts, Napa Valley, CA, USA, 16-19 September 2013.

161. Gomari, K.R.; Hamouda, A. Effect of fatty acids, water composition and $\mathrm{pH}$ on the wettability alteration of calcite surface. J. Pet. Sci. Eng. 2006, 50, 140-150. [CrossRef]

162. Fathi, S.J.; Austad, T.; Strand, S.; Puntervold, T. Wettability alteration in carbonates: The effect of water-soluble carboxylic acids in crude oil. Energy Fuels 2010, 24, 2974-2979. [CrossRef]

163. Fathi, S.J.; Austad, T.; Strand, S. Effect of water-extractable carboxylic acids in crude oil on wettability in carbonates. Energy Fuels 2011, 25, 2587-2592. [CrossRef]

164. Carroll, D. Ion exchange in clays and other minerals. Geol. Soc. Am. Bull. 1959, 70, 749-779. [CrossRef]

165. Hughes, R.V.; Pfister, R.J. Advantages of Brines in Secondary Recovery of Petroleum by Water-flooding. SPE J. Pap. 1947, 170, 187-201. [CrossRef]

166. Smith, K.W. Brines as flooding liquids. In Proceedings of the 7th Annual Technical Meetings of the Bradford District Research Group, State College, PA, USA, 6-7 November 1942. 
167. Reiter, P.K. A Water-Sensitive Sandstone Flood Using Low Salinity Water; University of Oklahoma: Norman, OK, USA, 1961.

168. Wickramathilaka, S.; Howard, J.; Morrow, N.; Buckley, J. An experimental study of low salinity waterflooding and spontaneous imbibition. In Proceedings of the IOR 2011 16th European Symposium on Improved Oil Recovery, Cambridge, UK, 12-14 April 2011.

169. Appelo, C.A.J.; Postma, D. Geochemistry, Groundwater and Pollution, 2nd ed.; CRC Press: Boca Raton, FL, USA, $2005 ;$ p. 668.

170. Law, S.; McDonald, A.; Fellows, S.; Reed, J.; Sutcliffe, P.G. Influence of Clay Content and Type on Oil Recovery Under Low Salinity Waterflooding in North Sea Reservoirs. In Proceedings of the SPE Offshore Europe Conference and Exhibition, Aberdeen, Scotland, UK, 8-11 September 2015.

171. Tong, Z.; Yin, P.; Morrow, N.R.; Brabec, D.J. Improvement of Water Flood Performance of Low-Permeability Sandstone Reservoirs. In Proceedings of the AAPG Rocky Mountain Section Annual Meeting, Billings, MT, USA, 10-13 June 2006.

172. Lager, A.; Webb, K.J.; Black, C.J.J. Impact of brine chemistry on oil recovery. In Proceedings of the 14th European Symposium on Improved Oil Recovery, Cairo, Egypt, 22-24 April 2007.

173. Seccombe, J.C.; Lager, A.; Webb, K.J.; Jerauld, G.; Fueg, E. Improving wateflood recovery: LoSal ${ }^{\mathrm{TM}} \mathrm{EOR}^{\mathrm{N}}$ field evaluation. In Proceedings of the SPE Symposium on Improved Oil Recovery, Tulsa, OK, USA, 20-23 April 2008.

174. Zhou, Z.; Gunter, W.D. The nature of the surface charge of kaolinite. Clays Clay Miner. 1992, 40, 365-368. [CrossRef]

175. Lebedeva, E.V.; Fogden, A. Micro-CT and wettability analysis of oil recovery from sand packs and the effect of waterflood salinity and kaolinite. Energy Fuels 2011, 25, 5683-5694. [CrossRef]

176. Pu, H.; Xie, X.; Yin, P.; Morrow, N. Application of coalbed methane water to oil recovery by low salinity waterflooding. In Proceedings of the SPE Improved Oil Recovery Symposium, Tulsa, OK, USA, 19-23 April 2008; pp. 19-23.

177. Hassenkam, T.; Pedersen, C.S.; Dalby, K.; Austad, T.; Stipp, S.L.S. Pore scale observation of low salinity effects on outcrop and oil reservoir sandstone. Colloids Surf. A Physicochem. Eng. Asp. 2011, 390, 179-188. [CrossRef]

178. Lee, S.Y.; Webb, K.J.; Collins, I.; Lager, A.; Clarke, S.; Sullivan, M.; Routh, A.; Wang, X. Low Salinity Oil Recovery: Increasing Understanding of the Underlying Mechanisms. In Proceedings of the SPE Improved Oil Recovery Symposium, Tulsa, OK, USA, 24-28 April 2010; p. 11.

179. Brady, P.V.; Morrow, N.R.; Fogden, A.; Deniz, V.; Loahardjo, N. Electrostatics and the low salinity effect in sandstone reservoirs. Energy Fuels 2015, 29, 666-677. [CrossRef]

180. Farooq, U.; Tweheyo, M.T.; Sjøblom, J.; Øye, G. Surface characterization of model, outcrop, and reservoir samples in low salinity aqueous solutions. J. Dispers. Sci. Technol. 2011, 32, 519-531. [CrossRef]

181. Awolayo, A.; Sarma, H.; Nghiem, L. Thermodynamic Modeling of Brine Dilution-Dependent Recovery in Carbonate Rocks with Different Mineralogical Content. Energy Fuels 2018, 32, 8921-8943. [CrossRef]

182. Mazzullo, S.; Chilingarian, G.V.; Bissell, H.J. Carbonate rock classifications. Dev. Pet. Sci. 1992, 30, 59-108. [CrossRef]

183. Megawati, M.; Hiorth, A.; Madland, M. The impact of surface charge on the mechanical behavior of high-porosity chalk. Rock Mech. Rock Eng. 2013, 46, 1073-1090. [CrossRef]

184. Korsnes, R.I.; Madland, M.V.; Austad, T.; Haver, S.; Røsland, G. The effects of temperature on the water weakening of chalk by seawater. J. Pet. Sci. Eng. 2008, 60, 183-193. [CrossRef]

185. Korsnes, R.I.; Strand, S.; Hoff, Ø.; Pedersen, T.; Madland, M.V.; Austad, T. Does the chemical interaction between seawater and chalk affect the mechanical properties of chalk. In Proceedings of the International Symposium of the International Society for Rock Mechanics, Liège, Belgium, 9-12 May 2006; pp. 427-434.

186. Awolayo, A.N.; Sarma, H.K.; AlSumaiti, A.M. An Experimental Study of Smart Waterflooding on Fractured Carbonate Reservoirs. In Proceedings of the ASME 2014 33rd International Conference on Ocean, Offshore and Arctic Engineering, San Francisco, CA, USA, 8-12 June 2014; p. V005T011A024.

187. Pierre, A.; Lamarche, J.M.; Mercier, R.; Foissy, A.; Persello, J. Calcium as potential determining ion in aqueous calcite suspensions. J. Dispers. Sci. Technol. 1990, 11, 611-635. [CrossRef]

188. Zhang, P.; Austad, T. Wettability and oil recovery from carbonates: Effects of temperature and potential determining ions. Colloids Surf. A Physicochem. Eng. Asp. 2006, 279, 179-187. [CrossRef] 
189. Austad, T.; Strand, S.; Madland, M.V.; Puntervold, T.; Korsnes, R.I. Seawater in Chalk: An EOR and Compaction Fluid. SPE J. Pap. 2008, 11, 648-654. [CrossRef]

190. Strand, S.; Standnes, D.C.; Austad, T. Spontaneous imbibition of aqueous surfactant solutions into neutral to oil-wet carbonate cores: Effects of brine salinity and composition. Energy Fuels 2003, 17, 1133-1144. [CrossRef]

191. Fathi, S.J.; Austad, T.; Strand, S. Water-based enhanced oil recovery (EOR) by "smart water": Optimal ionic composition for EOR in carbonates. Energy Fuels 2011, 25, 5173-5179. [CrossRef]

192. Kasha, A.; Al-Hashim, H.; Abdallah, W.; Taherian, R.; Sauerer, B. Effect of $\mathrm{Ca}^{2+}, \mathrm{Mg}^{2+}$ and $\mathrm{SO}_{4}{ }^{2-}$ ions on the zeta potential of calcite and dolomite particles aged with stearic acid. Colloids Surf. A Physicochem. Eng. Asp. 2015, 482, 290-299. [CrossRef]

193. Ravari, R.R.; Strand, S.; Austad, T. Care must be taken to use outcrop limestone cores to mimic reservoir core material in SCAL linked to wettability alteration. In Proceedings of the 11th Intenational Symposium on Reservoir Wettability, Calgary, CA, USA, 7-9 September 2010.

194. Vdović, N.; Bišćan, J. Electrokinetics of natural and synthetic calcite suspensions. Colloids Surf. A Physicochem. Eng. Asp. 1998, 137, 7-14. [CrossRef]

195. Karimi, M.; Al-Maamari, R.S.; Ayatollahi, S.; Mehranbod, N. Mechanistic study of wettability alteration of oil-wet calcite: The effect of magnesium ions in the presence and absence of cationic surfactant. Colloids Surf. A Physicochem. Eng. Asp. 2015, 482, 403-415. [CrossRef]

196. Dias, H.P.; Gonçalves, G.R.; Freitas, J.C.; Gomes, A.O.; de Castro, E.V.; Vaz, B.G.; Aquije, G.M.; Romão, W. Catalytic decarboxylation of naphthenic acids in crude oils. Fuel 2015, 158, 113-121. [CrossRef]

197. Shimoyama, A.; Johns, W.D. Catalytic conversion of fatty acids to petroleum-like paraffins and their maturation. Nat. Phys. Sci. 1971, 232, 140-144. [CrossRef]

198. Jurg, J.; Eisma, E. Petroleum hydrocarbons: Generation from fatty acid. Science 1964, 144, 1451-1452. [CrossRef] [PubMed]

199. Zhou, X.-M.; Torsaeter, O.; Xie, X.; Morrow, N. The effect of crude-oil aging time and temperature on the rate of water imbibition and long-term recovery by imbibition. SPE Form. Eval. 1995, 10, 259-266. [CrossRef]

200. Gamage, P.; Thyne, G. Systematic investigation of the effect of temperature during aging and low salinity flooding of Berea sandstone and Minn. In Proceedings of the IOR 2011 16th European Symposium on Improved Oil Recovery, Cambridge, UK, 12-14 April 2011.

201. Vinogradov, J.; Jackson, M.D. Zeta potential in intact natural sandstones at elevated temperatures. Geophys. Res. Lett. 2015, 42, 6287-6294. [CrossRef]

202. Saunders, J.; Jackson, M.; Gulamali, M.; Vinogradov, J.; Pain, C. Streaming potentials at hydrocarbon reservoir conditions. Geophysics 2012, 77, E77-E90. [CrossRef]

203. Jaafar, M.Z.; Vinogradov, J.; Jackson, M.D. Measurement of streaming potential coupling coefficient in sandstones saturated with high salinity $\mathrm{NaCl}$ brine. Geophys. Res. Lett. 2009, 36. [CrossRef]

204. Revil, A.; Pezard, P.A.; Glover, P.W.J. Streaming potential in porous media: 1. Theory of the zeta potential. J. Geophys. Res. Solid Earth 1999, 104, 20021-20031. [CrossRef]

205. Rao, D.N. Wettability Effects in Thermal Recovery Operations. SPE Reserv. Eval. Eng. 1999, 2, 420-430. [CrossRef]

206. Heidari, M.A.; Habibi, A.; Ayatollahi, S.; Masihi, M.; Ashoorian, S. Effect of time and temperature on crude oil aging to do a right surfactant flooding with a new approach. In Proceedings of the Offshore Technology Conference-Asia, Kuala Lumpur, Malaysia, 25-28 March 2014.

207. Mahani, H.; Menezes, R.; Berg, S.; Fadili, A.; Nasralla, R.; Voskov, D.; Joekar-Niasar, V. Insights into the impact of temperature on the wettability alteration by low salinity in carbonate rocks. Energy Fuels 2017, 31, 7839-7853. [CrossRef]

208. Tang, G.Q.; Morrow, N.R. Oil recovery by waterflooding and imbibition-Invading brine cation valency and salinity. In Proceedings of the International Symposium of the Society of Core Analysts, Golden, CO, USA, 1-4 August 1999.

209. Webb, K.; Black, C.; Edmonds, I. Low salinity oil recovery-The role of reservoir condition corefloods. In Proceedings of the 13th EAGE Symposium on Improved Oil Recovery, Budapest, Hungary, 25-27 April 2005; pp. 25-27.

210. Webb, K.J.; Black, C.J.J.; Al-Ajeel, H. Low Salinity Oil Recovery-Log-Inject-Log. In Proceedings of the SPE/DOE Symposium on Improved Oil Recovery, Tulsa, OK, USA, 17-21 April 2003. 
211. Wideroee, H.C.; Rueslaatten, H.; Boassen, T.; Crescente, C.M.; Raphaug, M.; Soerland, G.H.; Urkedal, H. Investigation of low salinity water flooding by NMR and CryoESEM. In Proceedings of the 2010 International Symposium of the Society of Core Analysts, Halifax, Nova Scotia, 4-7 October 2010; p. 12.

212. Matthiesen, J.; Bovet, N.; Hilner, E.; Andersson, M.P.; Schmidt, D.; Webb, K.; Dalby, K.N.; Hassenkam, T.; Crouch, J.; Collins, I. How naturally adsorbed material on minerals affects low salinity enhanced oil recovery. Energy Fuels 2014, 28, 4849-4858. [CrossRef]

213. Webb, K.; Black, C.; Tjetland, G. A laboratory study investigating methods for improving oil recovery in carbonates. In Proceedings of the International Petroleum Technology Conference, Doha, Qatar, 21-23 November 2005.

214. Alshakhs, M.J.; Kovscek, A.R. Understanding the role of brine ionic composition on oil recovery by assessment of wettability from colloidal forces. Adv. Colloid Interface Sci. 2016, 233, 126-138. [CrossRef] [PubMed]

215. Chandrasekhar, S.; Mohanty, K. Wettability Alteration with Brine Composition in High Temperature Carbonate Reservoirs. In Proceedings of the SPE Annual Technical Conference and Exhibition, New Orleans, LA, USA, 30 September-2 October 2013.

216. Vo, L.T.; Gupta, R.; Hehmeyer, O.J. Ion Chromatography Analysis of Advanced Ion Management Carbonate Coreflood Experiments. In Proceedings of the Abu Dhabi International Petroleum Conference and Exhibition, Abu Dhabi, UAE, 11-14 November 2012.

217. Nyström, R.; Lindén, M.; Rosenholm, J.B. The Influence of $\mathrm{Na}^{+}, \mathrm{Ca}^{2+}, \mathrm{Ba}^{2+}$, and $\mathrm{La}^{3+}$ on the $\zeta-$ Potential and the Yield Stress of Calcite Dispersions. J. Colloid Interface Sci. 2001, 242, 259-263. [CrossRef]

218. Seccombe, J.; Lager, A.; Jerauld, G.; Jhaveri, B.; Buikema, T.; Bassler, S.; Denis, J.; Webb, K.; Cockin, A.; Fueg, E. Demonstration of low-salinity EOR at interwell scale, Endicott field, Alaska. In Proceedings of the SPE Improved Oil Recovery Symposium, Tulsa, OK, USA, 24-28 April 2010.

219. Lager, A.; Webb, K.J.; Collins, I.; Richmond, D. LoSal enhanced oil recovery: Evidence of enhanced oil recovery at the reservoir scale. In Proceedings of the SPE/DOE Symposium on Improved Oil Recovery, Tulsa, OK, USA, 20-23 April 2008.

220. Robertson, E. Low-Salinity Waterflooding to Improve Oil Recovery-Historical Field Evidence. In Proceedings of the SPE Annual Technical Conference and Exhibition, Anaheim, CA, USA, 11-14 November 2007.

221. Thyne, G.D.; Gamage, S.; Hasanka, P. Evaluation of the effect of low salinity waterflooding for 26 fields in Wyoming. In Proceedings of the SPE Annual Technical Conference and Exhibition, Denver, CO, USA, 30 October-2 November 2011.

222. Vledder, P.; Gonzalez, I.; Carrera Fonseca, J.; Wells, T.; Ligthelm, D. Low Salinity Water Flooding: Proof of Wettability Alteration On A Field Wide Scale. In Proceedings of the SPE Improved Oil Recovery Symposium, Tulsa, OK, USA, 24-28 April 2010.

223. Mahani, H.; Sorop, T.; Ligthelm, D.J.; Brooks, D.; Vledder, P.; Mozahem, F.; Ali, Y. Analysis of field responses to low-salinity waterflooding in secondary and tertiary mode in Syria. In Proceedings of the SPE EUROPEC/EAGE Annual Conference and Exhibition, Vienna, Austria, 23-26 May 2011.

224. Hegre, E. Low Salinity Water Injection-Case Study Heidrun Field; FORCE Seminar: Stavanger, Norway, 2008; Volume 15.

225. Abdulla, F.; Hashem, H.S.; Abdulraheem, B.; Al-Nnaqi, M.; Al-Qattan, A.; John, H.; Cunningham, P.R.P.; Briggs, P.J.; Thawer, R. First EOR Trial using Low Salinity Water Injection in the Greater Burgan Field, Kuwait. In Proceedings of the SPE Middle East Oil and Gas Show and Conference, Manama, Bahrain, 10-13 March 2013.

226. Al-Qattan, A.; Sanaseeri, A.; Al-Saleh, Z.; Singh, B.B.; Al-Kaaoud, H.; Delshad, M.; Hernandez, R.; Winoto, W.; Badham, S.; Bouma, C.; et al. Low Salinity Waterflood and Low Salinity Polymer Injection in the Wara Reservoir of the Greater Burgan Field. In Proceedings of the SPE EOR Conference at Oil and Gas West Asia, Muscat, Oman, 25-28 March 2018.

227. Rotondi, M.; Callegaro, C.; Masserano, F.; Bartosek, M. Low Salinity Water Injection: Eni's Experience. In Proceedings of the Abu Dhabi International Petroleum Exhibition and Conference, Abu Dhabi, UAE, 10-13 November 2014.

228. Callegaro, C.; Bartosek, M.; Nobili, M.; Masserano, F.; Pollero, M.; Baz, D.M.M.; Kortam, M.M. Design and Implementation of Low Salinity Waterflood in a North African Brown Field. In Proceedings of the Abu Dhabi International Petroleum Exhibition and Conference, Abu Dhabi, UAE, 9-12 November 2015. 
229. Zeinijahromi, A.; Ahmetgareev, V.; Bedrikovetsky, P. Case Study of 25 Years of Low Salinity Water Injection. In Proceedings of the SPE/IATMI Asia Pacific Oil \& Gas Conference and Exhibition, Bali, Indonesia, 20-22 October 2015.

230. Zeinijahromi, A.; Ahmetgareev, V.; Badalyan, A.; Khisamov, R.; Bedrikovetsky, P. Case study of low salinity water injection in Zichebashskoe field. J. Pet. Sci. Res. 2015. [CrossRef]

231. Akhmetgareev, V.; Khisamov, R. 40 Years of Low-Salinity Waterflooding in Pervomaiskoye Field, Russia: Incremental Oil. In Proceedings of the SPE European Formation Damage Conference and Exhibition, Budapest, Hungary, 3-5 June 2015.

232. Robbana, E.; Buikema, T.A.; Mair, C.; Williams, D.; Mercer, D.J.; Webb, K.J.; Hewson, A.; Reddick, C.E. Low Salinity Enhanced Oil Recovery_Laboratory to Day One Field Implementation—LoSal EOR into the Clair Ridge Project. In Proceedings of the Abu Dhabi International Petroleum Conference and Exhibition, Abu Dhabi, UAE, 11-14 November 2012.

233. Erke, S.I.; Volokitin, Y.E.; Edelman, I.Y.; Karpan, V.M.; Nasralla, R.A.; Bondar, M.Y.; Mikhaylenko, E.E.; Evseeva, M. Low Salinity Flooding Trial at West Salym Field. In Proceedings of the SPE Improved Oil Recovery Conference, Tulsa, OK, USA, 11-13 April 2016.

234. Suijkerbuijk, B.M.J.M.; Sorop, T.G.; Parker, A.R.; Masalmeh, S.K.; Chmuzh, I.V.; Karpan, V.M.; Volokitin, Y.E.; Skripkin, A.G. Low Salinity Waterflooding at West-Salym: Laboratory Experiments and Field Forecasts. In Proceedings of the SPE Improved Oil Recovery Symposium, Tulsa, OK, USA, 12-16 April 2014.

235. Thomas, L.; Dixon, T.; Evans, C.; Vienot, M. Ekofisk waterflood pilot. J. Pet. Technol. 1987, 39, $221-232$. [CrossRef]

236. Hermansen, H.; Landa, G.; Sylte, J.; Thomas, L. Experiences after 10 years of waterflooding the Ekofisk Field, Norway. J. Pet. Sci. Eng. 2000, 26, 11-18. [CrossRef]

237. Barkved, O.; Heavey, P.; Kjelstadli, R.; Kleppan, T.; Kristiansen, T.G. Valhall field-still on plateau after 20 years of production. In Proceedings of the Offshore Europe, Aberdeen, UK, 2-5 September 2003.

238. Griffin, T.A.; Best, K.D.; Thingvoll, T.T.; Stockden, I.L.; Tjetland, G. Monitoring Waterflood Performance in a Depleted Fractured Chalk Reservoir. In Proceedings of the Offshore Europe, Scotland, UK, 4-7 September 2007.

239. Tjetland, G.; Kristiansen, T.G.; Buer, K. Reservoir management aspects of early waterflood response after 25 years of depletion in the Valhall field. In Proceedings of the International Petroleum Technology Conference, Dubai, UAE, 4-6 December 2007.

240. Al-adasani, A.; Bai, B.; Wu, Y.-S. Investigating low-salinity waterflooding recovery mechanisms in sandstone reservoirs. In Proceedings of the SPE Improved Oil Recovery Symposium, Tulsa, OK, USA, 14-18 April 2012.

241. Lever, A.; Dawe, R.A. Water-sensitivity and migration of fines in the hopeman sandstone. J. Pet. Geol. 1984, 7, 97-107. [CrossRef]

242. Fogden, A.; Kumar, M.; Morrow, N.R.; Buckley, J.S. Mobilization of fine particles during flooding of sandstones and possible relations to enhanced oil recovery. Energy Fuels 2011, 25, 1605-1616. [CrossRef]

243. Hussein, F.; Zeinijahromi, A.; Bedrikovetsky, P. Improved Oil Recovery with Waterflooding by Mobilising Fines (laboratory-based incremental recovery). In Proceedings of the North Africa Technical Conference and Exhibition, Cairo, Egypt, 20-22 February 2012.

244. Sarkar, A.K.; Sharma, M.M. Fines migration in two-phase flow. J. Pet. Technol. 1990, 42, 646-652. [CrossRef]

245. Alagic, E.; Skauge, A. Combined low salinity brine injection and surfactant flooding in mixed-wet sandstone cores. Energy Fuels 2010, 24, 3551-3559. [CrossRef]

246. Ashraf, A.; Hadia, N.; Torsaeter, O.; Tweheyo, M.T. Laboratory Investigation of Low Salinity Waterflooding as Secondary Recovery Process: Effect of Wettability. In Proceedings of the SPE Oil and Gas India Conference and Exhibition, Mumbai, India, 20-22 January 2010; p. 12.

247. Al-Sarihi, A.; Zeinijahromi, A.; Genolet, L.; Behr, A.; Kowollik, P.; Bedrikovetsky, P. Effects of Fines Migration on Residual Oil during Low-Salinity Waterflooding. Energy Fuels 2018, 32, 8296-8309. [CrossRef]

248. Alhuraishawy, A.K.; Bai, B.; Wei, M.; Geng, J.; Pu, J. Mineral dissolution and fine migration effect on oil recovery factor by low-salinity water flooding in low-permeability sandstone reservoir. Fuel 2018, 220, 898-907. [CrossRef]

249. Nasralla, R.A.; Nasr-El-Din, H.A. Double-Layer Expansion: Is It a Primary Mechanism of Improved Oil Recovery by Low-Salinity Waterflooding? SPE Reserv. Eval. Eng. 2014, 17, 49-59. [CrossRef] 
250. Al-Saedi, H.N.; Alhuraishawy, A.K.; Flori, R.; Brady, P.V. Sequential injection mode of high-salinity/low-salinity water in sandstone reservoirs: Oil recovery and surface reactivity tests. J. Pet. Explor. Prod. Technol. 2018. [CrossRef]

251. Omekeh, A.V.; Evje, S.; Fjelde, I.; Friis, H.A. Experimental and modeling investigation of ion exchange during low salinity waterflooding. In Proceedings of the International Symposium of the Society of Core Analysts, Austin, TX, USA, 18-21 September 2011; pp. 18-21.

252. Fjelde, I.; Asen, S.M.; Omekeh, A.V. Low salinity water flooding experiments and interpretation by simulations. In Proceedings of the SPE Improved Oil Recovery Symposium, Tulsa, OK, USA, 14-18 April 2012.

253. Kadeethum, T.; Awolayo, A.N.; Sarma, H.K.; Maini, B.; Jaruwattanasakul, C. Uncertainty Analysis of Smart Waterflood Recovery Performance in Clastic Reservoirs. Adv. Pet. Explor. Dev. 2017, 14, 18-32. [CrossRef]

254. Takahashi, S.; Kovscek, A.R. Wettability estimation of low-permeability, siliceous shale using surface forces. J. Pet. Sci. Eng. 2010, 75, 33-43. [CrossRef]

255. Buckley, J.S.; Takamura, K.; Morrow, N.R. Influence of electrical surface charges on the wetting properties of crude oils. SPE Reserv. Eval. Eng. 1989, 4, 332-340. [CrossRef]

256. Valluri, M.K.; Alvarez, J.O.; Schechter, D.S. Study of the Rock/Fluid Interactions of Sodium and Calcium Brines with Ultra-Tight Rock Surfaces and their Impact on Improving Oil Recovery by Spontaneous Imbibition. In Proceedings of the SPE Low Perm Symposium, Denver, CO, USA, 5-6 May 2016; p. 17.

257. Brady, P.V.; Krumhansl, J.L. A surface complexation model of oil-brine-sandstone interfaces at $100{ }^{\circ} \mathrm{C}$ : Low salinity waterflooding. J. Pet. Sci. Eng. 2012, 81, 171-176. [CrossRef]

258. Brady, P.V.; Krumhansl, J.L.; Mariner, P.E. Surface Complexation Modeling for Improved Oil Recovery. In Proceedings of the SPE Improved Oil Recovery Symposium, Tulsa, OK, USA, 14-18 April 2012.

259. Xie, Q.; Saeedi, A.; Pooryousefy, E.; Liu, Y. Extended DLVO-based estimates of surface force in low salinity water flooding. J. Mol. Liq. 2016, 221, 658-665. [CrossRef]

260. Karoussi, O.; Hamouda, A.A. Imbibition of sulfate and magnesium ions into carbonate rocks at elevated temperatures and their influence on wettability alteration and oil recovery. Energy Fuels 2007, 21, 2138-2146. [CrossRef]

261. Austad, T.; Strand, S.; Puntervold, T. Is wettability alteration of carbonates by seawater caused by rock dissolution. In Proceedings of the International Symposium of the Society of Core Analysts, Noordwijk, The Netherlands, 27-30 September 2009.

262. Den Ouden, L.; Nasralla, R.; Guo, H.; Bruining, H.; van Kruijsdijk, C. Calcite dissolution behaviour during low salinity water flooding in carbonate rock. In Proceedings of the IOR 2015 18th European Symposium on Improved Oil Recovery, Dresden, Germany, 14-16 April 2015.

263. Nasralla, R.A.; Snippe, J.R.; Farajzadeh, R. Coupled Geochemical-Reservoir Model to Understand the Interaction Between Low Salinity Brines and Carbonate Rock. In Proceedings of the SPE Asia Pacific Enhanced Oil Recovery Conference, Kuala Lumpur, Malaysia, 11-13 August 2015.

264. Awolayo, A.N.; Sarma, H.K.; AlSumaiti, A.M. Impact of Ionic Exchanges between Active and Non-active Ions on Displacement Efficiency in Smart Waterflood Application. In Proceedings of the 76th EAGE Conference and Exhibition 2014, Amsterdam, The Netherlands, 16-19 June 2014.

265. Chandrasekhar, S.; Sharma, H.; Mohanty, K.K. Wettability Alteration with Brine Composition in High Temperature Carbonate Rocks. In Proceedings of the SPE Annual Technical Conference and Exhibition, Dubai, UAE, 26-28 September 2016.

266. Takamura, K.; Chow, R.S. The electric properties of the bitumen/water interface Part II. Application of the ionizable surface-group model. Colloids Surf. 1985, 15, 35-48. [CrossRef]

267. Brady, P.V.; Thyne, G. Functional wettability in carbonate reservoirs. Energy Fuels 2016, 30, 9217-9225. [CrossRef]

268. Goldberg, S.; Forster, H.S. Boron sorption on calcareous soils and reference calcites. Soil Sci. 1991, 152, 304-310. [CrossRef]

269. Sø, H.U.; Postma, D.; Jakobsen, R.; Larsen, F. Sorption of phosphate onto calcite; results from batch experiments and surface complexation modeling. Geochim. Cosmochim. Acta 2011, 75, 2911-2923. [CrossRef]

270. Lemon, P.; Zeinijahromi, A.; Bedrikovetsky, P.; Shahin, I. Effects of injected-water salinity on waterflood sweep efficiency through induced fines migration. J. Can. Pet. Technol. 2011, 50, 82-94. [CrossRef] 
271. Rahbar, M.; Ayatollahi, S.; Ghatee, M.H. The Roles of Nano-Scale Intermolecular Forces on the Film Stability during Wettability Alteration Process of the Oil Reservoir Rocks. In Proceedings of the Trinidad and Tobago Energy Resources Conference, Port of Spain, Trinidad, 27-30 June 2010; p. 10.

272. Awolayo, A.; Sarma, H.; Nghiem, L.; Emre, G. A Geochemical Model for Investigation of Wettability Alteration during Brine-Dependent Flooding in Carbonate Reservoirs. In Proceedings of the SPE Abu Dhabi International Petroleum Exhibition \& Conference, Abu Dhabi, UAE, 13-16 November 2017.

273. Tripathi, I.; Mohanty, K. Instability due to wettability alteration in displacements through porous media. Chem. Eng. Sci. 2008, 63, 5366-5374. [CrossRef]

274. Wu, Y.-S.; Bai, B. Efficient simulation for low salinity waterflooding in porous and fractured reservoirs. In Proceedings of the SPE Reservoir Simulation Symposium, The Woodlands, TX, USA, 2-4 February 2009.

275. Omekeh, A.V.; Evje, S.; Friis, H.A. Modeling of low salinity effects in sandstone oil rocks. Int. J. Numer. Anal. Model. 2012, 1, 1-18.

276. Dang, C.T.Q.; Nghiem, L.X.; Chen, Z.; Nguyen, N.T.B.; Nguyen, Q.P. $\mathrm{CO}_{2}$ Low Salinity Water Alternating Gas: A New Promising Approach for Enhanced Oil Recovery. In Proceedings of the SPE Improved Oil Recovery Symposium, Tulsa, OK, USA, 12-16 April 2014.

277. Korrani, A.K.N.; Jerauld, G.R.; Sepehrnoori, K. Coupled Geochemical-Based Modeling of Low Salinity Waterflooding. In Proceedings of the SPE Improved Oil Recovery Symposium, Tulsa, OK, USA, 12-16 April 2014.

278. Elakneswaran, Y.; Shimokawara, M.; Nawa, T.; Takahashi, S. Surface Complexation and Equilibrium Modelling for Low Salinity Waterflooding in Sandstone Reservoirs. In Proceedings of the Abu Dhabi International Petroleum Exhibition \& Conference, Abu Dhabi, UAE, 13 November 2017; p. 15.

279. Erzuah, S.; Fjelde, I.; Omekeh, A.V. Wettability Estimation by Surface Complexation Simulations. In Proceedings of the SPE Europec featured at 79th EAGE Conference and Exhibition, Paris, France, 12-15 June 2017; p. 17.

280. Lima, S.A.; Murad, M.A.; Domingues, R. A New Multiscale Computational Model for Low Salinity Alkaline Waterflooding in Clay-Bearing Sandstones. In Proceedings of the SPE Reservoir Simulation Conference, Montgomery, TX, USA, 20-22 February 2017; p. 17.

281. Korrani, A.K.N.; Jerauld, G.R. Modeling Wettability Change in Sandstones and Carbonates Using a Surface-Complexation-Based Method. In Proceedings of the SPE Improved Oil Recovery Conference, Tulsa, OK, USA, 14-18 April 2018; p. 27.

282. Yu, L.; Evje, S.; Kleppe, H.; Kårstad, T.; Fjelde, I.; Skjaeveland, S. Spontaneous imbibition of seawater into preferentially oil-wet chalk cores-Experiments and simulations. J. Pet. Sci. Eng. 2009, 66, 171-179. [CrossRef]

283. Evje, S.; Hiorth, A.; Madland, M.V.; Korsnes, R.I. A mathematical model relevant for weakening of chalk reservoirs due to chemical reactions. Netw. Heterog. Media 2009, 4, 755-788. [CrossRef]

284. Andersen, P.; Evje, S. A Mathematical Model for Interpretation of Brine-Dependent Spontaneous Imbibition Experiments. In Proceedings of the ECMOR XIII-13th European Conference on the Mathematics of Oil Recovery, Biarritz, France, 10-13 September 2012.

285. Al-Shalabi, E.W.; Delshad, M.; Sepehrnoori, K. Does the Double Layer Expansion Mechanism Contribute to the LSWI Effect on Hydrocarbon Recovery from Carbonate Rocks? In Proceedings of the SPE Reservoir Characterization and Simulation Conference and Exhibition, Abu Dhabi, UAE, 16-18 September 2013.

286. Al-Shalabi, E.W.; Sepehrnoori, K.; Pope, G. Mechanistic Modeling of Oil Recovery Due to Low Salinity Water Injection in Oil Reservoirs. In Proceedings of the SPE Middle East Oil \& Gas Show and Conference, Manama, Bahrain, 8-11 March 2015.

287. Al-Shalabi, E.W.; Sepehrnoori, K.; Pope, G. Geochemical Interpretation of Low-Salinity-Water Injection in Carbonate Oil Reservoirs. SPE J. 2015, 20, 211-212. [CrossRef]

288. Korrani, A.K.N.; Fu, W.; Sanaei, A.; Sepehrnoori, K. Mechanistic Modeling of Modified Salinity Waterflooding in Carbonate Reservoirs. In Proceedings of the SPE Annual Technical Conference and Exhibition, Houston, TX, USA, 28-30 September 2015.

289. Qiao, C.; Johns, R.T.; Li, L. Modeling Low Salinity Waterflooding in Chalk and Limestone Reservoirs. Energy Fuels 2016, 30, 884-895. [CrossRef]

290. Eftekhari, A.A.; Thomsen, K.; Stenby, E.H.; Nick, H.M. Thermodynamic Analysis of Chalk-Brine-Oil Interactions. Energy Fuels 2017, 31, 11773-11782. [CrossRef] 
291. Abdou, M.; Carnegie, A.; Mathews, S.G.; McCarthy, K.; O’Keefe, M.; Raghuraman, B.; Wei, W.; Xian, C. Finding value in formation water. Oilfield Rev. 2011, 23, 24-35.

292. Crabtree, M.; Eslinger, D.; Fletcher, P.; Miller, M.; Johnson, A.; King, G. Fighting scale-Removal and prevention. Oilfield Rev. 1999, 11, 30-45.

293. Vetter, O.J.; Farone, W.A.; Veith, E.; Lankford, S. Calcium carbonate scale considerations: A practical approach. In Proceedings of the SPE Production Technology Symposium, Lubbock, TX, USA, 16-17 November 1987.

294. Puntervold, T.; Strand, S.; Austad, T. Coinjection of seawater and produced water to improve oil recovery from fractured North Sea chalk oil reservoirs. Energy Fuels 2009, 23, 2527-2536. [CrossRef]

295. Kajenthira, A.; Siddiqi, A.; Anadon, L.D. A new case for promoting wastewater reuse in Saudi Arabia: Bringing energy into the water equation. J. Environ. Manag. 2012, 102, 184-192. [CrossRef] [PubMed]

296. Burnett, D. Desalinating brine from oil and gas operations in Texas. Southwest Hydrol. 2005. Available online: http:/ / www.swhydro.arizona.edu/archive/V4_N6/feature4.pdf (accessed on 27 August 2018).

297. Burnett, D.B.; Siddiqui, M. Recovery of Fresh Water Resources from Desalination of Brine Produced during Oil and Gas Production Operations; Texas Engineering Experiment Station: College Station, TX, USA, 2006.

298. Ayirala, S.C.; Uehara-Nagamine, E.; Matzakos, A.N.; Chin, R.W.; Doe, P.H.; van den Hoek, P.J. A designer water process for offshore low salinity and polymer flooding applications. In Proceedings of the SPE Improved Oil Recovery Symposium, Tulsa, OK, USA, 24-28 April 2010.

299. Collins, I.R. Water Flooding Method. U.S. Patent 7455109B2, 25 November 2008.

300. Henthorne, L.; Movahed, B. Method and Control Devices for Production of Consistent Water Quality from Membrane-Based Water Treatment for Use in Improved Hydrocarbon Recovery Operations. U.S. Patent 20130213892A1, 22 August 2013.

301. Curole, M.A.; Greene, E.B. Water Injection Systems and Methods. U.S. Patent 8,789,594, 29 July 2014.

302. Ligthelm, D.J.; Romanuka, J.; Suijkerbuijk, B.M.J.M. Water Injection Systems and Methods. U.S. Patent 20120090833A1, 19 April 2012.

303. Ayirala, S.C.B.; Chin, R.W.-Y.; Matzakos, A.N.; Uehara-Nagamine, E. Water Injection Systems and Methods. U.S. Patent 9234413B2, 12 January 2016.

304. Yousef, A.A.; Ayirala, S.C. A novel water ionic composition optimization technology for SmartWater flooding application in carbonate reservoirs. In Proceedings of the SPE Improved Oil Recovery Symposium, Tulsa, OK, USA, 12-16 April 2014.

305. Ayirala, S.C.; Yousef, A.A. A Critical Review of Alternative Desalination Technologies for Smart Waterflooding. Oil Gas Facil. 2016. [CrossRef] 